\title{
Informal payments for healthcare services in Albania
}

Citation for published version (APA):

Tomini, S. (2011). Informal payments for healthcare services in Albania. [Doctoral Thesis, Maastricht University]. Boekenplan. https://doi.org/10.26481/dis.20111103st

Document status and date:

Published: 01/01/2011

DOI:

10.26481/dis.20111103st

Document Version:

Publisher's PDF, also known as Version of record

\section{Please check the document version of this publication:}

- A submitted manuscript is the version of the article upon submission and before peer-review. There can be important differences between the submitted version and the official published version of record.

People interested in the research are advised to contact the author for the final version of the publication, or visit the DOI to the publisher's website.

- The final author version and the galley proof are versions of the publication after peer review.

- The final published version features the final layout of the paper including the volume, issue and page numbers.

Link to publication

\footnotetext{
General rights rights.

- You may freely distribute the URL identifying the publication in the public portal. please follow below link for the End User Agreement:

www.umlib.nl/taverne-license

Take down policy

If you believe that this document breaches copyright please contact us at:

repository@maastrichtuniversity.nl

providing details and we will investigate your claim.
}

Copyright and moral rights for the publications made accessible in the public portal are retained by the authors and/or other copyright owners and it is a condition of accessing publications that users recognise and abide by the legal requirements associated with these

- Users may download and print one copy of any publication from the public portal for the purpose of private study or research.

- You may not further distribute the material or use it for any profit-making activity or commercial gain

If the publication is distributed under the terms of Article $25 \mathrm{fa}$ of the Dutch Copyright Act, indicated by the "Taverne" license above, 
INFORMAL PAYMENTS FOR HEALTH CARE SERVICES

IN ALBANIA 


\section{(c) Sonila Tomini}

All rights reserved. No part of this publication may be reproduced, stored in a retrieval system, or transmitted in any form, or by any means, electronic, mechanical, photocopying, recording or otherwise, without the prior permission in writing, from the author.

ISBN 9789086662258

Publisher: Boekenplan, Maastricht 


\title{
INFORMAL PAYMENTS FOR HEALTH CARE SERVICES IN ALBANIA
}

\author{
Dissertation \\ to obtain the degree of Doctor at the Maastricht University, \\ on the authority of the Rector Magnificus Prof. dr. G.P.M.F. Mols \\ in accordance with decision of the Board of Deans, \\ to be defend in public on Thursday 3 November 2011, at $14.00 \mathrm{hrs}$ \\ by
}

Sonila Tomini 


\section{Promoter:}

Prof. dr. Wim Groot

\section{Co-promoter:}

Dr. Milena Pavlova

\section{Assessment Committee:}

Prof. dr. Frits van Merode, (chairman);

Prof. dr. Helmut Brand;

Prof. dr. Dirk Ruwaard;

Prof. dr. Wynand van de Ven, (Erasmus University, Rotterdam);

Dr. Maureen Lewis, (World Bank)

\section{Acknowledgement:}

The study is part of Project ASSPRO CEE 2007 (Grant Agreement no. 217431) funded by the European Commission under the 7th Framework Programme, Theme 8 Socio-economic Sciences and Humanities. The content of the publication is the sole responsibility of the authors and it in no way represents the views of the Commission or its services. 


\section{Acknowledgments}

Lots of work, passion, patience, tiredness, happiness have come together in these four years. Writing a PhD dissertation about your own country is not easy and you have to put extra efforts in order to be objective and impartial. But I am proud that a part of it can contribute to improvements of health care in Albania. I am eternally grateful to all the people that have supported me in this endeavour.

Everything started at the School of Governance. I am really glad that I had the chance to develop my research ideas at such an international and intellectually stimulating environment. Thank you Chris, Franziska and Mindel for the support, guidance and encouragement especially during the first year when we had to develop our proposals!

My deepest gratitude goes to my promoter Wim Groot and co-promoter Milena Pavlova for all their highly valuable advice and guidance during the writing of this PhD. I have really enjoyed working with them and benefited a lot from their knowledge and experience. I have especially enjoyed the constructive discussions during our meetings. It was really fortunate for me to come across you and to have similar research interests. Exploring the complex nature of informal payments in health care has been rendered easier from your assistance and knowledge. Dear Wim and Milena, thanks for letting me make my decisions and learning from my mistakes! I am really happy that I had the chance to work with you and benefit from your experience.

I would like to sincerely thank my other co-authors. My interest in this topic started growing from the work that I started together with Hans Maarse. It was with great pleasure that I discovered that we shared the same passion in exploring the health systems of transition countries. Thank you Hans for our fruitful collaboration! I would also like to thank Truman G. Packard (my other co-author) with whom I came in contact because of the same research. Thank you Truman for continuously encouraging and praising my work and efforts!

Next, I wanted to thank all my colleagues at School of Governance. Special thanks to all the fellows of my PhD cohort, (Dorcas, Cheng, Patrycja, Kwan, Lenka, Nyasha and SiuHing). I will always remember our long discussions, our long dinners at the (PhD) kitchen, the endless courses we have attended together and, of course, my nickname (Sonali) generously used by Kwan and Dorcas. Dear friends, many thanks for all the beautiful moments we have had together, they will always be part of my $\mathrm{PhD}$ experience! Then, special thanks also to Geranda to whom I have talked for the first time about my PhD project and who has helped me so much with the coordination of the seminar series. Many thanks to all other $\mathrm{PhD}$ fellows for having had such a great time during our joint dinners, drinks, writing camps and other social events! Thanks also to all of you who have had always the patience to listen to my presentations and have always given your opinions on my research. Dear all thank you for having made this period so enjoyable!

It was with great pleasure that I contributed in growing the small community of Albanian researchers in Maastricht. But it was much greater pleasure to share my time with Zamira and Ilire, my two other conational fellows. Dear ladies, many thanks for having made me feeling home away from home! Faleminderit! 
I have had the opportunity to spend the last year of my studies in another equally intellectually inspiring and socially stimulating organization. A special word of gratitude goes to my colleagues of Health Service Research department (formerly Department of Health Organization, Planning and Economics) and especially to the young researchers working under ASSPRO CEE 2007 project (Marzena, Petra, Vladimir, Jelena, Elka, Tetiana and Andriy,). I have really enjoyed being part of this group and I have certainly benefited from our common interests in studying patient payments. Thank you my friends for all the conversations, comments, social gatherings, but also for being together during our periodical conferences in Maastricht, Kiev and Budapest!

Many things can be difficult in a foreign country without a proper knowledge and support on how to get the essential things done. For this, I would also like to thank the support staff of School of Governance (Celine, Susane, Mieke, Janneke) and Health Service Research department (Suus, Brigitte) for their patience in dealing with every bureaucratic details of my everyday work and for being so friendly and comprehensive.

A special requirement of writing a $\mathrm{PhD}$ in The Netherlands is that you have to translate the summary of it in the local language. Even though my Dutch skills are getting better with time (very slowly though) I do not think I am up to the challenge of translating an academic paper. This translation would have not been possible without the patient work of Zamira and Suus. Thank you Suus and Zamira for your generous help, I really appreciate it!

Earlier versions of the papers in this $\mathrm{PhD}$ have been published or will be published as articles. For this I would also like to thank all other anonymous readers that have contributed to the constant improvements of my papers and that have furthered enhanced the quality of this research. I thank also the reading committee for carefully reviewing this dissertation and for the valuable comments they have given.

Special words of gratitude go to my parents and sisters for having supported me throughout this period. Faleminderit veçanërisht ty Mami dhe Babi që më keni mësuar me dashurinë për dijen dhe të bukurën. Siguria dhe kurajo juaj kanë qenë githmonë një shtysë për të ecur përpara. Faleminderit Tini, Suela, Xhulka, Alfred, Irdi dhe Ilion. Pa mbështetjen, besimin dhe dashurinë tuaj gjithshka do të ishte më e vështirë për mua. Falenderoj mami Aferditën, babi Skënderin, Nënën, Ortencën, Alfredin dhe Andin për dashurinë dhe besimin që kanë treguar ndaj meje. Faleminderit të gjithëve nga zemra!

I would like to dedicate the last words to my Family, to my Florian. Your support has always meant the World to me!

\section{Thank You!}




\section{Tables of Contents}

Acknowledgments $\quad$ v

Tables of Contents vii

List of Tables $\quad x$

List of Figures $\quad$ xii

CHAPTER 1. Introduction $\quad 1$

1.1 General context 3

1.2 The Albanian health care system 3

1.3 Informal payments in Albania 4

1.4 Aim of the dissertation 6

1.5 Outline of the dissertation 9

CHAPTER 2. Are health care payments in Albania catastrophic? Evidence from ALSMS 2002, 2005 and 2008

2.1 Introduction $\quad 13$

2.2 Data and methodology 14

2.3 Out-of-pocket spending in Albania $\quad 21$

2.4 Catastrophic payments in health care in Albania 26

2.5 The impoverishing impact of out-of-pocket expenditures in Albania 27

2.6 Discussion and conclusions 31

2.7 Appendix 2A 32

CHAPTER 3. Informal payments in public health care: scarce resources or governance failure? $\quad 43$

3.1 Introduction 44

3.2 The Determinants of informal health care payments 46

3.3 Informal payments and recent reforms in the health care sector in Albania 47

$\begin{array}{lll}3.4 & \text { Data and descriptive statistics } & 48\end{array}$

3.5 Empirical strategy $\quad 50$

$\begin{array}{lll}3.6 & \text { Results } & 52\end{array}$

$\begin{array}{lll}3.7 & \text { Discussion } & 54\end{array}$

$\begin{array}{lll}3.8 & \text { Conclusions } & 62\end{array}$

3.9 Appendix 3A 64

CHAPTER 4. Informal payments and intra-household allocation of resources for health care in Albania

$\begin{array}{lll}4.1 & \text { Introduction } & 74\end{array}$

$\begin{array}{lll}4.2 & \text { Theoretical background } & 75\end{array}$

$\begin{array}{lll}4.3 & \text { Descriptive statistics and methodology } & 77\end{array}$

4.4 Results and discussion $\quad 80$

$\begin{array}{lll}4.5 & \text { Conclusion } & 82\end{array}$

$\begin{array}{lll}4.6 & \text { Discussion and Conclusions } & 89\end{array}$

$\begin{array}{lll}4.7 & \text { Appendix 4A } & 91\end{array}$ 
CHAPTER 5. Paying informally in the Albanian health care sector: A two-tiered stochastic frontier model

5.1 Introduction 98

5.2 Theoretical background 100

$\begin{array}{lll}5.3 & \text { Methodology and model } & 103\end{array}$

$\begin{array}{lll}5.4 & \text { Data } & 107\end{array}$

$\begin{array}{lll}5.5 & \text { Results } & 109\end{array}$

5.6 Estimation of ignorance about informal payments 116

$\begin{array}{lll}5.7 & \text { Discussion } & 119\end{array}$

$\begin{array}{lll}5.8 \text { Conclusion } & 121\end{array}$

$\begin{array}{lll}5.9 & \text { Appendix 5A } & 122\end{array}$

CHAPTER 6. Concluding Remarks $\quad 129$

$\begin{array}{lll}6.1 & \text { Introduction } & 130\end{array}$

6.2 Main statements based on the research findings 135

$\begin{array}{ll}\text { Samenvatting } & 138\end{array}$

BIBLIOGRAPHY

MGSOoG Dissertation Series $\quad 142$ 


\section{List of Tables}

Table 1.1. Definitions of informal payments in health care 3

Table 1.2. Expenditures on informal payments in FSU and CEE countries 4

Table 1.3. Out-of-pocket expenditures for outpatient and inpatient health care $\quad 10$

Table 2.1. The mean per capita expenditures on health and non-health items 20

Table 2.2. Financing budget shares on health and non-health items 21

Table 2.3. Incidence and intensity of catastrophic health payments 22

Table 2.4. Distribution-sensitive catastrophic payments measures 23

Table 2.5. Measures of poverty based on per capita expenditure $\quad 24$

Table A2.1. Incidence and intensity of catastrophic health payments 28

Table 3.1. Causes of informal payments and observed effects 32

Table 3.2. Responsibilities in the health care sector $\quad 35$

Table 3.4. The share of patients paying informal payments to medical staff 37

Table 3.5. The mean of the amount paid informally 38

Table 3.6. Outpatient services - Results from tobit and Heckman selection models $\quad 42$

Table 3.7. Propensity Score Matching results for outpatient care 44

Table 3.8. Propensity Score Matching results for outpatient care - paying informally $\quad 45$

Table 3.9. Inpatient services - Results from tobit and Heckman selection models $\quad 47$

Table 3.10. Propensity Score Matching results for inpatient care $\quad 48$

Table 3.11. Propensity Score Matching results for inpatient care - paying informally 49

Table A3.1. Logit results $\quad 54$

Table 4.1. The incidence and amounts paid informally in health care 62

Table 4.2. Characteristics of spouses and children in nuclear and extended households 62

Table 4.3. Methods to raise money to pay for health care 63

Table 4.4. The incidence of informal payments to medical staff in health care 65

Table 4.5. The amount of informal payments to medical staff in health care 67

Table 4.6. The amount paid out-of-pocket for outpatient and inpatient care $\quad 70$

Table A4.1. Descriptive statistics of households for outpatient care $\quad 73$

Table A4.2. Descriptive statistics of households for inpatient care $\quad 74$ 
Table 5.1. Sample means of characteristics for patients that have paid informally

Table 5.2. Diseases and illness grouped according to the factor analysis

Table 5.3. Parameter estimates OLS and two-tiered stochastic frontier model

Table 5.4. Imperfect information of medical staff and patients for various subgroups 88

Table 5.5. Willingness to pay informally to medical staff 89

Table A5.1. Descriptive statistics 91 


\section{List of Figures}

Figure 1.1. Health spending as \% of GDP for different countries in 2008

Figure 1.2. Health spending by source for different countries in $2008 \quad 8$

Figure 2.1. Poverty impact of health expenditure $\quad 25$

Figure 3.1. Corruption and bribes in the health sector for different countries in $2008 \quad 34$

Figure 3.2. Health Insurance Institute Expenditures 36

Figure 3.3. Monthly salaries of General Practitioners (in 000 ALL) 36

Figure A3.1. Histograms from the predicted scores used for matching 55 

Chapter 1. INTRODUCTION 


\subsection{General Context}

Health care payments are often the most important expenditure households make. All around the world people pay for health care services using formal mechanisms thought up by governments. Such mechanisms consist of collecting resources to pay for health care through general taxation, health care contributions or out-of-pocket payments. However, people may be compelled to use informal ways to compensate health care providers for the services rendered. Studies show that such informal transactions are not unusual in many of the Central Eastern European (CEE) and Former Soviet Union (FSU) countries (Killingsworth et al., 1999; McPake et al., 1999; Lewis, 2000; Gaal et al., 2006; Mæstad and Mwisongo, 2007).

CEE and FSU countries have faced similar challenges in reforming their health care systems after the fall of the communism. They had to move from a centrally planned economy, where health care for all was virtually achieved (McKee, 1991), to a model that included decentralised decision making (Preker and Feachem, 1994; WHO, 1996). The transition phase was characterised by the inheritance of an inefficient health system and the over-supply of physicians ${ }^{1}$ (Goldstein et al., 1996; Lewis, 2000, Nuri and Tragakes, 2002) who were not very well paid ${ }^{2}$ (McKee, 1991). Investments during the communist regime aimed to ensure access to health care rather than to improve quality of services and this had a decaying impact on the health service infrastructure (McKee, 1991). The transition was accompanied by the decline in public health funds and lack of good governance leading to barriers in access to health care and high levels of out-of-pocket payments (Lewis, 2000; Ensor, 2004).

The unregulated components of out-of-pocket payments are often labelled with different names. They are called 'under-the-table payments', 'envelope payments', 'underthe-counter payments', 'gifts', and even 'black money'. They can range from the ex-post (gratitude-like) in-kind gifts (Adam, 1989) to the ex-ante (bribe-like) cash payments given to the health care provider (Allin et al., 2006). There is no universally accepted definition for informal payments and usually this varies depending on the range of services and products included (see Table 1.1). Gratitude payments are most often defined as voluntary ex-post payment to "benevolent" doctors (Balázs, 1996; Adam, 1989), while informal payments are more generally defined as direct cash/in-kind unofficial payments to health care providers and/or private purchases of health services and other products meant to be covered by the health care system (Lewis, 1999; Killingsworth et al., 1999; Chawla, 1998; Thompson and Witter, 2000; Balabanova and McKee, 2002; Allin et al., 2006).

\footnotetext{
1 Central and Eastern European countries have an over-supply of physicians with 4.1 per 1000 population compared to the established market economies with 2.5 .

2 Central and Eastern European countries at the end of the 1980s spent only $40 \%$ of recurrent health budgets on staff wages compared to the $60 \%$ OECD average.
} 
Table 1.1. Definitions of informal payments in health care

Medical gratitude payment is an informal money transaction between a doctor and a patient, in the course of which the patient purchases a health service from the publicly employed doctor.

A gratuity can be defined as a financial or other material benefit, given to a doctor by a patient or his or her relatives after treatment has been terminated.

Informal payments are payments to individual and institutional providers in-kind or cash that are outside the official payment channels, or are purchases that are meant to be covered by the health-care system.

Unofficial health care fees at government health facilities can be defined as unauthorised fee payments that co-exist with 'free care' and formally approved 'official' health service charges collected at public facilities under the sanction of public policy.

Payments, in cash or in kind, made by patients, or others on behalf of the patients, to an individual or institutional public health care provider directly or to any person arranging for provision of health care from such public health care providers, for health services received or expected to be received that the recipients of these payments are not authorised to receive under existing laws of land, including the Constitution of Poland, 1997, and the Health Insurance Act, 1997, or under the rules of business of the health facility.

Informal payments can be described as payments made by individuals to state health workers or institutions but that are not sanctioned by the authorities.

Informal payments are defined as a monetary or in-kind transaction between a patient and a staff member for services that are officially free of charge in the state sector.
Balázs (1996)

Hungary

Adam (1989)

Hungary

Lewis (1999)

Killingsworth JR. et al. (1999)

Chawla (2000,cited in Shahriari et al. 2001)

Poland

Thompson and Witter (2000)

Balabanova and

McKee (2002)

Belli (2002)

The informal component of out-of-pocket is defined as the payments (in cash or in kind) made to service providers (individuals or institutions) by those people who are entitled to the services, in addition to any legally defined payment.

Informal, 'under-the-table' or 'envelope' payments are typically defined as direct payments by patients for services they are entitled to for free, usually in a public health system. Informal payments range from the ex-ante cash payment to the ex post gift-inkind.

The definitions of informal payments adopted by researchers vary greatly between studies and are shown to be linked to cultural differences, legal provisions, and also to data availability (Stepurko et al., 2010). Despite these differences, informal payments in this dissertation are also seen as a way to allocate scarce resources where the market prevails over the rationing systems thought up by the government. This definition allows analysing informal payments from both governance and market perspectives. Informal payments reflect the financial inability of government to cope with the demand for health care and the tolerance showed towards informal practices. On the other hand, the final amount paid informally is a result of price negotiations between patients and medical staff over services that patients would have not been able to get otherwise. 
The incidence of informal payments varies over the FSU and CEE countries and comparative studies are few since measurements vary depending on the definitions used (see above). However, empirical studies show that such payments are persistent all over the region. Hence, almost 60 per cent of individuals visiting inpatient services have declared to have paid an informal gift in Albania (World Bank, 2006), 57 per cent of all the interviewed have declared to have paid a bribe in Poland (Watson, 2006) and 18 per cent in Romania (Vlădescu,et al., 2008). The extent of such informal payments also varies depending on the particular situation of the country. Table 1.2 shows the most recent data from some of the FSU and CEE countries. The table indicates that informal payments constitute a considerable share of total health expenditures in all of these countries.

Table 1.2. Expenditures on informal payments in selected FSU and CEE countries

\begin{tabular}{clc}
\hline \hline COUNTRY & \multicolumn{1}{c}{ INFORMAL PAYMENTS } & SOURCE \\
\hline Albania, 2005 & $\begin{array}{l}\text { Informal gifts to medical staff amount to 6-7\% of the total OOP } \\
\text { expenditures in outpatient while 25\% in inpatient. }\end{array}$ & World Bank, 2006 \\
Armenia, 2005 & $\begin{array}{l}\text { Informal payments constitute 61\% of all health care expenditure } \\
\text { compared with 22\% coming from state budget. }\end{array}$ & Aristakesyan et al., 2005 \\
Bulgaria , 2003 & Informal payments constitute 25\% of health care expenditures. & Daskalova et al., 2005 \\
Moldova , 2005 & $\begin{array}{l}\text { Informal payments in Moldova are estimated at 30\% of total } \\
\text { health care expenditures. }\end{array}$ & Shishkin et al., 2006 \\
\hline \hline
\end{tabular}

\section{Reasons and purposes of informal payments}

The reasons and motivations for informal payments in CEE and FSU countries are complex and often interrelated. Looking at the main reasons for such payments, Ensor (2004) mentions the legacies of the past system, the culture of gifts, and the insufficient public funding for health care. Gaal and McKee (2005) list factors leading to informal payments (grouping them in social-cultural, legal-ethical and economic factors). We can broadly bundle these factors in three main groups: cultural, economic and governance.

The cultural group of explanations relates informal payments to the culture of gifts prominent in some of the FSU countries where gifts are considered as an integral part of professional relations (Ensor, 2004) or the elements of the culture of gifts reported in CEE countries (Delcheva et al., 1997; Balabanova and McKee, 2002; Vian et. al., 2006). Given the fixed prices and the absence of other motivators during communism, the gift was seen as indispensable to trade. Such cultural causes are often considered even older than the onset of the 'Semashko' systems in these countries.

The economic group of explanations directly refers to the former 'Semashko' system in CEE and FSU countries and the immediate gap between a growing demand and a rigid supply (Gaal and McKee, 2005). Whenever the formal financial mechanisms fail to provide an efficient allocation of resources, informal arrangements are used to fill the gap created and to deal with the distribution of services. Individuals and medical staff are therefore 
constrained to find ways and develop strategies to cope with the shortage of public/pooled financing and are privately engaged in negotiations between each-other. The decrease in public spending on health care (Delcheva et al., 1997; Chawla et al., 1998; Ensor and Witter, 2001; Gordeev et al., 2010) and the decline in real wages of medical staff in CEE and FSU countries (Ensor and Savelyeva, 1998; Ensor and Witter, 2001; Chawla et al., 1998; Lewis, 2002; Vian et al., 2006) are seen as the main reasons for informal payments.

The lack of good governance, as an explanation for informal payments, relates to the lack of accountability in the health sector after the 90's but also to unethical behaviour of medical staff. As in other sectors, governments were tolerating such informal practices while they were not able to raise the salaries of medical staff. Given the weak rule of law and the absence of accountability mechanisms, medical staff were also tempted to break the model of medical professionalism and use their market power to maximise their earnings (Miller et al., 2000; Thompson and Xavier, 2002).

Patients may choose to pay informally to contribute to the costs of health care (i.e., payments for medical supplies, the purchasing of the pharmaceuticals by private pharmacies, or payments to medical staff to compensate their low salaries), to have additional services (i.e., better hotel services, more specialised treatments, etc) or simply because physicians may misuse their market power (Ensor, 2004). In fact, it appears that most often payments to medical staff attract most of the attention. Differentiating between informal payments that fill up the gap of low salaries and the misuse of market power for extra profits always remains challenging. In many cases direct payments constitute a substantive part of medical staff's formal salaries (Abel-Smith and Falkingham, 1995; Delcheva et al., 1997; Chawla et al., 1998). The timing of the informal payments to medical staff and the presence of voluntary actions by patients are believed to be valuable measures in this regard. Requested payments that are given prior to health service delivery resemble more to bribes than to gratitude payments and therefore, they are seen as more problematic (Balabanova and McKee, 2002).

\section{The effects of informal payments}

The attitude towards informal payments in health care is very much determined by their effects on the performance of health care systems and their effects at the individual level. The ultimate objective of health care systems is to improve the health of the population and to increase customer satisfaction (Gaal et al., 2006). Generally, informal payments are considered harmful because of the illegal aspects involved (Lewis, 2007) 3 but also because they may be possible causes for harmful effects on the health system performance (Gaal et al., 2006).

Informal payments fall outside of the formal financing and planning channels and therefore, they may decrease the efficiency of the health care system. The misuse of market power by medical staff is likely to lead to 'monopoly-like' situation where patients are charged much more than the market price for services (Ensor, 2004) and thus, it creates welfare loss. Moreover, the allocation of resources to health care would not be optimal as

\footnotetext{
${ }^{3}$ Lewis (2007) mentions that such illegality arises as most often informal payments take place in circumstances where citizens are meant to get free health care.
} 
resources would be allocated first to those who are able to pay informally and not to those who need them most (Ensor, 2004; Tambor et al., 2010).

Informal payments affect the equity of the health care systems. Considered merely a market mechanism (that kicks in when formal mechanisms fail), such payments do not protect the poor and those who are not able to pay for frequent service use (Szende and Culyer, 2006). Individuals may be denied access and/or quality care if they do not meet the amount expected or required informally. This affects much more the poor than the rich (Falkingham, 2004). Evidence from CEE countries suggest that often there are no significant differences between the poor and the rich (Hotchkiss et al., 2005) and the poor may pay even more than the rich (Lewis, 2000). Szende and Culyer (2006) find that informal payments in Hungary are highly regressive because they do not vary across income groups and do not correspond to the ability to pay.

Informal payments may obstruct future health care reforms. One of the reasons is because they make the estimation of the overall expenditure on health care difficult (Delcheva et al., 1997). As a consequence, parts of the health care costs are underestimated making projections on future requirements difficult. Another reason is that informal payments could stimulate the hostile attitude of medical staff towards reforms that seek to limit the phenomenon. Physicians may be more interested in maximising their own income (Gaal and McKee, 2004) and therefore may hinder any reforms that would weaken their market power.

In this dissertation, the causes and effects of informal payments are analysed from the perspective of the Albanian context.

\subsection{The Albanian health care system}

The health care system in Albania has its roots in the Soviet 'Semashko' model, dominated by the public provision of the services. This system had been designed to cover the entire country including every single village, following the communist ideology of "free health care services for all". The health sector during the communist period was underfinanced and considered as a non-productive sector (Nuri and Tragakes, 2002). The funds allocated to the health sector were low and the investments in health technology were even lower. The priority of the government in health care was mainly related to providing access to primary and secondary care. This led to a widely distributed web of primary health care (PHC) posts and centres and to a relatively large number of local and regional hospitals (most of which had outdated equipments and were overstaffed).

The reforms that followed immediately after the onset of the democratic regime were focused mostly on reorganising the responsibilities of health care centres. Thus, with the regionalisation that followed in 1993 (the creation of 12 prefectures) some administering responsibilities were shifted to the local level. However, human resource policies and financing for hospitals still remain highly centralised. The decentralisation process in the mid-1990's gave ownership rights of some health care facilities to local governments (mainly PHC facilities in rural areas) while most of the policlinics and hospitals in urban areas were still owned by the Ministry of Health (MoH) (Nuri and Tragakes, 2002). Nowadays most of these facilities are owned by local governments while only hospitals remain under the $\mathrm{MoH}$. 
The PHC policy developed by the government in 1997 (World Bank, 2006) aimed to maintain a health post for each locality and a health centre for each commune centre. According to $\mathrm{MoH}$, in 1993, Albania had 2191 health posts (out of which only about half of them were operational), and 770 health care centres. In 2008, this number had dropped to about 1877 health posts and 580 health centres $(\mathrm{MoH}, 2010)$. Outpatient care in the public sector is delivered mainly through these PHC facilities but also at polyclinics in urban areas. The main reforms in PHC have sought to transfer the financing of the sector to the Health Insurance Institute (HII) established in 1994 to cover primary health care visits, reimburse approved drugs and cover the costs of secondary and tertiary care. Recurrent expenditures and wages of the medical staff are now financed directly through the HII. The hospital sector is still dominated by the public sector where the $\mathrm{MoH}$ is the owner and administrator of all hospitals (World Bank, 2006). The number of operative hospitals was 41 in 2008 out of which 4 are university hospitals in Tirana, 11 are regional hospitals, and 22 are district hospitals $(\mathrm{MoH}, 2010)$. Interventions in the hospital sector have mainly sought to improve the infrastructure of the sector and little has happened in terms of reforming the way providers are financed during 2002-2008.

Figure 1.1. Health spending as \% of GDP for different countries in 2008

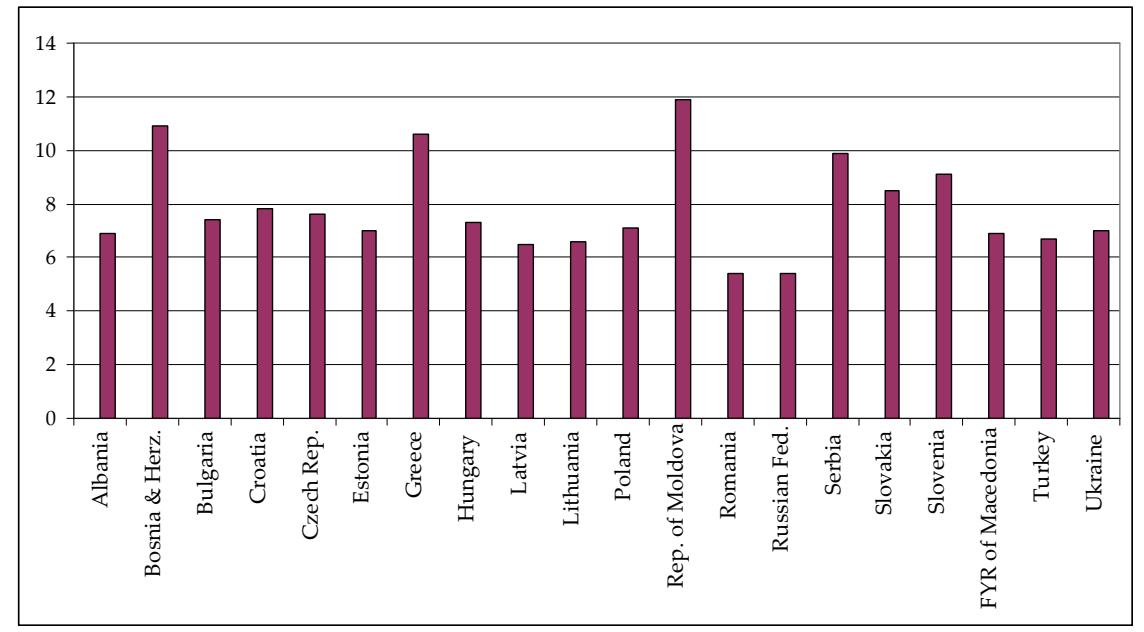

Source: WHO, 2010

Albania spent around 6.8 per cent of its GDP on health care in 2008 (WHO database). This is relatively high comparable to other former communist CEE or FSU countries, but lower compared to the average 8.5 per cent for the EU15 countries (Figure 1.1). However, only about 50 per cent of this amount is coming from the general state budget. The share of out-of-pocket expenditures remains high in Albania compared to similar countries (Figure 1.2). The utilisation of health insurance in Albania is low and reported out-of-pocket spending is high. Survey data report that for the lowest quintile the share of total out-ofpocket spending in inpatient services goes up to 60 per cent of the total monthly household expenditure (World Bank, 2006). This contributes both to increased inequalities and also to barriers to access for the most vulnerable categories. Although inpatient care is in principle 
free for everyone, in reality, most of the people visiting this service report to have paid substantial amounts of out-of-pocket payments (World Bank, 2006).

Figure 1.2. Health spending by source for different countries in 2008

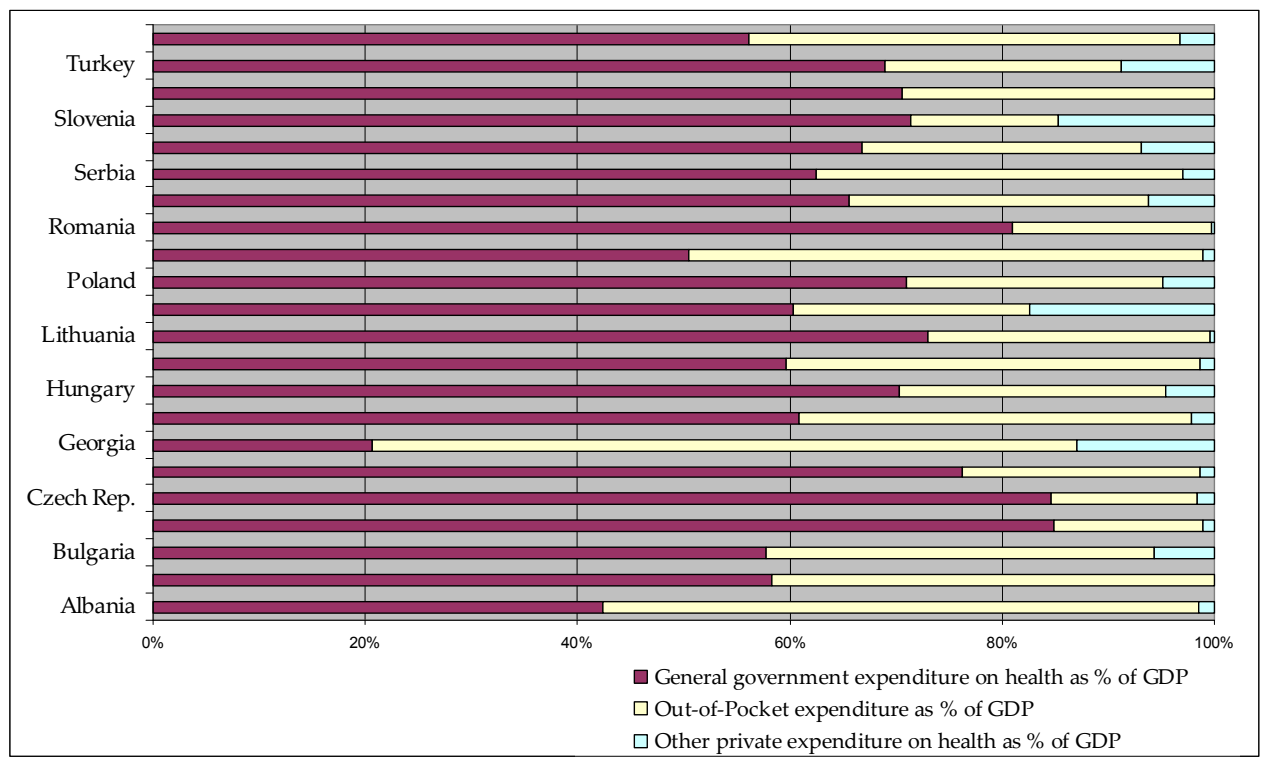

Source: WHO, 2010

Public health expenditures are financed by social health insurance contributions and revenues from tax collections. The health insurance contributions are collected by the Tax Authority and amount to 3.4 per cent of gross salaries of all formally employed individuals. However, the total number of contributors remains low because of the large informal sector in the labour market. Evidence suggests that about one third of the active labour force in 2005 was currently contributing to health insurance (World Bank, 2006). The HII is responsible for contracting health services with PHC and also selected services from hospitals. Although the funding of PHC is done through the HII, most of the funds (almost two thirds of the total budget) still come from the general state budget. The funding of hospitals in 2008 was still done through the $\mathrm{MoH}$.

Health insurance in Albania covers most of the costs of primary health care and all the costs of hospital care. Patients are required lately to pay a small fixed co-payment per visit in a PHC or specialised treatment in hospital care (DGESAEO-EC, 2008). Despite the fact that the law states that all citizens ${ }^{4}$ should be covered by health insurance, surveys show that about 40-45 per cent of the population declares to have a health insurance booklet (World Bank, 2006). Moreover, the same studies show that there are also large inequalities in

\footnotetext{
${ }^{4}$ Apart from people paying health insurance through formal employment (or self declarations), the law provides coverage also for other groups like; children below age one, unemployed, social assistance recipients, soldiers, students, pensioners and war veterans, pregnant women, and other vulnerable categories.
} 
health insurance coverage when considering different regions of Albania (i.e. only 20 per cent of the population in mountainous areas have health insurance).

\subsection{Informal payments in Albania}

Albania's limited public spending on the health care sector (as compared to other Balkan or Eastern European countries) has resulted in an increased reliance on out-of-pocket payments for both inpatient and outpatient care (Nuri and Tragakes, 2002). The supply of health care is clearly limited, forming a perfect ground for cultivating informal payments.

In general, there is a lack of clarity between formal and informal payments in Albania. The changes in legislation in early transition years imposed co-payments for users of primary health care. Albanian health care seekers are therefore confronted with other formal out-of-pocket payments for laboratory tests, medicines, and transportation costs. However, it is not always clear whether such payments are paid formally or informally (Hotchkiss et al., 2005). As the Albanian legislation prohibits direct payments to medical staff, most of the informal payments studies focus exclusively on payments paid to medical staff.

Various studies confirm the high level of informal payments in Albania. Albanian LSMS data of 1996 show that such payments amount to about 18 US\$ per capita for those who sought health care (Lewis, 2002). Hotchkiss et al., (2005) using data from Albania Baseline Health Survey (2000) find that almost 24.7 per cent of acutely-ill outpatients pay (informal) gifts to medical staff. Other estimates show that almost $60-78 \%$ of the Albanian patients paid informally in hospitals in 2000 and 2002 (MoH, 2000; Bonilla and Chacin, 2003).

Studies of health care services in Albania have provided some insights on the main reasons why people pay informally to medical staff. In a survey of patients in three districts of Albania, Vian et al. (2006) have asked both patients and providers on this. The main reasons listed relate to the motivation of health care staff (i.e. recognition of their low salaries), gaining access to health care (denial of the service if gift was not paid), getting a better/faster health service, and paying as a gratitude (rewarding the medical staff). The fear associated with denial of (or poor) service is also mentioned in other studies (Vian and Burak, 2006; World Bank, 2006). The general perception is that the service gets much better if the medical staff is paid informally. Both Vian et al. (2006) and Vian and Burak (2006) found that social connections between patients and medical staff are important factors in determining the payments. Patients tend to be less likely to pay beforehand to medical staff that they know and more likely to pay when using facilities in other neighbourhoods or districts.

The amount paid informally to medical staff also differs (Vian et al., 2006). The main factors for this relate to attributes of patients (i.e. economic status, residence in the same locality, personal relations, and societal/political position) attributes of providers (specialists vs. general practitioners, highly specialised medical staff, and availability), the type of services (inpatient/outpatient, locality, specialty, complexity of treatment, and technology involved), and other contextual factors (like urbanisation of the locality, social norms, etc). Paying mechanisms also tend to differ and are complex. Despite the illegal nature of such payments they are reported to take place in the open and often not something to be hidden. 
Patients may gather information from social networks but in many cases the nurses or physicians induce directly the payments. Some of these strategies involve talking about the low salaries, leaving money on the table (to show that others have also paid), requesting them form patients or relatives accompanying the patient, acting unfriendly or delaying care.

The amount paid informally also differs if looked at by type of care. Informal payments are very sizeable for inpatient care (World Bank, 2006). Varying on their position and medical profile, the official wages of hospital physicians may increase by a factor 3 because of informal payments. Informal payments for outpatient physicians may amount to almost 50 per cent of their wages. ${ }^{5}$ The amount of informal payments for the auxiliary staff is pretty low (compared to their official wage level) both in inpatient and outpatient care. This suggests an unequal distribution of these payments among health care staff. If the amount paid from every patient is considered individually, it results that these payments have a big impact on patient's welfare. The situation is particularly dramatic for people in the lowest quintile of the expenditure distribution (World Bank, 2006).

Table 1.3 shows the breakdown of out-of-pocket health expenditures by the main subcategories for outpatient and inpatient care in 2002, 2005 and 2008 respectively. As can be seen, the payments vary by types of services. Expenses on medicines are the highest in outpatient care while payments for treatment are the highest expenses in inpatient care.

Table 1.3. Out-of-pocket expenditures ${ }^{6}$ by main components for outpatient and inpatient health care service

\begin{tabular}{|c|c|c|c|c|c|c|}
\hline YEAR & TREATMENT & $\begin{array}{l}\text { INFORMAL } \\
\text { PAYMENTS }\end{array}$ & MEDICINE & $\begin{array}{c}\text { LABORATORY } \\
\text { WORK }\end{array}$ & $\begin{array}{c}\text { TRANSPORT } \\
\text { EXPENDITURES }\end{array}$ & $\begin{array}{c}\text { OUT-OF-POCKET } \\
\text { AS } \% \text { OF } \\
\text { MONTHLY PER } \\
\text { CAPITA } \\
\text { CONSUMPTION }\end{array}$ \\
\hline \multicolumn{7}{|c|}{ Outpatient care - (Lek paid per health care visit for those who made payments) } \\
\hline Year 2002 & 302.68 & 101.86 & 1040.86 & 215.59 & 166.57 & 0.22 \\
\hline Year 2005 & 327.37 & 70.99 & 939.64 & 158.25 & 83.66 & 0.19 \\
\hline Year 2008 & 618.63 & 67.63 & 1198.45 & 289.7 & 194.08 & 0.12 \\
\hline \multicolumn{7}{|c|}{ Inpatient care - (Lek paid per day hospitalised for those who made payments) } \\
\hline Year 2002 & 4738.46 & 4903.6 & 2897.47 & 981.96 & 1126.44 & 1.98 \\
\hline Year 2005 & 6769.23 & 4825.37 & 8700.19 & 1912.73 & 1713.25 & 3.26 \\
\hline Year 2008 & 15729.2 & 4802.31 & 11664.11 & 3595.19 & 3272.06 & 2.55 \\
\hline
\end{tabular}

Source: Own compilation using ALSMS 2002, 2005, 2008

The table shows that payments per health care episode occupy a substantive share of total monthly per capita expenditures. In 2002, this share was 22 per cent in outpatient and 198 per cent in inpatient care, while it varies over the successive years reaching 12 and 255

\footnotetext{
${ }^{5}$ These differences may be also due to the fact that outpatient patient pay less to these medical doctors and that their salaries are higher on average (since they have a contract with health insurance).

${ }^{6} \mathrm{WHO}$ defines out-of-pocket expenditures as the sum of all out-pocket-payments made by individuals at the time of delivery.
} 
per cent in 2008. Throughout all years, the highest burden is posed over the lowest quintiles demonstrating the regressive nature of such payments. The table shows that informal payments to medical staff are evident in both services but are much higher for inpatient care. Informal payments for outpatient care have declined over the years in real terms, whereas these payments for inpatient services have not changed much from 2002 to 2008. They represent a relatively low share of total out-of-pocket payments but if a more inclusive definition of informal payments is used (see the definitions above) this share will be much higher in inpatient care where the services are supposed to be free of charge.

\subsection{Aim of the dissertation}

The main goal of this dissertation is to shed new light on the causes of informal payments in public health care services and to understand how such payments affect the allocation of resources at the micro-level between patients and medical staff and within households in Albania. This study presents a new approach to test the determinants and effects of such payments at the micro level by giving a perspective on the dynamics of the relationships between patients and medical staff and between household members. The following issues are addressed in the dissertation.

The first aim of this thesis is to look at the effect of out-of-pocket and informal payments on household expenditures. Uninsured health care events may have catastrophic consequences for households and hinder their long-term income generating capabilities. Health care costs are considered catastrophic when they force individuals or households to significantly decrease their standard of living now or in the future (Stiglitz, 1988). This may not only push them into a closed circle of inter-generational transmission of poverty (Baeza and Packard, 2006), but may also prevent them from getting necessary health care services. But, are out-of-pocket and informal payments in Albania catastrophic to households? And if yes, what is their effect on poverty? A decomposition of out-of-pocket payments by different consumption quintiles is used to capture their effect on different population groups.

The second aim is to test if informal payments to medical staff in a post-communist country like Albania are a consequence of cultural factors, lack of resources and economic factors, or lack of good governance. The causes of informal payments are mostly related to the former 'Shemasko' systems and inefficiencies in provision of health care (McKee 1991). Previous studies (Delcheva et al., 1997; Balabanova and McKee, 2002; Vian et al., 2006; Ensor and Savelyeva, 1998; Ensor and Witter, 2001; Chawla et al., 1998; Lewis, 2002; Miller et al., 2000; Thompson and Xavier, 2002; Gaal and McKee, 2005) have listed a series of factors that may lead to informal payments in the Eastern European countries. The long term persistence of informal payments in countries like Albania has proven that understanding the causes and linking them to effective policies against informal payments it is not an easy task. Empirical papers have shown that isolated measures like increasing the salaries of medical staff and enforcing the links between health insurance and service provision will not reduce informal payments (Lewis, 2002). A profound analysis of the main causes would certainly help in identifying the remedies. The three main models explaining informal payments in the country (a) cultural, (b) economic and (c) governance are tested for by using results from modelling the amount paid using tobit and Heckman selection model. 
Propensity score matching technique is also used to investigate the change in individual characteristics of people paying informally over different years (2002, 2005 and 2008).

Looking at the strategies that different households use when deciding on how to allocate their resources over different members for informal payments is the third aim of this research. The households here are divided in nuclear and extended according to the kinship relation. Nuclear households include two generation families (the household head, spouse and children) or single headed households. The extended households include families with more than two generations, multiple couples living together, or couples living together with more distant relatives. Households differ in the strategies employed to cope with health care expenditures. They may decide to sell assets, use savings or simply allocate strategically their scarce resources between household members. The human capital theory predicts that when faced with financial constraints households prefer to invest more on members with higher expected returns in the future. Household members with higher income generating capabilities also have more bargaining power within the household. These predictions imply that household members may be treated differently, and that household's reaction to informal payments may also differ depending on the number of household members and the type of service required. To date, little is known on the impact that decision-making within the household has on the amounts paid for different members. In societies where the patriarchal structure is still in place, like in Albania, it is important to see if decision making on health expenditure depends on future expected returns or the position that the patient has in the household. The decision to distribute resources for informal payments among household heads, spouses and children is compared between nuclear and extended households.

The fourth aim is to measure the imperfect information that exists on the amount paid informally to medical staff for inpatient care and measure its effect on the actual amount paid. If it is assumed that patients are willing to pay a certain amount and physicians are expecting a certain minimum one. The difference with the actual amount reflects 'ignorance' of patients and physicians on this. The actual payment may therefore be influenced by the information that each party have on it. Studies on such effects are scarce. This study presents a new approach to capture such effects and measure imperfect information. The indicators of patients and medical staff imperfect information on the amount that the other party is requesting or willing to pay respectively are captured by a two-tiered stochastic frontier model. This allows measuring the extent to which patients pay more than the amount medical staff expect and the extent to which medical staff request less than patients are willing to pay.

The empirical analysis of this dissertation is performed using data from the Albanian Living Standard Measurement Surveys (ALSMS) 2002, 2005 and 2008. ${ }^{7}$ The ALSMS uses a

\footnotetext{
7 LSMS is a national representative survey that collects information on different indicators of health, education, economic activities, housing and utilities for households all around Albania. The 2002, 2005 and 2008 Albania Living Standard Measurement Surveys (ALSMS) provides individual level and household level socio-economic data from households drawn from urban and rural areas in Albania. The sample was designed to be representative of Albania as a whole, Tirana, other urban/rural locations, and the three main agro-ecological areas (Coastal, Central, and Mountain). The survey was
} 
stratified geographical sample dividing Albania in four main areas; Tirana (the capital) and three main other agro-ecological/economic areas (Coastal, Central and Mountainous). The survey is therefore representative for all areas. The cities and the villages were divided into enumeration areas (EAs) according to the 2001 General Census of Population and Housing. The sample size was set to $450 \mathrm{EA}$ and in each EA 8 households were selected (World Bank and INSTAT, 2003). ${ }^{8}$ So, the total sample size of the LSMS aimed was 3599 in 2002, 3640 in 2005, (Tirana has been oversampled by 25 EA in 2005 due to the migration process) and 3600 in 2008. The questionnaires include information on household demography, education, labour, income, health status and health care episodes, and health care payments. The health module includes questions on visits to public hospitals in the last 12 months (hereafter referred to as inpatient services), and health care posts/centres/polyclinics in the last 4 weeks (hereafter referred to as outpatient services).

\subsection{Outline of the dissertation}

This dissertation is conceptualised as a series of studies investigating different aspects of informal payments of the Albanian health care system. The dissertation starts by giving a general overview of the impoverishing effect of out-of-pocket and informal payments and narrows down in more analytical studies of informal payments.

Chapter 2 looks at the effect that out-of-pocket and informal payments have on the expenditures of households and poverty. The analysis uses newly available data from ALSMS 2002, 2005, and 2008 to decompose this effect by different consumption quintiles.

Chapter 3 looks at the main determinants of informal payments to medical staff in Albania. Inpatient and outpatient care are analysed separately so that the differences in the organisation of these two services are taken into account. The analysis uses household level data (ALSMS 2002, 2005 and 2008) for those patients who have visited outpatient and inpatient care. The effect of the individual characteristics (visiting health care services) on informal payments is explored using tobit and Heckman selection models and their dynamics over time are explored using propensity score matching techniques.

The intra-household allocation of resources for informal payments to medical staff is analysed in chapter 4 . The differences between nuclear (spouses and children) and extended (spouses, children and others) are tested for using a generalised Hausman specification test for both outpatient and inpatient care. The analysis compares how nuclear and extended households allocate resources for informal payments to household heads, spouses and children, using ALSMS 2002 and 2005.

Chapter 5 looks at the price determination process between patients and medical staff in inpatient service. Imperfect information of patients and medical staff is estimated using a two-tiered stochastic frontier model. Patient's maximum willingness to pay informally and

carried out by the Albanian Institute of Statistics (INSTAT) with the technical and financial assistance of the World Bank and the Department for International Development (DfiD).

${ }^{8}$ Given a certain level of non-response expected, for each of the sample EA there were selected 4 reserve units. 
medical staff's minimum expected amounts are also estimated using pooled data from ALSMS 2002 and 2005.

Chapter 6 draws the main conclusion from the empirical analyses in the previous chapters. The conclusion provides the basis for main recommendations on effective policies to eliminate informal payments for health care. Such policies should not only limit informal payments but also increase the efficiency of the health sector while protecting the most vulnerable groups. 


\section{Chapter 2. ARE HEALTH CARE \\ PAYMENTS IN ALBANIA \\ CATASTROPHIC? EVIDENCE \\ FROM ALSMS 2002, 2005 \\ AND 2008}

Part of the analysis in this chapter is used for:

World Bank, 2011 (expected). "Out-of-Pocket Payments in Albania's Health System" Country policy report, Accountability for Better Governance AAA task (P107759), Europe and Central Asia Regional Office, World Bank, Washington DC 


\begin{abstract}
The absent or poorly functioning risk pooling mechanisms and high amounts of out-ofpocket payments for health care expose households to financial risks associated with major illnesses or accidents. The aim of this chapter is to analyse the extent to which out-of-pocket health spending impoverish households in Albania. The study augments the existing evidence by analysing the dynamics of such payments over different years and the weight that informal payments have in the total out-of-pocket health spending.

The data used in this study come from the Albania Living Standard Measurement Survey (ALSMS) for 2002, 2005 and 2008. We measure headcount catastrophic payments using different thresholds and the decomposition of indicators by expenditure quintiles to understand better their effects. We find that out-of-pocket and informal payments have increased in real value throughout the years. Even though their catastrophic effect has gone down (due also to declining trends in absolute poverty), the effect for the poorest expenditure quintiles remains high. Out-of-pocket payments deepen the poverty headcount and also enlarge the poverty gap and again the effect is larger for the poorest quintiles. Future policy interventions should provide better protection mechanisms for the poor by providing exemption criteria or subsidised transport and should seek to address the widespread informal payments in the country.
\end{abstract}




\subsection{Introduction}

High levels of out-of-pocket payments for health care expose households to financial risks associated with major illness (World Bank, 1993, 1995a; WHO 2005). Expecting households to make some financial contribution for their health care is reasonable even in wealthy countries with sophisticated public and private health insurance, and particularly for frequently occurring conditions that are inexpensive to remedy. However, an over reliance on out-of-pocket payments for health care may endanger households' customary standards of living and disrupt household welfare (Berki, 1986; O'Donnell et al., 2005 \& 2008; Gertler and Gruber, 2002; Xu et al., 2003), particularly for serious, less-frequently occurring conditions for which the costs of treatment can quickly mount. Households, especially in developing countries, may not be able to insure their basic needs (World Bank 1993, 1995a) and uninsured health care events can therefore increase the risks of loss of incomes from reduced labour supply or lower productivity. This can cause long-term consequences pushing them into a "trans-generational cycle" of poverty (Baeza and Packard, 2006). High out-of-pocket payments for health care can also prevent some people from seeking necessary health care creating thus barriers to access for the most poor ( $\mathrm{Xu}$ et al., 2007).

In essence, health care costs can be considered catastrophic when they force individuals or households to significantly decrease their standard of living now or in the future (Stiglitz, 1988). A survey of 89 countries has showed that almost 150 million people globally suffer financial catastrophe because of high out-of-pocket health care expenditures (Xu et al., 2007). Giving that one of the main objectives of health care systems should be ensuring the equity among health care seekers, households should be protected against such catastrophic medical expenditures (WHO 2000).

While cross country comparisons show that out-of-pocket payments are prevalent in most Western Balkans Countries, recent studies (Bredenkamp et al., 2010) show that catastrophic out-of-pocket payments (including informal payments) in Albania are higher than in most other countries. When this finding is examined alongside the much higher share of out-of-pocket over total health financing in Albania and the much higher incidence of informal payments, concern that these payments are further raising barriers to care and increasing the financial vulnerability of households grows.

This chapter looks at the effect of out-of-pocket and informal payments on household expenditures by exploring the existing and the newly available ALSMS (Albania Living Standard Measurement Survey) data for 2002, 2005 and 2008. The chapter focuses on two main aspects of out-of-pocket payments: (i) the incidence and intensity of 'catastrophic' health care expenditure, and (ii) the effect of out-of-pocket payments on poverty headcount and poverty gap measures. The main questions that this chapter attempts to answer are: Does out-of-pocket health spending impoverish the households in Albania? And what weight do informal payments have in increasing the burden of out-of-pocket health spending? The chapter uses the decomposition of out-of-pocket payments in health care by main expenditure quintiles to look at the particular burden for different categories. Further 
decomposition of such payments by main components and public/private sector aims to give a 'panoramic' picture of the main developments over the years.

\subsection{Data and methodology}

Out-of-pocket expenditures for health care in Albania are assessed in this chapter using ALSMS data for three different years, 2002, 2005 and 2008. The data are representative for Albania and are collected using a similar methodology. However they can only offer crosssection features and lack the longitudinal dimension. Longitudinal data would be ideally if we want to estimate the extent to which living standards are disrupted by the purchase of medical care in response to illness shocks (O'Donnell et al., 2008). This allows to see how household well-being is affected by certain health shocks (Gertler and Gruber, 2002; Wagstaff, 2007). However, as often only cross-section data are available, it has been proposed to define out-of-pocket payments as catastrophic if they exceed a critical share of households' resources during one year (Berki, 1986; Russell, 2004; Wagstaff and van Doorslaer, 2003; Xu et al., 2003). In this chapter we exploit the same definitions used in different ALSMS to compare the trends of out-of-pockets and their impoverishing effects over the years.

One of the debatable points in the literature is the choice of the comparators of out-ofpocket payments (O'Donnell et al., 2008). The two possibilities are to calculate out-of-pocket as a share of household's income, consumption or expenditure. All measures have advantages and disadvantages. Income is often argued to be a better denominator as it is completely irresponsive of health care expenditures. However, this advantage is offset by the fact that an out-of-pocket-to-income ratio will not account for the use of other resources available to some of the households and not available to others (e.g. the use of savings). Total expenditures on the other hand may be more responsive to health care. For example for the poor households resources tend be directed to items that are indispensable (i.e. food). Given this the poorest will always tend to spend more on such subsistence items leaving little to health care. One of the solutions mentioned in O'Donnell et. al. (2008) is to consider catastrophic payments as the share of out-of-pocket payments to the non-necessity total expenditures (defined often as the expenditure on non-food items). Because of the nonindispensable nature, non-food expenditure may distinguish better between the poor and the rich. Given these reasons and also the fact that poverty measures in countries like Albania are based primarily on expenditures rather than income (World Bank, 2006) we present here the estimated catastrophic health payments based on non-health expenditure. To test for the consistency of the results when expenditures on non-food items are considered we have also estimated the tables for the catastrophic effect of out-of pocket payments on such expenditures (see also Table A2.1 in the Appendix 2A).

Health economists have not yet agreed on a uniformly accepted threshold of out-ofpocket spending that triggers alarm or that unambiguously motivates a policy response. Different researchers have used varying thresholds from 5 percent (Berki, 1986), 10 percent (Waters et al., 2004) and up to 40 percent when non-subsistence spending is used as a denominator (Xu et al., 2003; Wagstaff and van Doorslaer, 2003). In order to test the sensibility of our estimations we discuss here the results for different thresholds. 


\subsection{Out-of-pocket spending in Albania}

Previous work on Albania and other Western Balkan countries has shown that out-ofpocket payments remain high for most of these countries (Bredenkamp et al., 2010). Such spending has been reported to amount to more than $6 \%$ of the per capita expenditures in Albania. However, the aggregate figures can only tell about the overall impact of these outof-pocket expenditures. The separate effects of private and public expenditures or formal and informal payments over the last years are less known.

Table 2.1 gives the mean per capita expenditures on health and non-health items (indexed with 2002 prices). As it can observed the gross per capita expenditures for households who have paid out-of-pocket payments have increased in real value during the years from 11092 Albanian Leks (ALL) ${ }^{9}$ in 2002 to 11923 in 2008.

This is consistent with the decrease in the headcount poverty indexed throughout the same years (INSTAT, 2009). On the other hand, this increase has been mostly dedicated to both out-of-pocket expenditures and other non-health expenditures. Spending on all out-ofpocket items was on average 808.30 ALL in 2002 and increased to 1125.65 in 2008. The same trend is almost true for all the items of spending (formal payments, informal payment, transport or expenditures on private health care providers and drugs purchased on own initiative). Formal payments and payments in the health sector are two categories with the largest increase over the years. Formal payments per capita have increased with almost 500ALL from 2002 to 2008 (from 767ALL to 1269ALL) while expenditures on private sector have increased with 175ALL over the same period (from 298ALL to 473ALL). The value of informal payments per capita has also increased substantially over the years from 220ALL in 2002 to 384ALL in 2008. The constant increase of such payments throughout the whole period demonstrates once more their prevailing incidence in the health sector (despite any measures taken).

The dynamic of categories of payments over the years is also interesting. Payments for most of the categories, i.e. formal payments, transport or payments in private, seem to have decreased in real value from 2002 to 2005 while they have increased substantially in 2008 . The increase in formal payments may be due to a more aggressive policy in enforcing the referral system or increasing the fees paid for both outpatient and inpatient care. On the other side, the increased share of the private sector is more evident in 2008 causing also a substantial increase in the money spent in this sector. While the increase in total out-ofpocket payments in 2008 seems warring, another warring trend is the distribution of informal payments between quintiles of per capita expenditure. As it can be observed, the amount that the lowest quintiles pay informally have increased almost five times over the years (from 121 in 2002 to 777ALL in 2008) while this is accompanied by a more moderated increase in the amount paid informally by the other higher quintiles. The formal payments for the same quintile have almost doubled for the same period, demonstrating that the effects of any increase in fees are mostly transmitted to the lowest quintiles.

\footnotetext{
${ }^{9}$ All prices are deflated to 2002 prices. 100 ALL = 0.73 Euros in June 2002 (Bank of Albania, 2010).
} 
Table 2.1. The mean per capita expenditures on health and non-health items (in Albanian Leks)

\begin{tabular}{|c|c|c|c|c|c|c|c|}
\hline $\begin{array}{l}\text { Non-health } \\
\text { expenditure } \\
\text { quintiles }\end{array}$ & $\begin{array}{c}\text { Per capita gross } \\
\text { expenditure (health } \\
\text { payment inc) }\end{array}$ & $\begin{array}{c}\text { Per capita } \\
\text { health } \\
\text { expenditures } \\
\text { on formal } \\
\text { payments }\end{array}$ & $\begin{array}{c}\text { Per capita } \\
\text { informal } \\
\text { payments in } \\
\text { public health } \\
\text { care }\end{array}$ & $\begin{array}{c}\text { Per capita } \\
\text { health } \\
\text { expenditures } \\
\text { on transport }\end{array}$ & $\begin{array}{c}\text { Per capita } \\
\text { total } \\
\text { expenditures } \\
\text { in private } \\
\text { health sector }\end{array}$ & $\begin{array}{l}\text { Overall per } \\
\text { capita health } \\
\text { expenditures }\end{array}$ & $\begin{array}{l}\text { Per capita net } \\
\text { expenditure } \\
\text { (health } \\
\text { payments exc) }\end{array}$ \\
\hline \multicolumn{8}{|c|}{ YEAR 2002} \\
\hline $\begin{array}{l}\text { Lowest } \\
\text { quintile }\end{array}$ & $4296.69^{* * *}$ & $475.14^{* * *}$ & $121.17^{* * *}$ & $101.82^{* * *}$ & $144.49^{* * *}$ & $493.94^{* * *}$ & $3802.75^{* * *}$ \\
\hline 2 & $6230.03^{* * *}$ & 659.04 & 165.96 & 188.14 & $183.04^{* * *}$ & $653.82^{* *}$ & $5576.20^{* * *}$ \\
\hline 3 & $7915.78^{* * *}$ & $591.48^{* * *}$ & $177.93^{*}$ & $128.94^{* *}$ & 265.7 & $698.51^{*}$ & $7217.28^{* * *}$ \\
\hline 4 & $10317.47^{* * *}$ & 777.19 & 229.42 & 248.82 & $236.42^{*}$ & 780.42 & $9537.05^{* * *}$ \\
\hline $\begin{array}{l}\text { Highest } \\
\text { quintile }\end{array}$ & $18077.70^{* * *}$ & $1041.31^{* * *}$ & $318.72^{* * *}$ & $286.27^{*}$ & $471.78^{* * *}$ & $1071.82^{* * *}$ & $17005.89^{* * *}$ \\
\hline Total & \multicolumn{6}{|c|}{ YEAR 2005} & 10284.00 \\
\hline $\begin{array}{l}\text { Lowest } \\
\text { quintile }\end{array}$ & $4394.93^{* * *}$ & $496.82^{* * *}$ & $152.64^{* * *}$ & $104.60^{* *}$ & $157.97^{* * *}$ & $519.44^{* * *}$ & $3875.50^{* * *}$ \\
\hline 2 & $6446.95^{* * *}$ & 639.36 & 278.78 & 128.55 & $179.59^{* * *}$ & 617.97 & $5828.98^{* * *}$ \\
\hline 3 & $8698.88^{* * *}$ & 749.24 & 267.69 & 127.79 & 271.39 & 763.44 & $7935.44^{* * *}$ \\
\hline 4 & $11147.78^{* *}$ & 753.25 & 252.24 & 141.84 & 264.33 & 708.37 & $10439.42^{* *}$ \\
\hline $\begin{array}{l}\text { Highest } \\
\text { quintile }\end{array}$ & $19054.34^{* * *}$ & $1041.77^{* * *}$ & $348.80^{* *}$ & $202.30^{*}$ & $381.92^{* * *}$ & $902.40^{* * *}$ & $18151.94^{* * *}$ \\
\hline Total & 10801.00 & 748.55 & 256.89 & 136.39 & 267.80 & 723.05 & 10077.95 \\
\hline \multicolumn{8}{|c|}{ YEAR 2008} \\
\hline $\begin{array}{l}\text { Lowest } \\
\text { quintile }\end{array}$ & $5438.88^{* * *}$ & $865.67^{*}$ & 777.96 & 182.29 & $203.18^{* * *}$ & 849.31 & $4589.57^{* * * *}$ \\
\hline 2 & $7655.03^{* * *}$ & 1039.79 & 208.58 & $150.78^{*}$ & 327.82 & 866.62 & $6788.40^{* * *}$ \\
\hline 3 & $9520.95^{* * *}$ & $972.28^{*}$ & 230.17 & 186.8 & $307.83^{*}$ & $769.02^{* *}$ & $8751.93^{* * *}$ \\
\hline 4 & $12837.11^{* *}$ & 1494.32 & 426.61 & 288.23 & 727.13 & 1463.46 & $11373.65^{* *}$ \\
\hline $\begin{array}{l}\text { Highest } \\
\text { quintile }\end{array}$ & $21422.69^{* * *}$ & $1797.93^{*}$ & 336.94 & 236.36 & $658.98^{*}$ & $1520.30^{*}$ & $19902.39^{* * *}$ \\
\hline Total & 11923.66 & 1269.22 & 384.54 & 208.19 & 473.96 & 1125.65 & 10798.01 \\
\hline
\end{tabular}

Note: Stars indicate if the mean for the particular group is significantly different from the mean of all other groups (*** $\left.\mathrm{p}<0.01,{ }^{* *} \mathrm{p}<0.05,{ }^{*} \mathrm{p}<0.1\right)$.

Expenditures are given as mean for each of the categories only for those households which have actually spent for that particular category. Per capita health expenditures on formal payments include out-of-pocket expenditures on medical fees, laboratory works and drugs purchased in public outpatient and inpatient care (expenditures incurred in hospitals outside from Albania are omitted in the table). Informal payments include gifts paid to medical staff for public outpatient and inpatient care. Health expenditures in private sector include out-of-pocket expenditures on medical fees, laboratory works, drugs purchased and gifts to medical staff for private care.

Similarly to the previous table, Table 2.2 above shows the distribution of health and non-health expenditures across each of the quintiles. The table shows that generally the most poor, i.e. the lowest quintile, spend much more in non-direct costs, i.e. transportation or informal payments, compared to the other items. Moreover, the table shows that such figures have increased substantially over the years for this lowest quintile. Hence, in 2008 almost 30 per cent of all the amount of informal payments and 21 per cent of all 
transportation costs belonged to the lowest quintile (while these shares were 7 and 9 per cent respectively in 2002).

Table 2.2. Financing budget shares on health and non-health items

\begin{tabular}{|c|c|c|c|c|c|c|c|}
\hline $\begin{array}{l}\text { Non-health } \\
\text { expenditure } \\
\text { quintiles }\end{array}$ & $\begin{array}{c}\text { Per capita } \\
\text { expenditure } \\
\text { gross of health } \\
\text { payments }\end{array}$ & $\begin{array}{c}\text { Per capita } \\
\text { health } \\
\text { expenditures } \\
\text { on formal } \\
\text { payments }\end{array}$ & $\begin{array}{c}\text { Per capita } \\
\text { informal } \\
\text { payments in } \\
\text { health care }\end{array}$ & $\begin{array}{c}\text { Per capita } \\
\text { health } \\
\text { expenditures } \\
\text { on transport }\end{array}$ & $\begin{array}{c}\text { Per capita } \\
\text { private } \\
\text { expenditures } \\
\text { in private } \\
\text { sector }\end{array}$ & $\begin{array}{l}\text { Overall per } \\
\text { capita health } \\
\text { expenditures }\end{array}$ & $\begin{array}{c}\text { Per capita } \\
\text { expenditure } \\
\text { net of } \\
\text { payments }\end{array}$ \\
\hline \multicolumn{8}{|c|}{ YEAR 2002} \\
\hline Lowest quintile & 0.04 & 0.08 & 0.07 & 0.09 & 0.07 & 0.07 & 0.04 \\
\hline 2 & 0.08 & 0.16 & 0.12 & 0.19 & 0.10 & 0.14 & 0.07 \\
\hline 3 & 0.11 & 0.15 & 0.17 & 0.17 & 0.18 & 0.16 & 0.11 \\
\hline 4 & 0.20 & 0.22 & 0.24 & 0.26 & 0.19 & 0.22 & 0.20 \\
\hline Highest quintile & 0.57 & 0.39 & 0.40 & 0.29 & 0.47 & 0.41 & 0.57 \\
\hline Total & 100.00 & 100.00 & 100.00 & 100.00 & 100.00 & 100.00 & 100.00 \\
\hline \multicolumn{8}{|c|}{ YEAR 2005} \\
\hline Lowest quintile & 0.06 & 0.11 & 0.10 & 0.15 & 0.07 & 0.10 & 0.06 \\
\hline 2 & 0.11 & 0.17 & 0.23 & 0.21 & 0.12 & 0.16 & 0.11 \\
\hline 3 & 0.15 & 0.20 & 0.20 & 0.21 & 0.19 & 0.20 & 0.15 \\
\hline 4 & 0.23 & 0.21 & 0.16 & 0.21 & 0.22 & 0.21 & 0.23 \\
\hline Highest quintile & 0.45 & 0.31 & 0.32 & 0.22 & 0.40 & 0.33 & 0.46 \\
\hline Total & 100.00 & 100.00 & 100.00 & 100.00 & 100.00 & 100.00 & 100.00 \\
\hline \multicolumn{8}{|c|}{ YEAR 2008} \\
\hline Lowest quintile & 0.08 & 0.13 & 0.30 & 0.21 & 0.08 & 0.13 & 0.08 \\
\hline 2 & 0.12 & 0.13 & 0.12 & 0.14 & 0.12 & 0.13 & 0.12 \\
\hline 3 & 0.16 & 0.18 & 0.13 & 0.16 & 0.15 & 0.17 & 0.16 \\
\hline 4 & 0.22 & 0.25 & 0.24 & 0.25 & 0.34 & 0.28 & 0.22 \\
\hline Highest quintile & 0.42 & 0.31 & 0.20 & 0.24 & 0.30 & 0.30 & 0.43 \\
\hline Total & 100.00 & 100.00 & 100.00 & 100.00 & 100.00 & 100.00 & 100.00 \\
\hline
\end{tabular}

Note: 1) Per capita health expenditures on formal payments include out-of-pocket expenditures on medical fees, laboratory works and drugs purchased in public outpatient and inpatient care (expenditures incurred in hospitals outside from Albania are omitted in the table). 2) Informal payments include gifts paid to medical staff for public outpatient and inpatient care. 3) Health expenditures in private sector include out-of-pocket expenditures on medical fees, laboratory works, drugs purchased and gifts to medical staff for private care.

The same could be said for other health expenditures like the formal payments or private costs which have increased to 13 per cent respectively for this quintile. Unfortunately, this increase in the relative shares of out-of-pocket payments has not been accompanied by a similar increase in the relative per capita non-health expenditure (which has only increased from 4 to 8 per cent for the poorest quintile). This shows again that policy measures through 2002 and 2008 have had a negative impact on the poorest quintiles. In 2008 the poorest households have on (average) relatively less budget than the rich if compared to 2002, but they face higher out-of-pocket payments. The dramatic increase in non-direct health care costs demonstrates that these people now face more barriers to health care than before. 


\subsection{Catastrophic payments in health care in Albania}

When total expenditure is used as the denominator the most common threshold employed in the literature to measure catastrophic spending is 10 percent - the threshold at which prior research has found households can be forced to sacrifice basic necessities (Pradhan and Prescott, 2002; Rason, 2002; Wagstaff and van Doorslaer, 2003).

Table 2.3 presents alternative measures for out-of-pocket payments for health care for each quintile of household non-health expenditure, over the three waves of the ALSMS.

Table 2.3. Incidence and intensity of catastrophic health payments defined with respect to total expenditure

\begin{tabular}{|c|c|c|c|c|}
\hline \multirow{2}{*}{ CATASTROPHIC PAYMENTS MEASURES } & \multicolumn{4}{|c|}{ "THRESHOLD BUDGET SHARE } \\
\hline & Thresh. 5\% & Thresh. 10\% & Thresh. 15\% & Thresh. $25 \%$ \\
\hline \multicolumn{5}{|c|}{ YEAR 2002} \\
\hline \multicolumn{5}{|l|}{ Headcount $(\mathrm{H})$} \\
\hline Lowest quintile & 45.2 & 29.9 & 20.6 & 12.2 \\
\hline 2 & 41.1 & 26.7 & 18.2 & 8.9 \\
\hline 3 & 37.2 & 24.1 & 15.1 & 8.6 \\
\hline 4 & 33.8 & 20.6 & 13.4 & 6.5 \\
\hline Highest quintile & 25.3 & 11.7 & 7.3 & 4.1 \\
\hline Total & 36.5 & 22.6 & 14.9 & 8.1 \\
\hline Overshoot (O) & 5.4 & 4.0 & 3.1 & 2.0 \\
\hline Mean positive overshoot (MPO) & 45.2 & 29.9 & 20.6 & 12.2 \\
\hline \multicolumn{5}{|c|}{ YEAR 2005} \\
\hline \multicolumn{5}{|l|}{ Headcount $(\mathrm{H})$} \\
\hline Lowest quintile & 42.9 & 28.7 & 20.6 & 13.2 \\
\hline 2 & 39.1 & 22.3 & 14.4 & 5.8 \\
\hline 3 & 33.6 & 18.5 & 12.8 & 6.4 \\
\hline 4 & 25.6 & 11.8 & 6.7 & 2.8 \\
\hline Highest quintile & 17.2 & 6.8 & 3.5 & 1.7 \\
\hline Total & 31.6 & 17.6 & 11.6 & 6.0 \\
\hline Overshoot (O) & 3.9 & 2.7 & 2.0 & 1.2 \\
\hline Mean positive overshoot (MPO) & 12.4 & 15.6 & 17.4 & 19.9 \\
\hline \multicolumn{5}{|c|}{ YEAR 2008} \\
\hline \multicolumn{5}{|l|}{ Headcount $(\mathrm{H})$} \\
\hline Lowest quintile & 28.9 & 20.0 & 13.8 & 10.0 \\
\hline 2 & 25.0 & 14.8 & 10.7 & 6.3 \\
\hline 3 & 22.4 & 12.0 & 7.9 & 4.5 \\
\hline 4 & 20.1 & 11.3 & 7.9 & 3.5 \\
\hline Highest quintile & 15.9 & 8.4 & 5.0 & 2.9 \\
\hline Total & 22.5 & 13.3 & 9.1 & 5.4 \\
\hline Overshoot $(\mathrm{O})$ & 5.0 & 4.1 & 3.5 & 2.8 \\
\hline Mean positive overshoot (MPO) & 22.1 & 30.8 & 38.9 & 52.2 \\
\hline
\end{tabular}

The headcount (incidence) in this table is the share of individuals for whom the proportion of out-of-pocket payments for health (shown as a percentage of total spending), exceeds a number of set thresholds, ranging from 5 per cent to 25 per cent. In 200222.6 per cent of the population paid health care out-of-pocket costs that exceeded 10 per cent of their total per capita budget. Encouragingly, this incidence declined to 17.6 per cent in 2005, and 
further to 13.3 in 2008. The largest drop occurred between 2005 and 2008 and may be related to the general fall in poverty during that period (INSTAT, 2009). However, as observed previously, households in the lowest quintile seemed to have suffered the most from catastrophic payments (according to this threshold) throughout the period of analysis. The share of individuals in the lowest quintiles paying more than 10 per cent of their total expenditures for out-of pocket health care was about 29-30 per cent in 2002 and 2005 and only decreased to 20 per cent in 2008.

The second part of Table 2.3 also gives information on the measures of catastrophic overshoot for each of the years. This measure represents the average extent by which health care expenditure (as a proportion of total non-health expenditure) exceeds the respective threshold. In other words it measures the intensity of catastrophic out-of-pocket payments. This is important as it complements the headcount measure of catastrophic payments (the incidence). The table shows that the intensity of catastrophic payments drops as the threshold is raised from 5 to 25 per cent of total non-health expenditure throughout all years. The mean positive overshoot on the other hand gives an idea of the average spending on out-of-pocket for all those exceeding the threshold. Hence, we observe that households spending more than 10 per cent of their expenditures on out-of-pocket spend on average 39.9 per cent in out-of-pocket in 2002, 25.6 per cent in 2005 and 40.8 per cent in $2008 .{ }^{10}$ As these numbers show the mean of out-of-pocket amount paid as a share of total non-health expenditure has increased sharply over the period 2005 and 2008. This reinforces our previous finding regarding the dramatic increase in certain categories of health care expenditure like the formal payments and the expenditures on private health care.

\subsection{The impoverishing impact of out-of-pocket expenditures in Albania}

Most societies care if the households paying catastrophic out-of-pocket payments belong to the poorest quintiles rather than the richest ones. The concentration index $\mathrm{CE}$ displayed in Table 2.4 can estimate such effect. A positive value of such concentration index shows that the better-off households have a greater tendency to fall into catastrophic payments and a negative value shows a greater tendency among the poorest. As we can see from the table in fact at every threshold we choose over the years, the poorest have a greater tendency to fall into catastrophic payments.

Table 2.4. Distribution-sensitive catastrophic payments measures - concentration index

\begin{tabular}{ccccc}
\hline \hline \multirow{2}{*}{ CONCENTRATION INDEX, CE } & \multicolumn{4}{c}{ THRESHOLD BUDGET SHARE } \\
Thresh. 5\% & Thresh. 10\% & Thresh . 15\% & Thresh. 25\% \\
\hline Year 2002 & -0.114 & -0.161 & -0.182 & -0.201 \\
Year 2005 & -0.168 & -0.257 & -0.299 & -0.364 \\
Year 2008 & -0.121 & -0.178 & -0.207 & -0.278 \\
\hline \hline
\end{tabular}

\footnotetext{
10 The mean of out-of-pocket payment as a ratio of total expenditures for households exceeding a certain threshold is given as the sum of the threshold and MPO (Z+MPO). For example in 2002 for the $10 \%$ threshold the mean of amount spent from those exceeding the threshold is $10 \%+29.9 \%=39.9 \%$.
} 
Table 2.5 shows that out-of-pocket health expenditures have increased the percentage of the poor Albanian households.

Table 2.5. Measures of poverty based on per capita expenditure gross and net of spending for health care.

\begin{tabular}{|c|c|c|c|c|}
\hline & $\begin{array}{c}\text { POVERTY } \\
\text { HEADCOUNT }\end{array}$ & POVERTY GAP & $\begin{array}{l}\text { NORMALISED } \\
\text { POVERTY GAP }\end{array}$ & $\begin{array}{c}\text { NORMALISED MEAN } \\
\text { POSITIVE POVERTY GAP }\end{array}$ \\
\hline \multicolumn{5}{|c|}{ YEAR 2002} \\
\hline Pre-payment headcount & 26.58 & 300.25 & 6.14 & 23.10 \\
\hline Post-payment headcount & 33.07 & 489.49 & 10.01 & 30.26 \\
\hline $\begin{array}{l}\text { Poverty impact- percentage } \\
\text { point change }\end{array}$ & 6.49 & 189.24 & 3.87 & 7.17 \\
\hline Percentage change & 24.42 & 63.03 & 63.03 & 31.03 \\
\hline \multicolumn{5}{|c|}{ YEAR 2005} \\
\hline Pre-payment headcount & 19.45 & 215.71 & 4.41 & 22.68 \\
\hline Post-payment headcount & 23.79 & 336.57 & 6.88 & 28.92 \\
\hline $\begin{array}{l}\text { Poverty impact- percentage } \\
\text { point change }\end{array}$ & 4.34 & 120.86 & 2.47 & 6.25 \\
\hline Percentage change & 22.33 & 56.03 & 56.03 & 27.54 \\
\hline \multicolumn{5}{|c|}{ YEAR 2008} \\
\hline Pre-payment headcount & 12.19 & 110.18 & 2.25 & 18.47 \\
\hline Post-payment headcount & 15.80 & 296.11 & 6.05 & 38.31 \\
\hline $\begin{array}{l}\text { Poverty impact- percentage } \\
\text { point change }\end{array}$ & 3.61 & 185.93 & 3.80 & 19.84 \\
\hline Percentage change & 29.60 & 168.75 & 168.75 & 107.38 \\
\hline
\end{tabular}

The poverty headcount has decreased from 2002 to 2008, but the post-payment poverty headcount are much higher if considering out-of-pocket expenditures for health care. Poverty increases by 6.49 percentage points in 2002, by 4.34 in 2005 and by 3.61 in 2008 . The poverty gap after payments has consistently been higher than the pre-payment one during all analysed years. The percent point impact for the poverty gap has increased from 189.24 in 2002 to 185.93 in 2008 showing the significant increase in inequalities due to out-of-pocket payments.

The catastrophic impact that out-of pocket expenditures have on households can be seen visually in Figure 2.1. The graphs are based on Jan Pen's parade of "dwarfs and a few giants" (see also Cowell, 1995; O'Donell et al., 2008) and give the impact of health care expenditures by plotting household expenditures gross and net of total out-of-pocket payments. The $x$-axis represents the cumulative proportion of households ranked by their total expenditures and y-axis gives the level of total expenditures and out-of-pocket payments in Albanian Leks. The two moments are represented by the pre and post expenditure per capita and are compared against the food poverty line (the horizontal line) that amounts to 3047ALL per capita. The drops in the expenditure levels are given by the vertical bars (which represent the exact amount of health care expenditures per capita). 
Figure 2.1. Poverty impact of health expenditure on the distribution of non-health expenditure

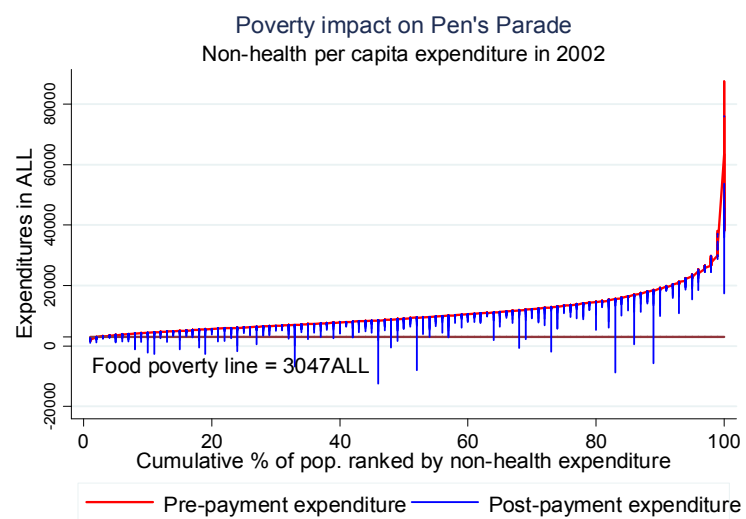

a) Year 2002

Poverty impact on Pen's Parade

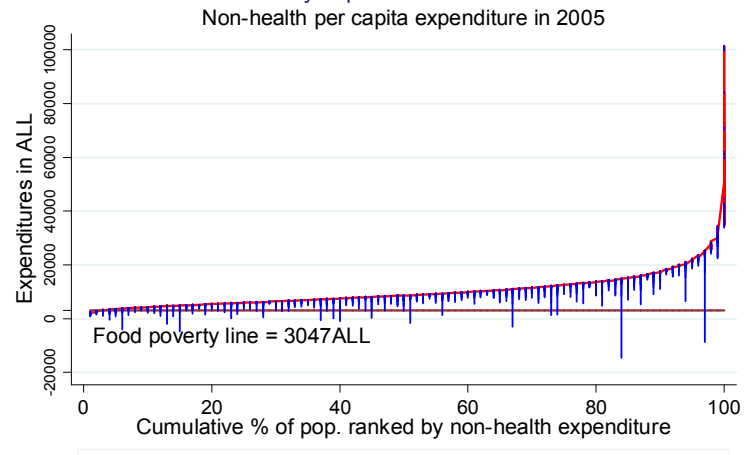

b) Year 2005

Poverty impact on Pen's Parade

Non-health per capita expenditure in 2008

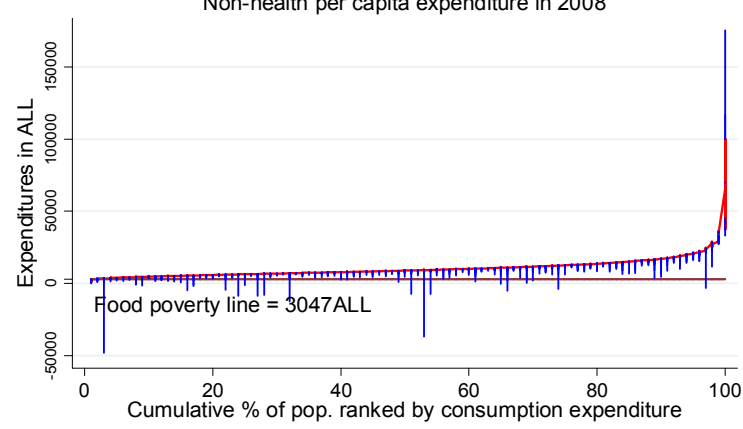

c) Year 2008

Cumulative $\%$ of pop. ranked by consumption expenditure

Pre-payment expenditure — Post-payment expenditure 
All graphs show that there are many households whose expenditures fall below the extreme poverty line if we assume that they forego other consumption for health care. Such effects are not only observed for the lowest quintiles but also for all the others. Out-ofpocket health expenditures tend to be higher for the higher quintiles (see Table 2.1) and when they are not insured they may drive also such quintiles in poverty. Graph (c) in Figure 2.1 shows that for 2008 catastrophic health care expenditures tend to be more severe for certain households. This is due to the increase in private health care expenditures and also the rise of formal payments. Such increases can be problematic even for the highest quintiles and show that can be problematic in the long-run if no forms of insurance are taken against them.

\subsection{Discussion and conclusions}

The weak role of national health insurance in Albania, especially for inpatient care (see also Chapter 1 and Chapter 3), exposes households to the financial risks associated with accidents and sickness. A large share of the health services have to be paid for out-ofpocket, sometimes up front at the point of service. Such payments include formal and informal payments to medical staff. Health insurance in Albania should cover most of the formal costs of primary health care and all the costs of hospital care. Patients are formally required to pay small, fixed co-payments per visit in PHC or for specialised treatments in hospital care. However, evidence from ALSMSs show that until 2008 the amounts reported as formal out-of-pocket payments remained high. This leads to believe that a large share of such payments is very likely to be defined as informal payments if a broader definition is employed (see also Table 1.1 in Chapter 1$).{ }^{11}$

The analysis of the trends of out-of-pocket payments over the different years in Albania has shown that they have increased in real value from 2002 to 2008. The increase has not been the same for all the categories and expenditure quintiles. Formal/informal payments and expenditure in the private sector have increased significantly from 2002 to 2008 while expenditure on transport has remained more or less stable. The data show that the poorest households remain the most financially vulnerable to the cost of health care. Generally the poorest people (in households in the lowest expenditure quintile) spend much more in nondirect health costs, i.e. transportation or informal payments, when compared with other items. This category of spending has also increased substantially over the years for households in the lowest quintile. The catastrophic headcounts for all thresholds show that out-of-pocket spending may lead to catastrophic health care expenditures in Albania. Considering a 10 percent threshold of total per capita expenditures these numbers are 22.6 per cent in 2002, 17.6 in 2005 and 13.3 in 2008. But eventhough catastrophic payments have declined substantially over the years, the decline for the poorest quintiles has not been in the same range remaining to 20.0 per cent in 2008.

Moreover, out-of-pocket health expenditures can contribute to poverty among Albanian households. Both poverty rates and poverty gaps after the occurrence of out-of-pocket expenditure for health become higher. This demonstrates an increased risk of falling in

\footnotetext{
${ }^{11}$ Payments for health care or medicals that otherwise should have been provided free are also consider informal payments under one for the definitions given in Table 1.1 in Chapter 1.
} 
poverty or extreme poverty among health care seekers. Such issues may also be more serious as we expect an underestimation of the figures presented here for the lower end of the income distribution. Generally these people face higher obstacles and financial constraints when seeking health care and therefore are more likely to not seek it at all.

Overall, the results show that Albanian authorities should consider more seriously the reduction of out-of-pocket payments through ensuring the effectiveness of prepaying mechanisms for health care. The impoverishing effects of such payments call for more attention from the policy makers. One of the possible interventions recommended would be revising the structure of user fees so that it reflects the income distribution (as the poor seem more likely to suffer the effects). This would include reinforcing fee exemptions for vulnerable groups (e.g. unemployed, recipients of social assistance, pregnant women, the disabled, people suffering severe illnesses, etc). Another potential policy measures are also price subsidies which have proven effective in reducing catastrophic payments in other countries (Pradhan and Prescott, 2002). Giving that particular items like informal payments or transportation costs have a significant contribution to overall out-of-pocket expenditures, the government should also have clear policies in addressing them. While informal payments are more difficult to address (as they require integrated measures dealing with governance, accountability and availability of resources), transportation costs may be cut down more easily through measures like subsidised transportation for the poor or simply a better distribution of health care centres. 


\subsection{Appendix 2A}

Table A2.1. Incidence and intensity of catastrophic health payments defined with respect to total non-food expenditure

\begin{tabular}{|c|c|c|c|c|c|}
\hline \multirow{2}{*}{$\begin{array}{c}\text { CATASTROPHIC PAYMENTS } \\
\text { MEASURES }\end{array}$} & \multicolumn{5}{|c|}{$\begin{array}{l}\text { THRESHOLD BUDGET SHARE } \\
\end{array}$} \\
\hline & Thresh. 5\% & Thresh. 10\% & Thresh. 15\% & Thresh. $25 \%$ & Thresh. $40 \%$ \\
\hline & & YEAR 2002 & & & \\
\hline \multicolumn{6}{|l|}{ Headcount $(\mathrm{H})$} \\
\hline Lowest quintile & 45.2 & 29.9 & 20.6 & 12.2 & 5.5 \\
\hline 2 & 41.1 & 26.7 & 18.2 & 8.9 & 4.4 \\
\hline 3 & 37.2 & 24.1 & 15.1 & 8.6 & 3.4 \\
\hline 4 & 33.8 & 20.6 & 13.4 & 6.5 & 3.8 \\
\hline Highest quintile & 25.3 & 11.7 & 7.3 & 4.1 & 1.4 \\
\hline Total & 36.5 & 22.6 & 14.9 & 8.1 & 3.7 \\
\hline Overshoot (O) & 5.4 & 4.0 & 3.1 & 2.0 & 1.2 \\
\hline Mean positive overshoot (MPO) & 14.9 & 17.6 & 20.6 & 24.7 & 31.4 \\
\hline \multicolumn{6}{|c|}{ YEAR 2005} \\
\hline \multicolumn{6}{|l|}{ Headcount $(\mathrm{H})$} \\
\hline Lowest quintile & 60.8 & 49.1 & 43.9 & 31.6 & 22.1 \\
\hline 2 & 54.7 & 43.7 & 36.1 & 28.3 & 15.8 \\
\hline 3 & 48.5 & 38.7 & 31.3 & 20.9 & 12.1 \\
\hline 4 & 44.6 & 30.4 & 22.3 & 13.6 & 6.0 \\
\hline Highest quintile & 33.0 & 21.6 & 14.7 & 8.0 & 4.5 \\
\hline Total & 48.3 & 36.7 & 29.6 & 20.5 & 12.1 \\
\hline Overshoot (O) & 17.2 & 15.1 & 13.4 & 11.0 & 8.6 \\
\hline Mean positive overshoot (MPO) & 35.6 & 41.1 & 45.3 & 53.5 & 70.7 \\
\hline \multicolumn{6}{|c|}{ YEAR 2008} \\
\hline \multicolumn{6}{|l|}{ Headcount $(\mathrm{H})$} \\
\hline Lowest quintile & 42.9 & 33.0 & 29.3 & 21.3 & 16.8 \\
\hline 2 & 41.1 & 31.5 & 24.7 & 17.6 & 13.0 \\
\hline 3 & 34.0 & 27.4 & 22.2 & 15.2 & 8.9 \\
\hline 4 & 35.4 & 25.8 & 19.7 & 13.2 & 7.1 \\
\hline Highest quintile & 26.1 & 19.3 & 14.4 & 8.8 & 5.2 \\
\hline Total & 35.9 & 27.4 & 22.0 & 15.2 & 10.2 \\
\hline Overshoot (O) & 17.0 & 15.5 & 14.3 & 12.5 & 10.6 \\
\hline Mean positive overshoot (MPO) & 47.5 & 56.5 & 64.8 & 81.9 & 103.8 \\
\hline
\end{tabular}




\section{Chapter 3. PAYING INFORMALLY IN \\ PUBLIC HEALTH CARE IN \\ ALBANIA: SCARCE RESOURCES \\ OR GOVERNANCE FAILURE?}

This chapter is based on the following article:

Tomini S, Maarse H. (2011). How do patient characteristics influence informal payments for inpatient and outpatient health care in Albania: Results of logit and OLS models using Albanian LSMS 2005. BMC Public Health 2011, 11:375doi:10.1186/1471-2458-11-375

Part of the analysis in this chapter is used for:

World Bank, 2011 (expected). "Out-of-Pocket Payments in Albania's Health System" Country policy report, Accountability for Better Governance AAA task (P107759), Europe and Central Asia Regional Office, World Bank, Washington DC 


\begin{abstract}
Informal payments for health care are common in most former communist countries. This chapter explores the demand side of these payments in Albania. By using pooled data from the Albanian Living Standard Measurement Survey 2002, 2005 and 2008 we control for individual determinants of informal payments in inpatient and outpatient health care. Using tobit and Heckman selection models we test three models to explain informal payments: the cultural, economic and governance model. Propensity score matching techniques are used to investigate the changes in the characteristics of people paying informally over the different years.

Our findings suggest that cultural factors in Albania may only be seen as one of the reasons for the existence of informal payments in health care. Other factors relating to economic and governance models better explain how widespread and high such payments are. We also show that economic factors may play a role in determining the amount of informal payments to medical staff, while governance issues are more closely linked to the incidence of such payments. The differences over the years show that factors that have contributed to the limitation of informal payments in the early years (like the role of health insurance or the increase of GPs wages) are losing their effectiveness in the long-run. This was due to lack of a follow up on reforms and the indexation of wages over the years. The effects of the latest policy measures in inpatient care should be closely monitored giving the long-term results of reforms in outpatient care.
\end{abstract}




\subsection{Introduction}

Informal payments for health care providers are widespread not only in the former communist countries (Central and Eastern Europe and Former Soviet Union) but also in other middle income and developing countries (Killingsworth et al., 1999; McPake et al., 1999; Lewis, 2000; Gaal et al., 2006; Vian et al., 2006). They are usually defined as payments made to health care providers for services, which are supposed to be provided at no charge to the patient (Lewis, 2000). Informal payments in health care can be conceptualised as strategies adopted by both the demand and supply side to cope with the lack of resources and poor performance (Lewis, 2000; Vian et al., 2006). Patients pay informally to jump the queue, receive higher quality of health services or more care (Lewis, 2000; Vian et al., 2006; Liaropoulos et al., 2008). For providers of medical care, informal payments can turn into an instrument to cope with low salaries or to satisfy the desire for a higher income (Liaropoulos and Tragakes, 1998).

In countries like Albania, informal payments to medical staff have accompanied the transition from a central planned economy to a market economy. Informal payments were very common in Albania, especially in inpatient health care, which because of state funding was officially free of charge for the entire population. The situation was particularly dramatic for people in the lowest quintile of income distribution (World Bank, 2006).

This chapter looks at how patients' characteristics influence informal payments to medical staff in outpatient and inpatient care. We test three models (i) cultural, (ii) economic and (iii) governance to explain the occurrence and the extent of informal payments. By controlling for the main demand-side factors, we seek to identify who pays, for what, and how much. We use pooled data from Albania LSMS 2002, 2005, 2008 and employ a tobit and Heckman selection model to identify individual determinants and propensity score matching to investigate how characteristics of patients paying informally have changed over years.

\subsection{The determinants of informal health care payments}

The causes and origins of informal payments have long been debated. Researchers have suggested many factors influencing informal payments including: a) a culture of gifts (Delcheva et al., 1997; Balabanova and McKee, 2002; Vian et al., 2006); b) low income of staff (Ensor and Savelyeva, 1998; Chawla et al., 1998; Ensor and Witter, 2001; Lewis, 2002; Vian and Burak, 2006); c) lack of resources and material supplies (Delcheva et al., 1997; Chawla et al., 1998, Ensor and Witter, 2001); d) bargaining power of medical doctors (Miller et al., 2000; Thompson and Xavier, 2002); and e) lack of regulation and unresponsive government (Lewis, 2000; Ensor and Witter, 2001). We base our theoretical framework on the main explanatory factors for informal payments identified by Gaal and McKee (2005). We group them in three models: (i) the cultural model, (ii) the economic model, and (iii) the governance model (see also Table 3.1). 
Table 3.1. Causes of informal payments and observed effects

\begin{tabular}{|c|c|c|}
\hline MODEL & Presumed Causal factor & OBSERVED EFFECTS \\
\hline 1. Cultural & 1. Culture of gratitude gifts and tipping & $\begin{array}{l}\text { 1. Money and in kind gifts paid to medical staff } \\
\text { (usually after the services received). } \\
\text { 2. Patients declare gifts to medical staff mostly } \\
\text { as voluntary. } \\
\text { 3. A relatively moderate incidence of such } \\
\text { payments, usually of modest value. }\end{array}$ \\
\hline 2. Economic & $\begin{array}{l}\text { 1. Demand side factors } \\
\text { - Free heath care access } \\
\text { 2. Supply side factors } \\
\text { - Inadequate funding } \\
\text { - Low salaries of health care staff. } \\
\text { - Investments oriented more towards } \\
\text { access rather than quality of services. }\end{array}$ & $\begin{array}{l}\text { 1. Unequal amounts paid for in patient and } \\
\text { outpatient health services. } \\
\text { 2. Informal payments resemble a 'fee-for- } \\
\text { service' model (as patients may use informal } \\
\text { payments as top ups or for getting better quality } \\
\text { of service). } \\
\text { 3. High income patients will pay higher } \\
\text { informal payment. } \\
\text { 4. Having health insurance will lower the } \\
\text { probability of paying informally. }\end{array}$ \\
\hline 3. Governance & $\begin{array}{l}\text { 1. Lack of control and accountability } \\
\text { leading to unethical behaviour of medical } \\
\text { staff. } \\
\text { 2. Weak rule of law and corruption } \\
\text { control. }\end{array}$ & $\begin{array}{l}\text { 1. High incidence of explicitly requested } \\
\text { payments. } \\
\text { 2. Probability of paying informally is } \\
\text { dependent on the knowledge and bargaining } \\
\text { power of the patients. } \\
\text { 3. Low numbers of prosecuted cases of } \\
\text { corrupted medical staff. }\end{array}$ \\
\hline
\end{tabular}

The cultural model considers informal payments to be a particular type of behaviour of care seekers who express their gratitude in the form of gifts. This model is found in many countries, in particular in Central and Eastern European (CEE) and Former Soviet Union (FSU) countries. The culture of gifts has its roots in values and traditions (Balabanova and McKee, 2002), and it can be conceptualised as institutionalised behaviour of patients. Seen as voluntary behaviour, it is sometimes argued that a gift does not put any particular burden on patients. The value of gifts is only modest and depends on the wealth of patients. Payments are supposed to improve the motivation of health care staff, ensure a personal relation, and provide incentives for physicians to feel appreciated (Gaal et al., 2006).

If this model is valid, we would expect a widespread incidence of informal payments. Furthermore, the amount of money paid is expected to be relatively low (i.e. compared to the total amount paid as out-of-pocket) and positively correlated to the patient's ability to pay (e.g. total consumption or income).

The economic model links informal payments to the increased demand for health care, inadequate budget, as well as ineffective investment policies. The demand side factors relate to the increased demand for health care. The communist system established in CEE and FSU countries after the Second World War propagated a free access to health care policy under the legacy of the 'Shemasko' health care system. Free health care access led to an unlimited demand which created a supply shortage (Gaal and McKee, 2005). After the fall of the 
communist regimes, governments in these countries were not financially capable to maintain an inefficient and universal health care system. With state revenues declining in many CEE and FSU countries in the early 1990s, health expenditures also fell but with little concomitant change in the number of staff or beds (Ensor and Witter, 2001; Lewis, 2002). The inevitable result was a large health system with underpaid and sometimes even unpaid staff. Albania's limited public spending on health care sector has resulted in an increased reliance on out-of-pocket payments for both inpatient and outpatient care (Nuri and Tragakes, 2002). According to the World Bank (2006), in 2005, about 97 per cent of private health expenditures were out-of-pocket expenditures, while they accounted for 59.7 percent of total health expenditures in the country. A rural-to-urban brain drain (Lerberghe et al., 2002) resulted in physicians' moving from rural areas to urban areas with better working conditions. This created a physician shortage in rural areas and small towns (especially visible in inpatient care). The lack of resources to respond to the growing demand led to a situation where informal payments were considered as coping strategies for both patients and medical staff. Finally, due to political sensibility, the investment continued to be directed mainly towards access rather than quality (Nuri and Tragakes, 2002). This made patients more willing to pay extra amounts in order to get better quality of care.

If informal payments are driven by economic reasons, we would expect significant differences in the amounts paid for inpatient and outpatient care. Severity of illnesses treated in these two different services differs greatly and so do the costs associated to treatments in these services. Moreover, the consequences of not getting the (appropriate) treatment are larger for inpatient care and therefore patients are likely to pay higher informal payments to medical doctors in hospitals than to general practitioners. As payments are used to upgrade services or get better quality treatment they would resemble more a 'fee-for-service' model depending on the type of service being delivered. Wealthier and better educated patients would be more willing to pay extra amounts of money in order to get better quality of services. Having paid for health insurance may lower the probability of paying as patients are more aware of their contribution to the costs of these services and treatments.

An efficient health care system relies on an effective combination of (financial and human) resources and an accurate delivery system that covers the entire territory of a country (Lewis, 2006). In the Albanian context, the lack of public policies to protect the most poor, the lack of accountability for medical staff, weak rule of law and corruption control (Gaal and McKee, 2005) unequal shares of the total budget distributed among different regions and underfunded services have created ground for informal payments in health care. The presence of widespread informal payments to medical staff is generally seen as an indicator of governance failure in the health care sector (Lewis and Petterssen, 2009). The incapability to maintain the rule of law leads to non-ethical behaviour of medical staff. Patients are not protected by public authorities and as a consequence are more exposed to exploitation from physicians. Physicians, despite their commitment to the model of medical professionalism (Wynia et al., 1999), are tempted to use their bargaining power to increase their earnings (Miller et al., 2000; Thompson and Xavier, 2002). The general low probability of being detected or penalised when engaging in such practices contributes directly to the spread of informal payments. At the same time, the widespread informal payments in the 
health care system (especially for the poorest groups of the population) can be directly linked to the failure of public policies in maintaining an equitable system (Tambor et al., 2010).

If governance is to be the main reason for informal payments, we expect: (i) a high incidence of informal payments (direct payments to physicians are forbidden by law in Albania and therefore asking for a gift/payment will certainly indicate unethical behaviour); (ii) the probability of paying informally to be dependent on the information and bargaining power of patients (lower educated and lower informed people have less bargaining power and are therefore easily exploited by medical staff), and (iii) corruption cases to be generally tolerated (i.e. number of prosecuted cases for corrupted medical staff is very low).

In summary, these three models provide a good basis for analysing informal payments in Albania and their main causes. However, it should be noted that they are not meant to be exclusive to each other. In countries where such payments are widespread, the policy options need to account for the interdependence of these models.

\subsection{Informal payments and recent reforms in the health care sector in Albania}

Albania, as most of the other ex-communist countries, has inherited a health care system based on the former Soviet 'Semashko' model (see for details Chapter 1).

Figure 3.1. Corruption and bribes in the health sector for different countries in 2008

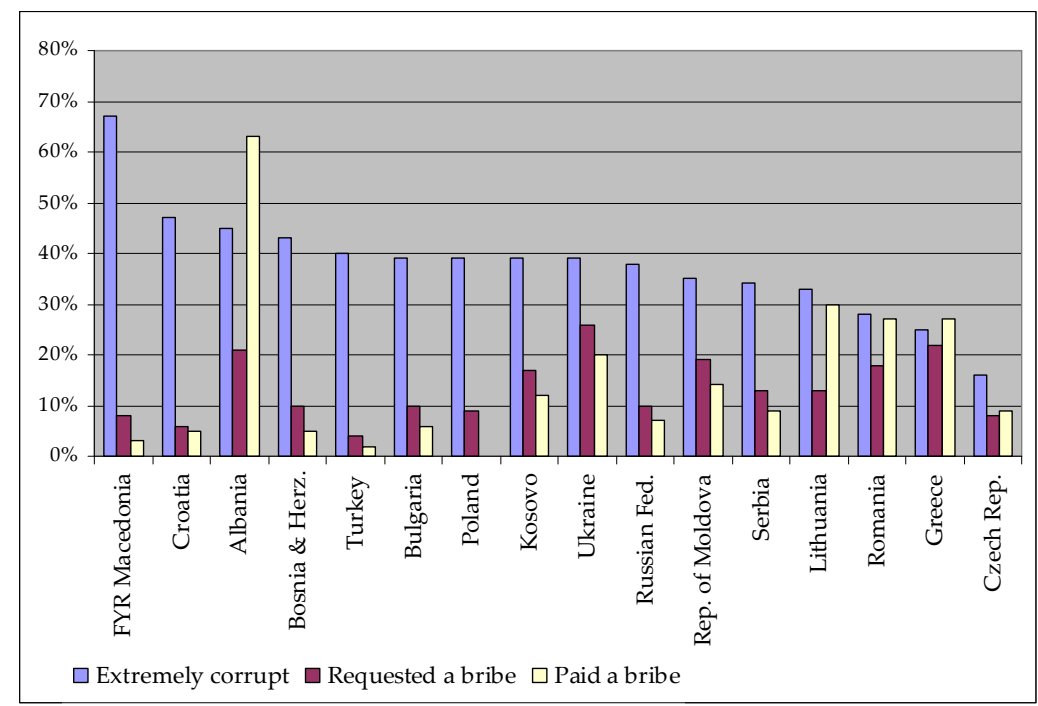

Source: Gallup, 2008

The health care system in Albania remains highly reliant on publicly delivered services and is one of the most quoted sectors for bribes in the country (IDRA, 2010). Recent surveys of Gallup International (2008) show that 45 per cent of the interviewed perceived medical services in Albania as extremely corrupted, showing one of the highest rates in the Western 
Balkans countries. Figure 3.1 shows that almost 21 per cent of the interviewed declared to have been requested a bribe, and 63 per cent had paid a bribe in 2008 for health care. This is much higher than in any other Western Balkan country.

The Ministry of Health $(\mathrm{MoH})$ in Albania (National Health Sector Strategy, 2004) has recognised informal payments in health care as widespread both in inpatient and outpatient care. However the government has not succeeded to contain such informality so far.

Table 3.2. Responsibilities in the health care sector

\begin{tabular}{|c|c|c|c|}
\hline YEAR & $\begin{array}{l}\text { MINISTRY OF HEALTH IS RESPONSIBLE } \\
\text { FOR: }\end{array}$ & $\begin{array}{l}\text { HEALTH INSURANCE INSTITUTE IS } \\
\text { RESPONSIBLE FOR: }\end{array}$ & $\begin{array}{l}\text { LOCAL GOVERNMENT UNITS } \\
\text { ARE RESPONSIBLE FOR: }\end{array}$ \\
\hline 2002 & $\begin{array}{l}\text { - Salaries of medical staff }{ }^{12} \\
\text { - Capital investments (hospitals } \\
\text { only) } \\
\text { - Operating costs } \\
\text { - Human resources planning }\end{array}$ & $\begin{array}{l}\text { - Salaries of GPs } \\
\text { - Salaries of PHC medical staff in } \\
\text { Tirana } \\
\text { - Durres hospital (pilot project) } \\
\text { - Drugs reimbursement }\end{array}$ & - PHC operating costs \\
\hline 2005 & $\begin{array}{l}\text { - Salaries of medical staff }{ }^{2} \\
\text { - Capital investments for hospitals } \\
\text { - Operating costs } \\
\text { - Human resources planning }\end{array}$ & $\begin{array}{l}\text { - Salaries of GPs } \\
\text { - Salaries of PHC medical staff in } \\
\text { Tirana } \\
\text { - Durres hospital (pilot project) } \\
\text { - Diagnostic reimbursements for } \\
\text { expensive tests } \\
\text { - Drugs reimbursement }\end{array}$ & $\begin{array}{l}\text { - PHC capital investments } \\
\text { (conditional grants) }\end{array}$ \\
\hline 2008 & $\begin{array}{l}\text { - Salaries of medical staff in hospitals } \\
\text { - Capital investments for hospitals } \\
\text { - Human resources planning }\end{array}$ & $\begin{array}{l}\text { - Contracting of PHC services (420 } \\
\text { PHC units since 2007) } \\
\text { - Durres hospital (pilot project) } \\
\text { - Diagnostic reimbursements for } \\
\text { expensive tests } \\
\text { - Drugs reimbursement }\end{array}$ & $\begin{array}{l}\text { - PHC capital investments } \\
\text { (conditional grants) }\end{array}$ \\
\hline $\begin{array}{l}2009- \\
2010\end{array}$ & $\begin{array}{l}\text { - Capital investments for hospitals } \\
\text { - Human resources planning }\end{array}$ & $\begin{array}{l}\text { - Contracting of PHC services } \\
\text { (salaries and operating costs) } \\
\text { - Contracting of hospital services } \\
\text { (salaries and operating costs) - } \\
\text { ongoing } \\
\text { - Drugs reimbursement }\end{array}$ & $\begin{array}{l}\text { - PHC capital investments } \\
\text { (conditional grants) }\end{array}$ \\
\hline
\end{tabular}

Source: World Bank 2006, MOH 2004, HII 2010

The reforms in the period 2002-2010 have mainly focussed on shifting the management and financial responsibilities from the $\mathrm{MoH}$ to the Health Insurance Institute (HII) and local government units (LGU). Table 3.2 gives an overview of the changes in responsibilities for health care throughout the recent years. As it can be seen from table 3.2, the main changes between years 2002 and 2005 relate to consolidating the financing of the Primary Health

12 This excludes the salaries of general practitioners, primary health staff in Tirana and medical staff in Durres hospital which are paid directly by the Health Insurance Institute. 
Care (PHC) through the HII (but limited in the salaries of general practitioners) and transferring PHC capital investments to LGUs. The reforms between 2005 and 2008 consist in further increasing the HII role in contracting PHC services. The first changes began in 2007 but to our best knowledge no evaluation of the effects exists. Generally, reforms between 2002 and 2008 were focused on primary health care and outpatient service. Little was done with regard to inpatient care (the contracting of such services from the HII will only be implemented in 2009-2010 and the effects are still to be seen).

Figure 3.2. Health Insurance Institute Expenditures for Primary Health Care Centres and Hospital Services

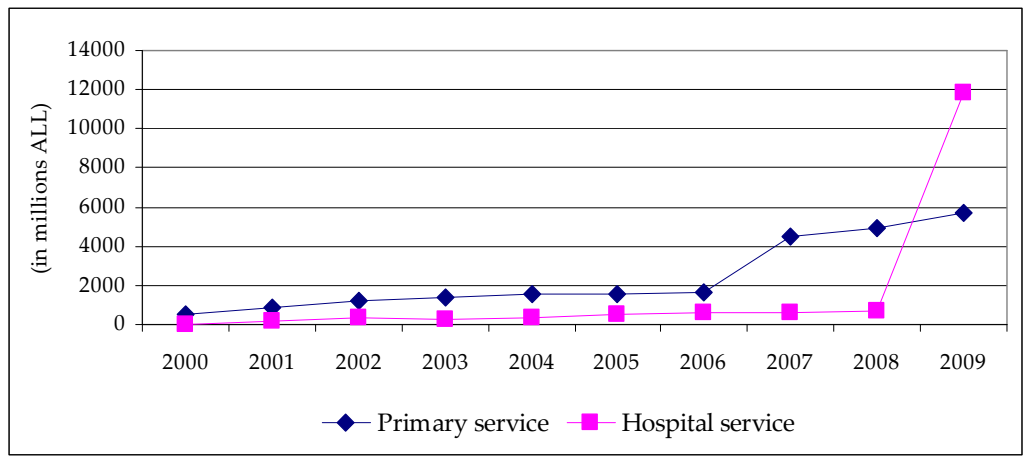

Source: Health Insurance Institute 2010. Note: All amounts are in Albanian Leks are deflated to 2002 prices. 100 ALL = 0.73 Euros in June 2002 (Bank of Albania, 2010)

Administrative data show that the funds going through the HII have increased throughout the years. The reforms in contracting the PHC services in 2007 and the hospital services in 2009 have further increased the allocation of funds going through the HII (Figure 3.2). This increase is mainly due to the transfer of administrative responsibilities. The overall effect on informal payments to medical staff is still to be seen.

Figure 3.3. Monthly salaries of General Practitioners (in 000 ALL)

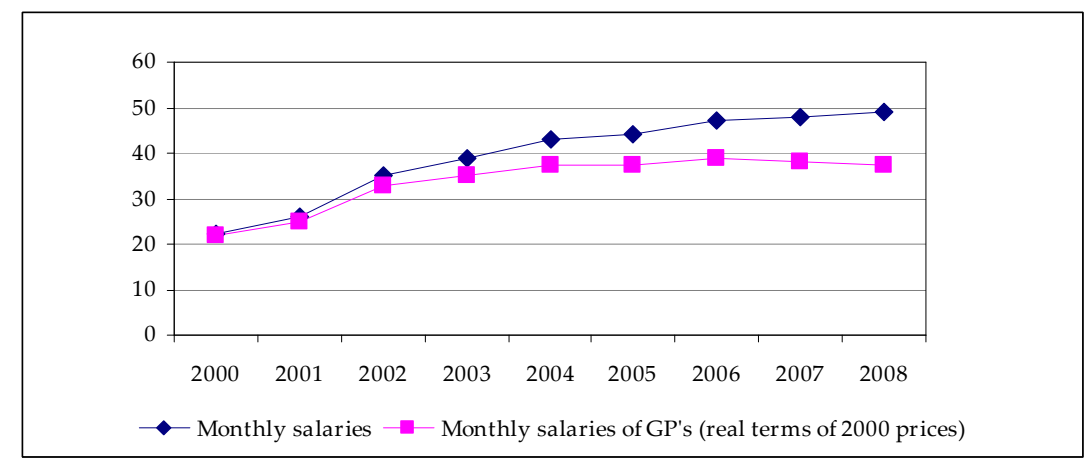

Source: Own calculations based on World Bank (2006) and Health Insurance Institute (2010). Note: All amounts are in Albanian Leks are deflated to 2002 prices. 100 ALL = 0.73 Euros in June 2002 (Bank of Albania, 2010) 
One of the measures linked to informal payment has been the increase of medical staff's salaries. Between 2002 and 2005 such salaries have significantly increased for the general practitioners (GPs) which were paid through the HII. Figure 3.3 shows the average salary level of GPs between 2000 and 2008 both in nominal value and real terms (adjusted for Consumer Price Index). This increase has been substantive in real terms between 2000 and 2005, but there is a decline of average salaries in real terms between 2006 and 2008.

Salaries of medical staff in the inpatient sector have also constantly increased during the same period (and especially after 2005), but the average wage for medical specialists in this sector still remains below the average wage of the medical staff in PHCs.

\subsection{Data and descriptive statistics}

The data used in this study come from Albania Living Standard Measurement Survey (ALSMS) 2002, 2005 and 2008. These are cross sectional surveys representative for four main stratified regions; Tirana (the capital), mountainous, coastal and central areas. The households sampled were 3599 in 2002, 3640 in 2005, and 3600 in 2008. The questionnaires include information on household demography, education, labour, income, health status, health care episodes and out-of-pocket payments in health care. The variables that we have used in our analysis all come from identical questions in these three years.

For the purpose of our analysis we restrict our samples to individuals that have visited outpatient care during the last four weeks (visited public ambulatory services), or individuals that have been visiting inpatient care in the last 12 months (hospitalised in the public hospitals). The selected individuals are then asked separately about the amount they have paid informally as payments to the medical staff.

Table 3.4. The share of patients paying informal payments to medical staff in outpatient and inpatient health care (ALSMS data 2002-2008)

\begin{tabular}{|c|c|c|c|c|c|c|}
\hline $\begin{array}{l}\text { CONSUMPTION } \\
\text { OUINTILES }\end{array}$ & \multicolumn{2}{|c|}{ YEAR 2002} & \multicolumn{2}{|c|}{ YEAR 2005} & \multicolumn{2}{|c|}{ YEAR 2008} \\
\hline \multicolumn{7}{|c|}{ Outpatient care } \\
\hline 1 & 0.228 & $(0.041)$ & 0.268 & $(0.042)$ & 0.221 & $(0.047)$ \\
\hline 2 & 0.293 & $(0.042)$ & 0.244 & $(0.046)$ & 0.158 & $(0.035)$ \\
\hline 3 & 0.268 & $(0.032)$ & 0.203 & $(0.039)$ & 0.200 & $(0.040)$ \\
\hline 4 & 0.327 & $(0.042)$ & 0.222 & $(0.035)$ & 0.215 & $(0.035)$ \\
\hline 5 & 0.271 & $(0.028)$ & $0.162^{* *}$ & $(0.029)$ & 0.150 & $(0.032)$ \\
\hline Total population & 0.281 & $(0.021)$ & 0.218 & $(0.021)$ & 0.190 & $(0.021)$ \\
\hline $\mathrm{Nr}$ of observations & \multicolumn{2}{|c|}{2120} & \multicolumn{2}{|c|}{1463} & \multicolumn{2}{|c|}{1151} \\
\hline \multicolumn{7}{|c|}{ Inpatient care } \\
\hline 1 & $0.479^{*}$ & $(0.063)$ & 0.548 & $(0.060)$ & 0.465 & $(0.071)$ \\
\hline 2 & 0.569 & $(0.060)$ & 0.602 & $(0.056)$ & 0.495 & $(0.085)$ \\
\hline 3 & 0.654 & $(0.048)$ & 0.586 & $(0.061)$ & 0.351 & $(0.080)$ \\
\hline 4 & 0.644 & $(0.049)$ & 0.529 & $(0.057)$ & 0.445 & $(0.078)$ \\
\hline 5 & 0.598 & $(0.048)$ & 0.517 & $(0.055)$ & 0.434 & $(0.086)$ \\
\hline Total population & 0.597 & $(0.030)$ & 0.559 & $(0.032)$ & 0.439 & $(0.041)$ \\
\hline $\mathrm{Nr}$ of observations & \multicolumn{2}{|c|}{707} & \multicolumn{2}{|c|}{677} & \multicolumn{2}{|c|}{377} \\
\hline
\end{tabular}

Note: Quintiles refer to total per capita consumption quintiles. Standard errors are in brackets. Stars indicate if the mean for the subgroup is significantly different from the mean of all other subgroups. ${ }^{* * *} p<.01,{ }^{* *} p<.05,{ }^{*} p<.1$ 
The incidence of informal payments is relatively high throughout the years. However, incidences of the informal payments for outpatient and inpatient care differ significantly when the two types of services are compared. Informal payments are less frequent in outpatient than in inpatient care. Hence, 28.1 per cent of the total patients pay an informal payment to medical staff for 2002 in outpatient care and 19 per cent in 2008. For inpatient care these number are 59.7 per cent in 2002 and 43.9 per cent in 2008.

These informal payments are widespread also across consumption quintiles, with the lowest quintiles having a large incidence of such payments. What is more interesting is that while there is a general declining trend of such payments in 2005 and 2008, the poorest quintiles are the ones to feel less such effect. In fact in the outpatient care in 2005 and 2008 the poorest quintile is the one with the highest incidence of informal payments (26.8 and 22.1 per cent respectively). The same holds to a lesser extent for inpatient care (54.8 and 46.5 per cent respectively). This tendency is certainly signalling that whatever measures were taken between years these were certainly not targeted to the poor (see Table 3.4).

The amounts paid informally to medical staff for inpatient care (per admission) are much higher than those paid in outpatient care (per visit). Over the years we observe a decline (in real terms) for the average amount paid in outpatient care, while there is an increase for the inpatient care between 2002 and 2005 and a slight decrease between 2005 and 2008. Again, as for the incidence of payments, the poorest quintiles are the most disadvantaged ones (see Tables 3.5).

Table 3.5. The mean of the amount paid informally per outpatient visit and per day hospitalised (ALSMS data 2002-2008)

\begin{tabular}{|c|c|c|c|c|c|c|}
\hline $\begin{array}{l}\text { CONSUMPTION } \\
\text { QUINTILES }\end{array}$ & \multicolumn{2}{|c|}{ YEAR 2002} & \multicolumn{2}{|c|}{ YEAR 2005} & \multicolumn{2}{|c|}{ YEAR 2008} \\
\hline \multicolumn{7}{|c|}{ The mean of the amount paid informally per outpatient visit in Albanian Leks (series with 2002 prices) } \\
\hline Quintile 1 & 74.733 & $(20.639)$ & 82.088 & $(20.486)$ & 67.548 & $(16.590)$ \\
\hline Quintile 2 & $76.037^{*}$ & $(11.757)$ & 71.665 & $(17.044)$ & 38.499 & $(9.838)$ \\
\hline Quintile 3 & 86.652 & $(20.342)$ & 80.278 & $(21.037)$ & 53.222 & $(11.613)$ \\
\hline Quintile 4 & 125.885 & $(37.708)$ & 71.945 & $(14.106)$ & 59.052 & (11.992) \\
\hline Quintile 5 & 122.419 & $(23.090)$ & 52.283 & $(10.410)$ & $35.356^{*}$ & $(7.874)$ \\
\hline Total Population & 103.163 & $(12.875)$ & 71.110 & $(9.866)$ & 50.810 & $(6.206)$ \\
\hline Nr of observation & 2120 & & 1463 & & 1151 & \\
\hline \multicolumn{7}{|c|}{ The mean of the amount paid informally per inpatient admission in Albanian Leks (series with 2002 prices) } \\
\hline Quintile 1 & $2698.463^{* * *}$ & $(612.398)$ & 4292.778 & $(899.461)$ & 2564.909 & $(710.817)$ \\
\hline Quintile 2 & $3348.461^{* *}$ & $(679.372)$ & 4809.482 & $(753.513)$ & 4127.072 & (1676.403) \\
\hline Quintile 3 & 4739.347 & $(828.564)$ & 5020.699 & (1033.697) & 2090.516 & (709.647) \\
\hline Quintile 4 & 6097.601 & (935.214) & 5289.257 & (1188.339) & 4924.746 & (1483.995) \\
\hline Quintile 5 & $6470.973^{*}$ & (1193.826) & 7679.654 & (1904.738) & 3396.170 & (1003.774) \\
\hline Total Population & 4835.322 & $(450.216)$ & 5284.280 & $(574.326)$ & 3341.701 & $(525.999)$ \\
\hline Nr of observation & \multicolumn{2}{|c|}{697} & \multicolumn{2}{|c|}{660} & \multicolumn{2}{|c|}{354} \\
\hline
\end{tabular}

Note: Quintiles refer to total per capita consumption quintiles. Standard errors are in brackets.

Stars indicate if the mean for the subgroup is significantly different from the mean of all other subgroups. ${ }^{* * *} \mathrm{p}<.01,{ }^{* *}$ $\mathrm{p}<.05,{ }^{*} \mathrm{p}<.1$ 


\subsection{Empirical strategy}

The descriptive statics show clearly that certain characteristics of the individuals (e.g. economic status) might be associated closely with the amount paid. There are also distinct changes between the years and between expenditure categories. In order to further explore this we look at how patients' characteristics influence informal payments during the years.

\subsubsection{Determinants of informal payments}

Albania LSMS it is not a panel survey so we have to rely on cross section analysis for determining the effect of individual characteristics on the amount paid informally to medical staff. To do this we pool the data from ALSMS 2002, 2005 and 2008.

Our first goal is to get more insights on the individual characteristics determining the amount paid informally. In this case, the amount of informal payments is determined by individual characteristics of individuals:

$$
y_{i}^{*}=x_{i} \beta^{\prime}+\varepsilon_{i}, \quad \mathrm{i}=1,2,3 \ldots, \mathrm{N}
$$

where, $y_{i}$ refers to the amount paid informally to medical staff in outpatient or inpatient care, $x_{i}$ denotes a vector of exogenous and observed individual characteristics, $\beta$ represents a vector of estimated coefficients corresponding to the such characteristics, and $\varepsilon_{i}$ is a vector of residuals errors having a normal distribution.

Not all patients that have reported to have visited health care have reported informal payments to medical staff. Therefore we have a share of people reporting zero payments. We suspect this may be linked to two possible reasons: 1) the left censoring at zero, or 2) a possible selection problem.

The left censoring means that the dependent variable is represented by a latent variable $y^{*}$ that is not observed when $y_{i}<0$. The distribution has full support within the interval $(-\infty ;+\infty)$ but we can only observe values that are equal or above 0 . The observed variable is thus related to the latent variable through the below observation rule:

$$
y=\left\{\begin{array}{r}
y^{*} \text { if } y^{*}>0 \\
0 \text { if } y^{*} \leq 0
\end{array}\right.
$$

As we are dealing here with informal payments in health care it is completely feasible to imagine a negative value for such payments (some people may be just aware that they should get treatment at no costs, as they have already contributed to the public health care either directly by paying health insurance or through taxes). Therefore it is completely feasible that the data can be better described by such model.

The possible selection bias may be a classical case when the selection and the outcomes are determined by different probability functions. This is a two part model where the first part is a binary outcome modelled as the probability that the binary variable is bigger than 0 , and the second part uses a linear regression to model the outcome if the outcome is bigger 
than 0 . The model introduces a latent variable $y_{1}^{*}$ and the outcome $y_{2}^{*}$ which is observed if $y_{1}^{*}>0$. In our case $y_{1}^{*}$ defines the probability that the patient pays informal payments, $y_{2}^{*}$ defines the level of these payments, $y_{1}^{*} \neq y_{1}^{*}$.

The model includes two equations, the first one being a selection equation for $y_{1}$, where:

$$
y_{1}=\left\{\begin{array}{l}
1 \text { if } y_{1}^{*}>0 \\
0 \text { if } y_{1}^{*} \leq 0
\end{array}\right.
$$

and the resultant outcome for $y_{2}$, where

$$
y_{2}= \begin{cases}y_{2}^{*} & \text { if } y_{1}^{*}>0 \\ - & \text { if } y_{1}^{*}<0\end{cases}
$$

The Heckman selection model is used to check whether there exist any potential biases with the selection of the respondents (i.e. people that under the given circumstances will not pay informal payments but that are included in our analysis). This model is supposed to capture the overall effect that certain observable characteristics may have on the selection. This is a very important aspect if we want to avoid any biases associated with the estimates from the tobit model. Results from the two models are compared with each other to check for inconsistencies.

\subsubsection{Impact over the years}

Evaluating the between-years changes in individual informal payments for health care requires a panel survey that would follow the same individuals over the years and measure the incidence and amounts paid informally. In the absence of such panel survey, we could use the potential of similar representative surveys for 2002, 2005 and 2008 and employ propensity score matching (PSM). PSM helps in identifying individuals with similar characteristics over different years in the absence of an experimental set up, where we would be able to construct counterfactuals. After these counterfactuals are identified we can use them to observe the changes over the years for those paying informal payments and those not paying. This would capture the real change over the years not for the total population but for people having similar characteristics and therefore produce more accurate estimates. Thus, PSM creates a situation equivalent to an experiment where everyone has the same probability of participating in the consecutive year, and this probability is balanced among the participants and not participants and conditional on observed variables.

We assume $y_{1 i}$ to be the participation outcome for individual i when this individual is subject to participating in the current and previous survey and $y_{0 i}$ to be the outcome in absence of the participation for the same individual (see also Deheija and Wahba, 2002; Dabalen et al., 2008). The effect for an individual is:

$$
\tau_{i}=y_{1 t}-y_{0 i}
$$

and population effect can therefore be defined as: 


$$
\tau_{i}=E\left(y_{1 i} \mid T_{i}=1\right)-E\left(y_{0 i} \mid T_{i}=0\right)
$$

where $T$ indicates the participation in the survey, and $T_{i}$ is equal to 1 if individual $\mathrm{i}$ participates in the survey and 0 if not. As the "treatment" here refers to the consecutive year of the survey we do not observe outcomes that would have materialised if corresponding individuals had not participated in the survey $E\left(y_{0 i} \mid T_{i}=1\right)$. In our case the "treatment" involves entire population and therefore the participation is independent of potential outcomes $\left(y_{1 i}, y_{0 i} \perp T_{i}\right)$. The average participation effect for the population participating is:

$$
\tau=E\left(y_{i} \mid T_{i}=1\right)-E\left(y_{i} \mid T_{i}=0\right)
$$

The variables used for matching correspond to observable characteristics of individuals that are stable over the years. The random selection of participants in the surveys makes sure that the qualities of the participants and not participants are identical in terms of the distribution of the observed characteristics. Given that all surveys were country representative, we can assume that individuals had the same probability of participating in the consecutive survey, and that both participants and not participants came from the same economic environment. Both the condition of random selection of participants and the similarities in the background (Heckman et al., 1997) are fulfilled in our analysis.

\subsection{Results}

Results are presented separately for outpatient and inpatient care.

\subsubsection{Results for outpatient care}

Table 3.6 gives the results of tobit and Heckman selection model for the amount paid informally in outpatient care. The exclusion instruments used for non-random assignment of systematic non-payers (patients that will not pay an informal payment under the given circumstances) are the dummies corresponding to having health insurance, having difficulties to pay for health care, and being a health practitioner (as the profession of the patient). These instruments are chosen so that they relate more to the probability of paying informally and not to the amount paid. The overidentifying restriction tests (Sargan, 1958; Barmann, 1960) indicate whether the exclusion instruments fulfil the requirement of being exogenous to the amount paid informally (while correlated to the probability of paying). The outcomes of the tests do not reject the null hypothesis (the lower part of Table 3.6) showing that our exclusion instruments can be considered valid. ${ }^{13}$ At the same time we also test for the validity of the selection correction. The likelihood-ratio test for $r h o=0$ rejects its null hypothesis showing that OLS estimates without the selection correction would be inconsistent.

\footnotetext{
${ }^{13}$ A statistically significant test statistic always indicates that the instruments may not be valid. A nonsignificant test indicates that the instruments may be considered as valid.
} 
Table 3.6. Informal payments for outpatient health care - Results from tobit and Heckman selection models

\begin{tabular}{|c|c|c|c|c|c|c|}
\hline \multirow{2}{*}{$\begin{array}{l}\text { VARIABLES } \\
\text { (Year 2002) }\end{array}$} & \multirow{2}{*}{\multicolumn{2}{|c|}{$\begin{array}{c}\text { TOBIT MODEL } \\
\text { Log of the amount paid } \\
\text { informally }\end{array}$}} & \multicolumn{4}{|c|}{ " HECKMAN SELECTION MODEL } \\
\hline & & & \multicolumn{2}{|c|}{ Selection model } & \multicolumn{2}{|c|}{$\begin{array}{l}\text { Log of the amount } \\
\text { paid informally }\end{array}$} \\
\hline Year 2005 & $-0.683^{* * *}$ & $(0.150)$ & $-0.240^{* * *}$ & $(0.050)$ & $0.123^{* *}$ & $(0.058)$ \\
\hline Year 2008 & $-0.672^{* * *}$ & $(0.175)$ & $-0.220^{* * *}$ & $(0.058)$ & -0.041 & $(0.069)$ \\
\hline Rural area & 0.039 & $(0.146)$ & -0.003 & $(0.049)$ & $0.147^{* * *}$ & $(0.050)$ \\
\hline \multicolumn{7}{|l|}{ (Stratum central) } \\
\hline Stratum coastal & $0.486^{* * *}$ & $(0.153)$ & $0.187^{* * *}$ & $(0.051)$ & $-0.162^{* * *}$ & $(0.055)$ \\
\hline Stratum mountain & $-0.870^{* * *}$ & $(0.183)$ & $-0.293^{* * *}$ & $(0.061)$ & 0.063 & $(0.071)$ \\
\hline Stratum Tirana & $-0.983^{* * *}$ & $(0.221)$ & $-0.316^{* * *}$ & $(0.073)$ & 0.111 & $(0.090)$ \\
\hline Gender (“0” male, “ 1 ” female) & 0.091 & $(0.126)$ & 0.031 & $(0.042)$ & 0.007 & $(0.045)$ \\
\hline Age (in years) & 0.009 & $(0.014)$ & 0.002 & $(0.005)$ & 0.008 & $(0.005)$ \\
\hline Age squared & $-0.000^{* *}$ & $(0.000)$ & -0.000 & $(0.000)$ & $-0.000^{*}$ & $(0.000)$ \\
\hline Chronic illness & 0.008 & $(0.176)$ & -0.001 & $(0.059)$ & 0.063 & $(0.062)$ \\
\hline \multicolumn{7}{|l|}{ (Health rate: bad) } \\
\hline Health rate: average & -0.034 & $(0.158)$ & -0.010 & $(0.053)$ & -0.035 & $(0.057)$ \\
\hline Health rate: good & -0.237 & $(0.198)$ & -0.066 & $(0.066)$ & -0.094 & $(0.072)$ \\
\hline \multicolumn{7}{|l|}{ (Primary/No education) } \\
\hline Secondary education & 0.014 & $(0.171)$ & -0.007 & $(0.057)$ & $0.122^{* *}$ & $(0.061)$ \\
\hline University education & -0.471 & $(0.322)$ & -0.164 & $(0.108)$ & $0.223^{*}$ & $(0.129)$ \\
\hline \multicolumn{7}{|l|}{ (Nuclear families) } \\
\hline Extended families & 0.116 & $(0.135)$ & 0.038 & $(0.046)$ & -0.008 & $(0.048)$ \\
\hline Quintile 1 & -0.033 & $(0.214)$ & -0.016 & $(0.072)$ & 0.050 & $(0.077)$ \\
\hline Quintile 2 & -0.008 & $(0.206)$ & 0.013 & $(0.069)$ & -0.104 & $(0.073)$ \\
\hline \multicolumn{7}{|l|}{ (Quintile 3) } \\
\hline Quintile 4 & $0.460^{* *}$ & $(0.189)$ & $0.154^{* *}$ & $(0.064)$ & -0.003 & $(0.067)$ \\
\hline Quintile 5 & 0.307 & $(0.197)$ & 0.080 & $(0.066)$ & $0.186^{* * *}$ & $(0.069)$ \\
\hline Has health insurance & $-0.748^{* * *}$ & $(0.142)$ & $-0.256^{* * *}$ & $(0.047)$ & - & - \\
\hline \multicolumn{7}{|l|}{$\begin{array}{l}\text { (Have no difficulties to pay for heal th care } \\
\text { services) }\end{array}$} \\
\hline $\begin{array}{l}\text { Have difficulties to pay for health care } \\
\text { services }\end{array}$ & $0.266^{*}$ & $(0.140)$ & $0.090^{*}$ & $(0.046)$ & - & - \\
\hline Health practitioners & -0.653 & $(0.495)$ & -0.215 & $(0.166)$ & - & - \\
\hline Constant & $2.031^{* * *}$ & $(0.386)$ & $-0.357^{* * *}$ & $(0.128)$ & $5.625^{* * *}$ & $(0.173)$ \\
\hline $\mathrm{N}$ (Left-censored $\mathrm{N}$ ) & \multicolumn{2}{|c|}{$4734(3634)$} & \multicolumn{4}{|c|}{$4734(3634)$} \\
\hline Log likelihood & \multicolumn{2}{|c|}{-4294.121} & \multicolumn{4}{|c|}{-3603.754} \\
\hline Pseudo $\mathrm{R}^{2}$ & \multicolumn{2}{|c|}{0.0317} & & \multirow{2}{*}{\multicolumn{2}{|c|}{$(0.120)$}} \\
\hline Rho: Correlation of error terms & & & -.39 & & & \\
\hline $\begin{array}{l}\text { LR test of independent eqns. (H0: rho } \\
=0),\left[\text { Prob }>\mathrm{chi}^{2}\right]\end{array}$ & & & \multicolumn{2}{|c|}{5.80} & \multicolumn{2}{|c|}{$[0.016]$} \\
\hline Wald chi ${ }^{2}\left[\right.$ Prob $>$ chi $\left.^{2}\right]$ Whole model & & & \multicolumn{2}{|c|}{69.72} & \multicolumn{2}{|c|}{$[0.000]$} \\
\hline \multicolumn{7}{|l|}{ Overidentification tests: } \\
\hline \multicolumn{3}{|c|}{$\begin{array}{l}\text { Sargan (score) } \mathrm{chi}^{2} \text { (H0: Instruments are exogenous to log of } \\
\text { amount paid informally) }\left[\mathrm{Prob}>\mathrm{chi}^{2}\right]\end{array}$} & 1.140 & {$[0.566]$} & & \\
\hline \multicolumn{3}{|c|}{$\begin{array}{l}\text { Basmann chi }{ }^{2} \text { (H0: Instruments are exogenous to to log of } \\
\left.\text { amount paid informally) [Prob }>\mathrm{chi}^{2}\right]\end{array}$} & 1.135 & [0.567] & & \\
\hline
\end{tabular}

Note: Stars indicate: ${ }^{* * *} \mathrm{p}<.01,{ }^{* *} \mathrm{p}<.05,{ }^{*} \mathrm{p}<.1$; Reference categories in italics. Standard errors are in brackets. Results of the middle column "Selection model" should be interpreted as the increase 
As we can see, the effects of individual characteristics on the amount paid informally (expressed here as the natural logarithm) vary slightly across tobit and Heckman selection models. The results show that the mean of amount paid informally for outpatient care has decreased over time. Patients pay lower amounts informally in 2008 and 2005 compared to 2002. However, the use of exclusion instruments in the selection model suggests that such decrease is mainly due to a lower probability of paying in these later years (some individuals are not likely to pay and their share increases over the years). The table shows that for every patient in 2005 the logs of paying informally decrease 0.24 times (compared to 2002) and in 2008 decrease 0.22 times. If we correct for this (the log of amount paid on the right part of the table), then the effect is not as large as before and also turns positive (and statistically significant) for 2005.

Residents of rural areas pay larger amounts of informal payments for outpatient care compared to residents of urban areas. The selection correction shows that such difference is statistically significant only for the amount paid and negative (not statistically significant) for the probability of paying. This shows that patients coming from rural areas are less likely to pay (for every patient from rural area the logs of paying informally decrease by 0.003 times compared to urban area patients), but pay in general higher amounts. Such differences can be a result of a mix of visits in health care centres located in rural or urban areas. Due to social connections they are less likely to pay informally in their own localities (Vian and Burak, 2006), but pay higher amounts in urban areas where such connections are lacking and higher opportunity costs are involved (e.g. higher transportation costs, staying over, etc).

The results of the geographic divisions (stratums) show that there exist significant regional differences in paying informally to medical staff. Results from tobit and Heckman selection models differ at this point. Residents of coastal areas seem to be more likely to pay in outpatient care compared to others areas but they pay lower amounts (after the selection correction). On the other hand, residents of mountainous areas and Tirana are less likely to pay informally compared to residents of coastal and central areas. This difference may be due to the fact that mountainous areas and Tirana are on average poorer than central and coastal areas (World Bank, 2006; INSTAT 2009).

Older people pay higher informal payments in outpatient care. This increase is related to the higher predisposition of getting health care (older people have a higher demand for health care). The negative slope of the age squared variable indicates an inverted-U shape of the amount paid informally to age. This shows that working-age adults are the ones who pay larger amounts informally and this can be linked to their higher income generating capabilities and higher opportunity costs. As expected, patients in the higher expenditure quintiles generally spend more for informal payments in outpatient care. However, we can also observe some deviations from this general rule. The selection correction shows that patients in quintile 1 may have a lower probability of paying but pay (for every patient from rural area the logs of paying informally decrease by 0.003 times compared to urban area patients) larger amounts than higher quintiles (though results are not statistically significant), or that quintile 4 may pay lower amounts than the lower ones (the coefficient for the logarithm of amount paid is negative but again not statistically significant). This 
shows that informal payments do not follow the trend of the income distribution and that the lowest quintiles may be the more disadvantaged ones.

Health insurance is among the exclusion correction instruments we have chosen. As we have shown it reduces significantly the probability of paying informally in outpatient care (this also explains its significance in the tobit model) but does less so for the amount paid. The use of the other correction instruments shows that people who have difficulties to pay for health care are more likely to pay informally. This demonstrates the unfairness of informal payments and also indicates that vulnerable groups (e.g. those who are also less likely to be protected by health insurance) are more prone to such payments. On the other hand, results show that groups with more social connections and information, like health practitioners, have a lower probability of paying informal payments for health care (though results are not statistically significant showing that informal payments are nevertheless spread across all groups).

The matching findings reported in Table 3.7 show that there were no big differences in the average amount paid informally in outpatient care between years 2002 and 2005, but there is a decrease in the average amount of such payments between years 2005 and 2008 (statistically significant). The effect of different measures (i.e. financing health services and wages directly from the HII and increasing the wages of GPs) could only be seen in later years. Even though this could be considered as a positive step a 11 or 12.5 per cent decrease of the average amount (in real terms) paid between 2002 and 2008 can be considered as a relatively small achievement in this regard.

Table 3.7. Propensity Score Matching results for outpatient care - Time impact on the average amount paid informally to medical staff

\begin{tabular}{lcc}
\hline \hline & OUTPATIENT HEALTH CARE SERVICE \\
\hline Year 2002 - 2005 & & $(0.059)$ \\
Nearest - neighbour matching & 0.021 & $(0.053)$ \\
Kernel matching & 0.020 & $(0.067)$ \\
Year 2005 - 2008 & & $(0.063)$ \\
Nearest - neighbour matching & $-0.152^{* *}$ & $(0.065)$ \\
Kernel matching & $-0.180^{* * *}$ & $(0.058)$ \\
Year 2002 - 2008 & & $-0.111^{*}$ \\
Nearest - neighbour matching & $-0.125^{* *}$ & \\
Kernel matching
\end{tabular}

Note: Stars indicate: ${ }^{* * *} \mathrm{p}<.01,{ }^{* *} \mathrm{p}<.05,{ }^{*} \mathrm{p}<.1$; Standard errors are in brackets.

Table 3.8 shows the time impact on the main characteristics of patients paying informally when individuals are matched following similar characteristics. For the geographical areas we notice that the share of patients paying informally does not change in a similar direction over the years.

Results show that residents of the central area and Tirana become more likely to pay informal payments in outpatient care if years 2005 and 2008 are compared to 2002. Patients living in the mountainous area are more likely to pay informally in 2008 compared to 2002. Only patients living in the coastal area, which is among the wealthier areas (World Bank, 2006), become less likely to pay informal payments over the observed years. Tobit and 
Heckman selection models show that patients living in coastal area have the highest probability to pay compared to all other areas and therefore the decline over the years can be attributed to the effectiveness of policy measures in this particular area. However, such policy measures fail to affect deprived regions (i.e. the mountainous areas, whose residents are less likely to pay in 2002 and 2005 but more likely to pay informally between 2002 and 2008).

Table 3.8. Propensity Score Matching results for outpatient care - Time impact for patients paying informally

\begin{tabular}{|c|c|c|c|c|c|c|}
\hline \multirow{2}{*}{$\begin{array}{l}\text { VARIABLES } \\
\text { Rural area }\end{array}$} & \multicolumn{2}{|c|}{$\begin{array}{l}\text { DIFFERENCE BETWEEN } \\
\text { YEARS (2002-2005) }\end{array}$} & \multicolumn{2}{|c|}{$\begin{array}{l}\text { DIFFERENCE BETWEEN } \\
\text { YEARS (2005-2008) }\end{array}$} & \multicolumn{2}{|c|}{$\begin{array}{l}\text { DIFFERENCE BETWEEN } \\
\text { YEARS (2002-2008) }\end{array}$} \\
\hline & $-0.139^{* * *}$ & $(0.040)$ & -0.039 & $(0.050)$ & -0.061 & $(0.047)$ \\
\hline Stratum central & $0.174^{* * *}$ & $(0.037)$ & 0.036 & $(0.049)$ & $0.170^{* * *}$ & $(0.044)$ \\
\hline Stratum coastal & $-0.090^{* *}$ & $(0.041)$ & $-0.144^{* * *}$ & $(0.048)$ & $-0.274^{* * *}$ & $(0.045)$ \\
\hline Stratum mountain & $-0.150^{* * *}$ & $(0.028)$ & $0.087^{* * *}$ & $(0.032)$ & 0.011 & $(0.035)$ \\
\hline Stratum Tirana & $0.066^{* * *}$ & $(0.023)$ & 0.021 & $(0.035)$ & $0.093^{* * *}$ & $(0.030)$ \\
\hline Gender ("0" male, " 1 " female) & 0.028 & $(0.040)$ & $-0.203^{* * *}$ & $(0.049)$ & $-0.128^{* * *}$ & $(0.047)$ \\
\hline Age (in years) & -0.023 & $(1.999)$ & 1.644 & $(2.493)$ & 0.071 & $(2.282)$ \\
\hline Age squared & 144.518 & $(158.960)$ & 181.639 & $(204.370)$ & 183.316 & $(186.134)$ \\
\hline Chronic illness & -0.020 & $(0.040)$ & 0.014 & $(0.049)$ & -0.007 & $(0.046)$ \\
\hline Health rate: bad & 0.025 & $(0.037)$ & -0.005 & $(0.047)$ & 0.047 & $(0.044)$ \\
\hline Health rate: average & -0.036 & $(0.038)$ & -0.008 & $(0.048)$ & $-0.107^{* *}$ & $(0.046)$ \\
\hline Health rate: good & 0.020 & $(0.038)$ & -0.001 & $(0.047)$ & 0.062 & $(0.044)$ \\
\hline Without education & -0.017 & $(0.014)$ & -0.004 & $(0.015)$ & -0.018 & $(0.018)$ \\
\hline Primary education & 0.059 & $(0.041)$ & -0.010 & $(0.050)$ & $0.080^{*}$ & $(0.048)$ \\
\hline Secondary education & $-0.072^{* *}$ & $(0.032)$ & 0.056 & $(0.042)$ & -0.035 & $(0.041)$ \\
\hline University education & $-0.039^{* * *}$ & $(0.013)$ & -0.001 & $(0.013)$ & $-0.065^{* * *}$ & $(0.016)$ \\
\hline Nuclear families & -0.049 & $(0.040)$ & $-0.431^{* * *}$ & $(0.042)$ & $-0.494^{* * *}$ & $(0.039)$ \\
\hline Extended families & 0.034 & $(0.040)$ & $0.440^{* * *}$ & $(0.043)$ & $.486^{* * *}$ & $(0.040)$ \\
\hline Quintile 1 & $0.080^{* * *}$ & $(0.029)$ & 0.037 & $(0.041)$ & .052 & $(0.035)$ \\
\hline Quintile 2 & 0.031 & $(0.031)$ & $-0.065^{*}$ & $(0.038)$ & -.029 & $(0.035)$ \\
\hline Quintile 3 & -0.042 & $(0.032)$ & 0.019 & $(0.041)$ & -.005 & $(0.039)$ \\
\hline Quintile 4 & -0.010 & $(0.035)$ & -0.007 & $(0.043)$ & .026 & $(0.042)$ \\
\hline Quintile 5 & $-0.059^{*}$ & $(0.034)$ & 0.016 & $(0.038)$ & -.044 & $(0.039)$ \\
\hline Has health insurance & 0.043 & $(0.041)$ & $0.145^{* * *}$ & $(0.049)$ & $0.133^{* * *}$ & $(0.046)$ \\
\hline $\begin{array}{l}\text { Have difficulties to pay for } \\
\text { health care services }\end{array}$ & -0.025 & $(0.039)$ & $-0.095^{*}$ & $(0.049)$ & $-0.156^{* * *}$ & $(0.046)$ \\
\hline Health practitioners & $-0.022^{* *}$ & $(0.009)$ & 0.011 & $(0.008)$ & -0.008 & $(0.012)$ \\
\hline
\end{tabular}

Note: Results are displayed for the matching using 5-nearest neighbour estimator. The caliper width is 0.01 . Stars indicate: ${ }^{* *} \mathrm{p}<.01,{ }^{* *} \mathrm{p}<.05,{ }^{*} \mathrm{p}<.1$; Standard errors are in brackets. Results should be interpreted as the differences in means for a particular group paying informal payments to medical staff (e.g. the number of identical rural residents paying informal payments to medical staff has gone down by 0.139 from to 2002 to 2005).

People with university education are less likely to pay informally in outpatient care if years 2005 and 2008 are compared to 2002. This effect shows that higher educated people have become more aware of their rights or are in a better negotiation position with medical staff. The time effect turns positively only for people with primary education if year 2008 is 
compared to 2002 showing that they become more likely to pay informally in outpatient care. Having very basic education reduces the chances to be formally employed (and therefore to benefit from health insurance) and may also limit the social connections with medical staff (the same table shows that being a health practitioner lowers the probability of paying over the years because of these connections).

The share of people in the highest quintile paying informal payments in outpatient care went down between years 2002 and 2005 and the same trend is more or less maintained for the three top quintiles throughout the years (even though not statistically significant). The contrary has happened for the first or second quintiles. The first quintile becomes consistently more likely to pay informally throughout all years confirming our previous findings and showing a regressive effect of measures taken to reduce informal payments in the Albanian outpatient care.

In the tobit and the Heckman selection models we have found that having health insurance reduces the probability of paying informally in outpatient care. Despite this, the effect of health insurance over the years has not been moving in the same direction. Patients having health insurance become more likely to pay if year 2008 is compared to 2002 and 2005. The positive (and statistically significant) coefficients show that the effect of health insurance in lowering the probability of paying has decreased over the years. In fact, it looks like that the lack of further policy measures between years 2005 and 2008 has created reverse incentives for participation in the social health insurance scheme.

\subsubsection{Results for inpatient services}

Table 3.9 gives the results for the tobit and Heckman selection models for the amount paid informally to medical staff in inpatient care. The exclusion instruments we have used here are similar to those in outpatient care and correspond to dummies for having health insurance, having difficulties to pay for health care, and being a health practitioner. The overidentifying restriction tests do not reject the null hypothesis (the lower part of Table 3.9) proving that our exclusion instruments can be considered valid as in outpatient care. The likelihood-ratio test for $\mathrm{rho}=0$ rejects its null hypothesis showing that OLS estimates without the selection correction would be inconsistent.

The results of the tobit model show that the amount of informal payments in inpatient care has decreased with years and especially between years 2005 and 2008. The correction for the selection model shows that in fact such results should be mainly attributed to the decrease in the probability of paying informally. The negative coefficients in the third column of the table show that such probability has decreased significantly both in 2005 and 2008, showing that the share of non-payers (individuals having a probability close to 0 on paying informally) has increased.

However, the Heckman selection model shows that the change in the amount paid over the years turns to be positive and significant. In other words, in 2005 and 2008 people may be less likely to pay informally for inpatient care than they were in 2002 but those who pay informally, pay higher amounts. 
Table 3.9. Informal payments for inpatient services - Results from tobit and Heckman selection models

\begin{tabular}{|c|c|c|c|c|c|c|}
\hline \multirow{2}{*}{$\begin{array}{l}\text { VARIABLES } \\
\text { (Year 2002) }\end{array}$} & \multirow{2}{*}{\multicolumn{2}{|c|}{$\begin{array}{c}\text { TOBIT MODEL } \\
\text { Log of the amount paid } \\
\text { informally }\end{array}$}} & \multicolumn{4}{|c|}{ HECKMAN SELECTION MODEL } \\
\hline & & & \multicolumn{2}{|c|}{ Selection model } & \multicolumn{2}{|c|}{$\begin{array}{l}\text { Log of the amount } \\
\text { paid informally }\end{array}$} \\
\hline Year 2005 & -0.080 & $(0.305)$ & -0.033 & $(0.071)$ & $0.192^{*}$ & $(0.111)$ \\
\hline Year 2008 & $-1.044^{* *}$ & $(0.405)$ & $-0.230^{* *}$ & $(0.092)$ & $0.354^{* *}$ & $(0.155)$ \\
\hline Rural area & 0.224 & $(0.320)$ & 0.046 & $(0.073)$ & -0.049 & $(0.113)$ \\
\hline \multicolumn{7}{|l|}{ (Stratum central) } \\
\hline Stratum coastal & $0.900^{* *}$ & $(0.359)$ & $0.169^{* *}$ & $(0.085)$ & 0.055 & $(0.132)$ \\
\hline Stratum mountain & $-1.799^{* * *}$ & $(0.339)$ & $-0.328^{* * *}$ & $(0.077)$ & $-0.416^{* * *}$ & $(0.129)$ \\
\hline Stratum Tirana & $-1.388^{* *}$ & $(0.540)$ & $-0.270^{* *}$ & $(0.122)$ & 0.144 & $(0.205)$ \\
\hline Gender (“ 0 ” male, “ 1 ” female) & 0.265 & $(0.279)$ & 0.060 & $(0.064)$ & -0.057 & $(0.104)$ \\
\hline Age (in years) & 0.024 & $(0.031)$ & 0.004 & $(0.007)$ & $0.033^{* * *}$ & $(0.011)$ \\
\hline Age squared & -0.000 & $(0.000)$ & -0.000 & $(0.000)$ & $-0.000^{* * *}$ & $(0.000)$ \\
\hline Chronic illness & $-0.864^{* *}$ & $(0.397)$ & $-0.180^{* *}$ & $(0.091)$ & -0.020 & $(0.149)$ \\
\hline \multicolumn{7}{|l|}{ (Health rate: bad) } \\
\hline Health rate: average & 0.023 & $(0.387)$ & -0.071 & $(0.088)$ & $0.437^{* * *}$ & $(0.144)$ \\
\hline Health rate: good & 0.496 & $(0.452)$ & -0.008 & $(0.104)$ & $0.650^{* * *}$ & $(0.166)$ \\
\hline \multicolumn{7}{|l|}{ (Primary/No education) } \\
\hline Secondary education & 0.547 & $(0.363)$ & 0.113 & $(0.084)$ & 0.025 & $(0.132)$ \\
\hline University education & 0.777 & $(0.711)$ & 0.088 & $(0.166)$ & 0.380 & $(0.255)$ \\
\hline \multicolumn{7}{|l|}{ (Nuclear families) } \\
\hline Extended families & -0.094 & $(0.298)$ & -0.035 & $(0.069)$ & $0.182^{*}$ & $(0.109)$ \\
\hline Quintile 1 & $-0.981^{* *}$ & $(0.426)$ & $-0.192^{* *}$ & $(0.097)$ & -0.016 & $(0.160)$ \\
\hline Quintile 2 & -0.149 & $(0.416)$ & -0.043 & $(0.095)$ & -0.084 & $(0.153)$ \\
\hline \multicolumn{7}{|l|}{ (Quintile 3) } \\
\hline Quintile 4 & 0.163 & $(0.427)$ & 0.052 & $(0.099)$ & -0.064 & $(0.155)$ \\
\hline Quintile 5 & 0.599 & $(0.441)$ & 0.103 & $(0.103)$ & $0.295^{*}$ & $(0.159)$ \\
\hline \multicolumn{7}{|l|}{$\begin{array}{l}\text { (Have no difficulties to pay for health } \\
\text { care services) }\end{array}$} \\
\hline Has health insurance & $-0.952^{* * *}$ & $(0.310)$ & $-0.216^{* * *}$ & $(0.062)$ & - & - \\
\hline $\begin{array}{l}\text { Have difficulties to pay for health } \\
\text { care services }\end{array}$ & $0.563^{*}$ & $(0.313)$ & $0.152^{* *}$ & $(0.062)$ & - & - \\
\hline Health practitioners & -0.368 & $(0.888)$ & -0.091 & $(0.170)$ & - & - \\
\hline Constant & $2.026^{* *}$ & $(0.910)$ & 0.252 & $(0.205)$ & $5.964^{* * *}$ & $(0.322)$ \\
\hline$N$ (Left-censored N) & \multicolumn{2}{|c|}{$1711(788)$} & \multicolumn{4}{|c|}{$1711(788)$} \\
\hline Log likelihood & \multicolumn{2}{|c|}{-3418.707} & \multicolumn{4}{|c|}{-2669.832} \\
\hline Pseudo $\mathrm{R}^{2}$ & \multicolumn{2}{|c|}{0.021} & & & & \\
\hline Rho: Correlation of error terms & & & \multicolumn{2}{|c|}{$-0.798^{* *}$} & \multicolumn{2}{|c|}{$(0.537)$} \\
\hline $\begin{array}{l}\text { LR test of independent eqns. }(\mathrm{H} 0: \\
\text { rho }=0),\left[\text { Prob }>\mathrm{chi}^{2}\right]\end{array}$ & & & \multicolumn{2}{|c|}{14.65} & \multicolumn{2}{|c|}{$[0.000]$} \\
\hline Wald $\mathrm{chi}^{2}\left[\right.$ Prob $\left.>\mathrm{chi}^{2}\right]$ Whole model & & & \multicolumn{2}{|c|}{101.23} & \multicolumn{2}{|c|}{$[0.000]$} \\
\hline \multicolumn{7}{|l|}{ Overidentification tests: } \\
\hline \multicolumn{3}{|c|}{$\begin{array}{l}\text { Sargan (score) chi }{ }^{2}(\mathrm{H} 0 \text { : Instruments are exogenous to log of } \\
\text { amount paid informally) }\left[\mathrm{Prob}>\mathrm{chi}^{2}\right]\end{array}$} & 0.218 & [0.896] & & \\
\hline \multicolumn{3}{|c|}{$\begin{array}{l}\text { Basmann chi }{ }^{2} \text { (H0: Instruments are exogenous to to log of } \\
\left.\text { amount paid informally) [Prob }>\mathrm{chi}^{2}\right]\end{array}$} & 0.215 & {$[0.897]$} & & \\
\hline
\end{tabular}

Note: Stars indicate: ${ }^{* * *} \mathrm{p}<.01,{ }^{* *} \mathrm{p}<.05,{ }^{*} \mathrm{p}<.1$; Reference categories in italics. Standard errors are in brackets. 
Being a rural resident does not have a statistical significant effect on the amount paid informally for inpatient care. This is evidence that the amounts paid informally in inpatient care do not differ significantly between patients living in rural or urban areas. However, we notice more differences when checking for the geographical area of the patients. Patients living in coastal areas pay higher amounts as informal payments to medical staff compared to patients living in central areas (though again the selection correction shows that this is due to the higher probability of paying rather than the amount paid). On the other hand, patients coming from mountainous areas pay smaller amounts. This may relate again to the poverty levels in these areas (see above).

We observe for inpatient care a positive correlation between age and both the probability of paying informally and the amount paid. The negative coefficient for age squared re-confirms the inverted-U shape of such relation (working age adults are again the ones to pay the higher amounts informally). On the other hand, chronic illness reduces the amount paid informally to medical staff in inpatient care. The selection correction indicates that a good part of the statistical effect could be dedicated to the fact that such patients are simply less likely to pay informally. The reasons behind this may relate to the financial burden of long-term illnesses but also to their better knowledge on how the system of informal payments works (as they tend to return to hospitals).

Similarly to outpatient care, the two highest consumption quintiles pay higher amounts informally compared to other quintiles. However, coefficients are not always statistically significant showing that differences between quintiles are not clearly drawn. The effect of our exclusion variables is also similar to that in outpatient care. The major contribution of health insurance is that it lowers the probability of paying informally (for every patient with health insurance the logs of probability to pay informally go down with 0.216 times compared to patients without insurance). Individuals facing difficulties to pay for health care are again more likely to pay informal payments and health care practitioners are less likely to pay to their colleagues (though the effect is again not statistically significant). For every patients working in health sector the logs of probability to pay informally go down with 0.091 times compared to other patients.

Table 3.10. Propensity Score Matching results for inpatient care - Time impact on the amount paid informally to medical staff

\begin{tabular}{lcc}
\hline \hline & \multicolumn{1}{c}{ INPATIENT HEALTH CARE SERVICE } \\
\hline Year 2002 - 2005 & & $(0.113)$ \\
Nearest - neighbour matching & 0.113 & $(0.106)$ \\
Kernel matching & 0.062 & $(0.152)$ \\
Year 2005 - 2008 & & $(0.138)$ \\
Nearest - neighbour matching & -0.026 & $(0.145)$ \\
Kernel matching & -0.044 & $(0.136)$ \\
Year 2002 - 2008 & & \\
Nearest - neighbour matching & 0.096 & 0.094 \\
Kernel matching
\end{tabular}

Note: Stars indicate: ${ }^{* * *} \mathrm{p}<.01,{ }^{* *} \mathrm{p}<.05,{ }^{*} \mathrm{p}<.1$; Standard errors are in brackets. 
The matching findings reported in Table 3.10 show that the trend of the average amount paid informally in inpatient care over the years is similar to what we found for outpatient care. There is an increase in the average amount paid informally between years 2002 and 2005, but there is a decrease in these amounts between years 2005 and 2008 (though not statistically significant if both matching techniques are used). This change makes the overall effect between years 2002 and 2008 positive (but statistically not significant). Again, it looks like there have been more incentives to reduce informal payments between years 2005 and 2008 than there were between years 2002 and 2005.

The time impact of different patient characteristics for inpatient care in Table 3.11 shows that changes between the years are similar to those for outpatient care.

Table 3.11. Propensity Score Matching results for inpatient care - Time impact for individuals paying informally

\begin{tabular}{|c|c|c|c|c|c|c|}
\hline \multirow{2}{*}{$\begin{array}{l}\text { VARIABLES } \\
\text { Rural area }\end{array}$} & \multicolumn{2}{|c|}{$\begin{array}{l}\text { DIFFERENCE BETWEEN } \\
\text { YEARS (2002-2005) }\end{array}$} & \multicolumn{2}{|c|}{$\begin{array}{c}\text { DIFFERENCE BETWEEN } \\
\text { YEARS (2005-2008) }\end{array}$} & \multicolumn{2}{|c|}{$\begin{array}{c}\text { DIFFERENCE BETWEEN } \\
\text { YEARS (2002-2008) }\end{array}$} \\
\hline & 0.060 & $(0.039)$ & 0.066 & $(0.051)$ & $0.109^{* *}$ & $(0.051)$ \\
\hline Stratum central & 0.047 & $(0.035)$ & $0.109^{* *}$ & $(0.050)$ & $0.177^{* * *}$ & $(0.049)$ \\
\hline Stratum coastal & $-0.064^{*}$ & $(0.037)$ & -0.053 & $(0.045)$ & $-0.150^{* * *}$ & $(0.046)$ \\
\hline Stratum mountain & -0.030 & $(0.037)$ & -0.006 & $(0.046)$ & -0.014 & $(0.046)$ \\
\hline Stratum Tirana & $0.047^{* *}$ & $(0.020)$ & $-0.049^{*}$ & $(0.031)$ & -0.013 & $(0.028)$ \\
\hline $\begin{array}{l}\text { Gender (" } 0 \text { " male, " } 1 \text { " } \\
\text { female) }\end{array}$ & 0.007 & $(0.039)$ & $-0.228^{* * *}$ & $(0.051)$ & $-0.220^{* * *}$ & $(0.050)$ \\
\hline Age (in years) & 1.101 & $(1.746)$ & $4.686^{* *}$ & $(2.278)$ & $5.367^{* *}$ & $(2.159)$ \\
\hline Age squared & 185.505 & $(140.670)$ & $377.037^{*}$ & $(202.331)$ & $522.859^{* * *}$ & $(194.429)$ \\
\hline Chronic illness & $-0.084^{* *}$ & $(0.039)$ & 0.057 & $(0.052)$ & -0.026 & $(0.052)$ \\
\hline Health rate: bad & $0.084^{* *}$ & $(0.035)$ & -0.058 & $(0.048)$ & $0.081^{*}$ & $(0.046)$ \\
\hline Health rate: average & $-0.092^{* * *}$ & $(0.033)$ & 0.005 & $(0.040)$ & $-0.080^{*}$ & $(0.043)$ \\
\hline Health rate: good & 0.043 & $(0.039)$ & 0.009 & $(0.051)$ & 0.017 & $(0.051)$ \\
\hline Without education & -0.011 & $(0.009)$ & 0.012 & $(0.009)$ & -0.011 & $(0.013)$ \\
\hline Primary education & 0.062 & $(0.039)$ & -0.038 & $(0.051)$ & 0.049 & $(0.051)$ \\
\hline Secondary education & $-0.060^{*}$ & $(0.032)$ & $0.077^{*}$ & $(0.044)$ & -0.009 & $(0.045)$ \\
\hline University education & $-0.032^{*}$ & $(0.017)$ & -0.007 & $(0.019)$ & $-0.038^{*}$ & $(0.020)$ \\
\hline Nuclear families & $-0.129^{* * *}$ & $(0.039)$ & $-0.439^{* * *}$ & $(0.042)$ & $-0.535^{* * *}$ & $(0.040)$ \\
\hline Extended families & $0.117^{* * *}$ & $(0.039)$ & $0.413^{* * *}$ & $(0.044)$ & $0.501^{* * *}$ & $(0.042)$ \\
\hline Quintile 1 & $0.076^{* * *}$ & $(0.029)$ & 0.054 & $(0.043)$ & 0.043 & $(0.041)$ \\
\hline Quintile 2 & 0.034 & $(0.032)$ & -0.036 & $(0.043)$ & 0.001 & $(0.041)$ \\
\hline Quintile 3 & 0.033 & $(0.033)$ & -0.051 & $(0.040)$ & $-0.077^{*}$ & $(0.039)$ \\
\hline Quintile 4 & $-0.053^{*}$ & $(0.032)$ & -0.040 & $(0.041)$ & -0.016 & $(0.042)$ \\
\hline Quintile 5 & $-0.090^{* * *}$ & $(0.032)$ & $0.073^{*}$ & $(0.040)$ & 0.048 & $(0.042)$ \\
\hline Has health insurance & -0.022 & $(0.039)$ & $0.176^{* * *}$ & $(0.051)$ & $0.169^{* * *}$ & $(0.051)$ \\
\hline $\begin{array}{l}\text { Have difficulties to pay for } \\
\text { health care services }\end{array}$ & -0.023 & $(0.036)$ & $-0.093^{*}$ & $(0.049)$ & $-0.105^{* *}$ & $(0.048)$ \\
\hline Health practitioners & $-0.027^{* *}$ & $(0.012)$ & 0.001 & $(0.011)$ & -0.023 & $(0.016)$ \\
\hline
\end{tabular}

Note: Stars indicate: ${ }^{* * *} \mathrm{p}<.01,{ }^{* *} \mathrm{p}<.05,{ }^{*} \mathrm{p}<.1$; Standard errors are in brackets. Results should be interpreted as the differences in means for a particular group paying informal payments to medical staff (e.g. the number of identical rural residents paying informal payments to medical staff has gone up by 0.060 from to 2002 to 2005). 
Rural area residents become more likely to pay informally if year 2008 is compared to year 2002 and this confirms that the burden is shifting towards those with higher opportunity costs (due to longer distances) or fewer social connections and information (since hospitals are mostly located in Tirana and urban areas). Similarly to outpatient services there are differences between residents of geographical regions of the country. Patients living in central Albania become more likely to pay informally in inpatient care if year 2008 is compared to 2002 while patients coming from other regions become less likely to pay informally (though differences are not always significant). These between-areas differences could be a consequence of higher resources allocated to certain geographical areas (e.g. higher salaries for medical staff willing to work in remote hospitals, etc).

The effect of informal payments over the years increasingly falls over the poorest members of the society. Patients from the lowest quintile become more likely to pay if different years are compared, while this is different for other patients. The effect of health insurance over the years is again questionable. People having health insurance become less likely to pay if year 2005 is compared to year 2002 (but the effect is not statistically significant). On the other hand they become more likely to pay if we compare year 2008 to 2002 (or year 2008 to 2005). This effect is similar to what we found for outpatient care and calls for attention towards the declining role of health insurance in reducing informal payments over the last years.

Many of the other determinants follow the same trends as in outpatient care. For example, older people become more likely to pay over the years (and this is significant if we compare year 2008 to 2005), higher educated individuals have a lower probability of paying informally throughout the years, etc.

\subsection{Discussion}

By using the results for inpatient and outpatient care, we aimed to test whether the causes of informal payments could be better explained using any of the three theoretical models: cultural, economic, and governance. Considering the cultural similarities between Albanian and other CEE and FSU countries (Bakacsi et al., 2002), we initially expected the cultural model (Delcheva et al., 1997; Balabanova and McKee, 2002) to be a strong model for explaining informal payments. However, our data and results do not confirm this expectation. We have found that patients are more likely to pay for inpatient care than for outpatient care. About 43.9 per cent of patients in 2008 pay informally for inpatient care while only 19.0 per cent pay for outpatient care (see Table 3.4). These findings are not in accordance with the cultural model which would predict no differences in the probability of paying informally for outpatient and inpatient care. The big difference on the amount paid between outpatient and inpatient care speaks also against the cultural model. Referring to table 3.5, the amount that patients pay informally in inpatient care is around 66 times higher than in outpatient care.

While cultural factors in Albania may only be seen as one of the reasons for the frequently encountered informal payments in health care, other factors relating to economic and governance models explain better how widespread and high such payments are. The highest informal payments are paid by groups of patients such as residents of coastal areas, 
patients in the highest consumption quintiles, or higher educated. These results are in accordance with the economic model (those who can afford will pay more to fill in the gaps created by the lack of resources and to get better services).

On the other hand, the high incidences of informal payments among certain groups of payers (e.g. rural residents, lower educated patients, and those with difficulties to pay for health care) support the governance model. The significant effects of having less information on the amount required (as with patients with basic or no education) or having less social connections (as with rural residents seeking health care in urban areas) clearly indicate a governance failure in the system and demonstrate that not all causal factors are exclusively linked to scarcity of resources as claimed by the economic model. Moreover, certain categories seem to be more disadvantaged than others. Patients belonging to the lower consumption quintiles pay similar amounts compared to the middle quintile, while rural residents pay higher amounts for outpatient care. This shows that they are very vulnerable to informal payments. The government fails to protect these categories that are left to cope with market mechanisms (You need care? You have to pay for it!). It is clear that lack of government support and lower bargaining power of these groups will make them more susceptible to poverty in the long-run.

Having national health insurance lowers the probability of paying informally both in outpatient and inpatient care. This may be due to the greater bargaining power of these patients in interacting with medical staff. They are better informed on what their rights are. However, such relation was proven to be fragile in the long-term as we showed that the role of health insurance has become weaker from year 2005 to 2008. This frail status of health insurance in Albania calls for more attention to evaluating the effect of ongoing reforms especially in the inpatient care.

Other aspects we have tested were also the effects of particular policy changes taking place mostly between 2002 and 2005 (such as the contractual agreement between HII and outpatient care and the increase of GPs salaries). Assuming that most of the changes took place in outpatient care (in terms of reorganisation and financing primary health care centres), we expect most of effects associated to this service. In fact, the matching techniques show that the amount paid by individuals did not change much during the first years after 2002. Moreover, the direction of the changes was not always as expected. Some of the unexpected results included: the increase in average the amount paid between year 2002 and 2005 in outpatient care; the gradual increase of the probability of paying among patients having health insurance between 2002 and 2005/2008; and the relatively high amounts (and probability) paid for patients in lower quintiles or patients having difficulties to pay. This is evidence for some debatable effects of the reforms or measures and clearly indicates that weak governance remains one of the biggest challenges in the sector.

Previous research has highlighted government failure as one of the main causes for informal payments in health care (Lewis, 2006). When the government fails to enforce accountability or fails to prevent non-ethical behaviour of medical staff, the most vulnerable will bear the consequences. Our findings show that in the Albanian context one of the main reforms directly linked with the underpaid health care staff (the increase of GPs wages), has proven ineffective in the long run in reducing informal payments. This was due to lack of a 
follow up on reforms and the indexation of wages over the years. The evidence shows that even though economic factors may play a role in determining the amount of informal payments to medical staff, governance issues are more closely linked to the incidence of such payments.

Although this chapter sheds more light on important determinants of informal payments it has some limitations because of the available data. ALSMS's do not allow us to distinguish between payments made to physicians or other staff, nor does it capture the payments made in kind or through favours rendered. Our analysis was based on the information on 'gifts made to medical staff'. As mentioned in the first chapter of this dissertation, the questionnaires do not ask explicitly for the overall amount of payments flowing outside formal channels (which would also include other payments, for example payments for pharmaceuticals or other medical materials that should have been provided free of charge). Furthermore, we are not able to determine whether social connections (e.g. knowing the physician beforehand) influence informal payments.

This chapter has mostly concentrated on patient characteristics. The ALSMS data for 2002, 2005 and 2008 provide limited information on the hierarchical position of physicians. Moreover medical staff's particular professional background would give more insights on who is requesting payments and who gets what. Information on the general culture towards corruption in particular health centres or hospitals (i.e. anti-corruption measures taken and number of punished medical staff for having accepted informal payments) would allow for better estimates of the effect of governance measures on informal payments.

One last limitation of this chapter is that, even though we explore the determinants of informal payments, we can not say anything about the causal effects. Data availability on key variables limit the use of statistical methods to explore more on this important aspect.

\subsection{Conclusions}

Informal payments to medical staff are widespread in Albania both for outpatient and inpatient care. Most of the evidence coming from ALSMS data for 2002, 2005 and 2008 support scarcity of resources and governance failures in health care as the main reasons behind them. The past reforms and reorganisation of the primary health sector have only managed to achieve small reductions in the amounts and incidence of informal payments. The empirical evidence shows that even though the wages of primary care medical staff have doubled (in real value) over the years the informal payments remain widely spread. The vulnerable groups of the society remain less protected against such payments and policy measures have not reached the most deprived regions of the country.

Patients and physicians are using informal payments as coping strategies to ease problems brought by lack of resources and poor governance. Judging from the evidence provided by ALSMS data for 2002, 2005 and 2008, the most effective policy measure in Albania from a supply-side perspective would be to include inpatient care in the benefits package of the health insurance scheme. The direct contracting of inpatient services from the health insurance fund would increase efficiency and accountability in inpatient care provision. Such measures have only started to be implemented in 2009. The effects on inpatient care are yet to be seen while the experience with outpatient care calls for more 
attention on the outcome of this reform. The data analysis in this chapter demonstrated that the people suffering the effects of informal payments are the poorest or regionally disadvantaged (i.e. residents of rural areas). Providing better protection for the most vulnerable groups of the population and adjusting the regional distribution of resources will certainly help in this direction. Moreover, every extension of health insurance to inpatient care must be combined with policy measures to protect the chronically ill and the uninsured. It goes without saying that the increased efficiency in financing the health care system would also require taking measures to eliminate the informal payments. Experiences from other countries (see also Lewis and Pettersson, 2009) have shown that providing more incentives for physicians (e.g. revenue sharing) and increasing control and accountability would contribute in this regard. 


\subsection{Appendix 3A}

Table A3.1. Logit results (dependent variable $=1$ if the individual participates in the next year survey)

\begin{tabular}{|c|c|c|c|c|c|c|}
\hline \multirow{2}{*}{$\begin{array}{l}\text { VARIABLES } \\
\text { Rural area }\end{array}$} & \multicolumn{2}{|c|}{ YEARS 2002 - 2005} & \multicolumn{2}{|c|}{ YEARS 20025- 2008} & \multicolumn{2}{|c|}{ YEARS 2002 - 2008} \\
\hline & $-0.057^{*}$ & $(0.033)$ & -0.040 & $(0.034)$ & $-0.058^{*}$ & $(0.034)$ \\
\hline Household size & $-0.082^{* * *}$ & $(0.009)$ & $-0.045^{* * *}$ & $(0.009)$ & $-0.133^{* * *}$ & $(0.010)$ \\
\hline Religion & $0.260^{* * *}$ & $(0.013)$ & $-0.205^{* * *}$ & $(0.018)$ & 0.011 & $(0.021)$ \\
\hline \multicolumn{7}{|l|}{ (Stratum central) } \\
\hline Stratum coastal & $0.105^{* * *}$ & $(0.033)$ & -0.024 & $(0.033)$ & 0.052 & $(0.034)$ \\
\hline Stratum mountain & $0.098^{* * *}$ & $(0.034)$ & $-0.329^{* * *}$ & $(0.035)$ & $-0.302^{* * *}$ & $(0.035)$ \\
\hline Stratum Tirana & $0.191^{* * *}$ & $(0.042)$ & $0.359^{* * *}$ & $(0.049)$ & $0.478^{* * *}$ & $(0.048)$ \\
\hline $\begin{array}{l}\text { Gender (" } 0 \text { " male, " } 1 \text { " } \\
\text { female) }\end{array}$ & 0.007 & $(0.027)$ & $-0.079^{* * *}$ & $(0.029)$ & $-0.074^{* * *}$ & $(0.029)$ \\
\hline Age (in years) & $0.003^{* * *}$ & $(0.001)$ & $0.004^{* * *}$ & $(0.001)$ & $0.007^{* * *}$ & $(0.001)$ \\
\hline Has health insurance & 0.005 & $(0.030)$ & -0.041 & $(0.031)$ & -0.028 & $(0.032)$ \\
\hline \multicolumn{7}{|l|}{ (Primary/No education) } \\
\hline Secondary education & $0.231^{* * *}$ & $(0.034)$ & -0.013 & $(0.035)$ & $0.213^{* * *}$ & $(0.036)$ \\
\hline University education & $0.345^{* * *}$ & $(0.060)$ & $0.352^{* * *}$ & $(0.062)$ & $0.692^{* * *}$ & $(0.062)$ \\
\hline Quintile 1 & $0.351^{* * *}$ & $(0.046)$ & $0.111^{* *}$ & $(0.045)$ & $0.479^{* * *}$ & $(0.047)$ \\
\hline Quintile 2 & $0.077^{*}$ & $(0.044)$ & 0.050 & $(0.045)$ & $0.139^{* * *}$ & $(0.046)$ \\
\hline \multicolumn{7}{|l|}{ (Quintile 3) } \\
\hline Quintile 4 & $-0.264^{* * *}$ & $(0.043)$ & -0.073 & $(0.045)$ & $-0.347^{* * *}$ & $(0.045)$ \\
\hline Quintile 5 & $-0.567^{* * *}$ & $(0.045)$ & $-0.163^{* * *}$ & $(0.048)$ & $-0.766^{* * *}$ & $(0.048)$ \\
\hline _cons & -0.055 & $(0.071)$ & $0.409^{* * *}$ & $(0.075)$ & $0.456^{* * *}$ & $(0.076)$ \\
\hline
\end{tabular}

Note: The results are used to estimate the propensity score for the matching of individuals over the years. Stars indicate: ${ }^{* * *} \mathrm{p}<.01,{ }^{* *} \mathrm{p}<.05,{ }^{*} \mathrm{p}<.1$; Reference categories in italics. Standard errors are in brackets. 
Figure A3.1. Histograms from the predicted scores from the logit models used for matching
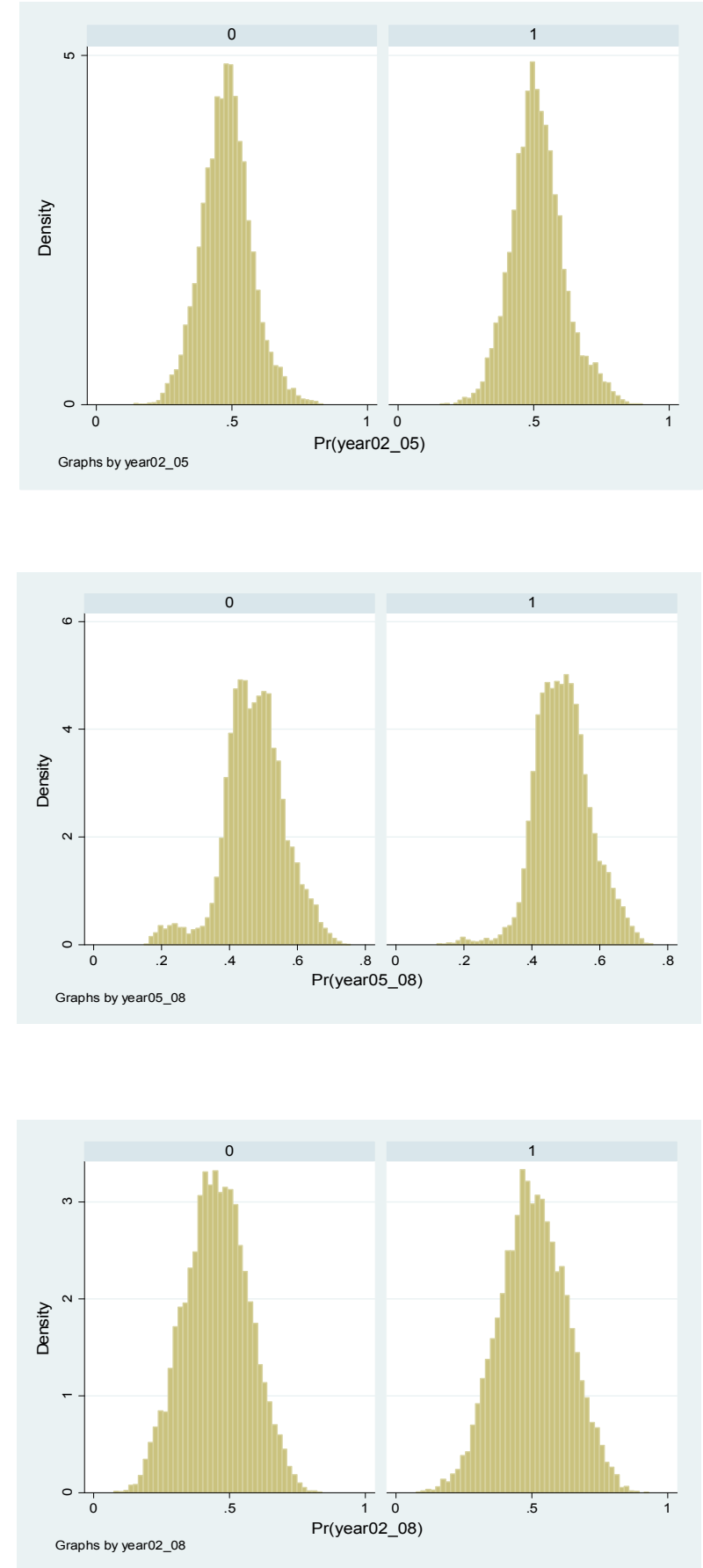

A31.1 Predicted scores for 2002 and 2005

A3.1.2 Predicted scores for 2005 and 2008

A3.1.3 Predicted scores for 2002 and 2008 


\section{Chapter 4. INFORMAL PAYMENTS \\ AND INTRA-HOUSEHOLD \\ ALLOCATION OF RESOURCES \\ FOR HEALTH CARE SERVICES \\ IN ALBANIA}

This chapter is based on the paper by Tomini S, Groot W, Pavlova M. (2011). Informal payments and intra-household allocation of resources for health care in Albania. 


\begin{abstract}
Informal payments for health care services can impose financial hardship on households. Many studies have found that the position within the household can influence the decision on how much is spent on each household member. This study analyses the intra-household differences in spending on informal payments for health care services by comparing the resources allocated between household heads, spouses and children.

Pooled data from two cross sectional surveys, the Albanian Living Standard Measurement Survey 2002 and 2005, are used to analyse both the probability and the amount paid in inpatient and outpatient health care services. A generalised Hausman specification test is used to compare the coefficients of probit and OLS models for nuclear and extended households. We find that due to the widespread informal payments there are no significant differences between households in the incidence of informal payments for households' members, but there are more differences in the amount paid informally. Results suggest that households strategically allocate their resources on health care by favouring individuals with higher earning potential who have invested more in human capital. Extended households pay higher amounts for spouses with higher education compared to nuclear households. On the other hand, nuclear households choose to pay higher amounts for children with a higher level of education compared to extended households. The differences between households should be taken into account by public policies which should compensate this by redistribution mechanisms targeting disadvantaged groups. Governments should implement effective measures to deal with informal patient payments.
\end{abstract}




\subsection{Introduction}

Health care expenditures are idiosyncratic risks imposed on households that can cause financial hardship, especially if the costs are uninsured. In many Central and Eastern European (CEE) countries and the Former Soviet Union (FSU) informal payments for health care are reported to be high and since they are informal, they are not covered by any formal insurance mechanism. The available strategies to cope with such risks can vary from digging into savings, selling assets, increasing labour supply, or reallocating resources within the household (Lewis, 2000; Sauerborn et al., 1996; Leive and Xu, 2008). The position within the household and the number of household members may influence the decision on how much is spent on informal health care payments. Nuclear and wealthy households are believed to be better able to protect their children against higher expenditures associated with health care use than extended households. On the other hand, the amount allocated to adult household members may depend on their contribution to household income but also on the type of household (Behrman, 1988).

This chapter looks at how different types of households respond to informal payments to medical staff when multiple household members use health care. We analyse the effect characteristics of household heads, spouses and children have on the probability or the amounts paid informally, and test for differences between these members of households. For this purpose, we use data from the Albanian Living Standards Measurement Survey 2002 and 2005. The chapter contributes to the existing literature on intra-household allocation of resources by providing insights on how households cope with unregulated payments in health care when the government policies fail and little is known about the actual prices.

The literature on informal payments has concentrated on the main causes and consequences of such payments (see also Chapters 1 and Chapter 3). Little is known on the impact that the decision-making within the household has on the amounts paid for different members of the household. The theory of social risk management (Holzmann and Jorgensen, 1999) predicts that when governments fail to provide protection, the family and social network may help in coping with particular shocks. In the case of informal payments in health care, household members may support each other by redirecting financial assets or being involved in direct care during the hospitalisation periods.

In countries like Albania, where many households have preserved their patriarchal structure and gender inequalities are prevalent (Martiri, 2009), it is important to see if decision making on health expenditure depends on the severity of illness or on the position that the patient has in the household. Such information is relevant not only to understand the dynamics of intra-household allocation of resources but also to guide policies that aim at redistributing income between household members. This can help to increase the effectiveness of programs like social cash transfers or health care subsidies to reach out to more household members (e.g. children or spouses). 


\subsection{General background}

The high incidence of informal payments in most CEE and FSU countries is frequently attributed to the similarities in health care systems and the common difficulties in the transition from planned to market economies (see also Chapter 3). The ideology adopted by the communist regimes emphasised universal access to health care but did not focus on improving efficiency and quality of such services (Belli, 2002). The fall of communism brought new challenges for these health care systems. The high number of hospital beds, overstaffed health facilities, underpaid health care professionals, and the reduction of the investments provided the conditions for informal payments (Lewis, 2000; Sauerborn et al., 1996; Vian et al., 2006).

The health sector in Albania has followed the same trends as other ex-communist countries where the health sector was underfinanced and considered a non-productive sector (Nuri and Tragakes, 2002). As explained in chapter 1 after the 1990s the public health care system is characterised by a low level of investments, a limited number of physicians (mainly concentrated in the big cities and the capital of the country), low quality of health care, unqualified staff, unmotivated medical personnel, and frequent lack of medicines in public hospitals. According to the WHO database, Albania spends around 6.5 per cent of its GDP on health. This level of spending is comparable to other countries in the region. However, only half of this amount is publicly financed and out-of-pocket payments remain considerably high.

Public health spending in Albania is financed by social health insurance contributions and general tax revenues. Health insurance in Albania should cover most of the formal costs of primary health care and all the costs of hospital care. Patients are formally required to pay small, fixed co-payments per visit for outpatient care or for specialised treatments in hospital care, but until 2005 the amounts required were very low. Payments or gifts made directly to medical staff are not foreseen in the financing of health care and episodes of 'under-the-table' payments requested by medical staff are considered as acts of bribery and punishable by law. However, a general lack of accountability and good governance combined with the lack of resources has contributed to a high incidence of informal payments in the public health sector (see also Chapter 3). Informal payments account for at least one quarter of hospital costs in 2005 (World Bank, 2006), even though by law inpatient care is free of charge.

In the literature, informal payments are defined as direct cash/in-kind unofficial payments to health care providers and/or private purchases of health care and other products meant to be covered by the health system (Lewis, 1999; Thompson and Witter, 2000). Country specific factors and data availability have a large influence on the use of this definition. Most of the previous papers in Albania based on LSMS (Living Standard Measurement Survey) data have identified informal payments as "gifts paid to medical staff" (World Bank, 2006). The same definition is also employed in this chapter. ${ }^{14}$

${ }^{14}$ Even though such definition does not fully capture all the informality in the health sector (e.g. payments for medicines or other materials that are otherwise provided free of charge), it clearly distinguishes the part of the out-of-pocket payments paid directly to medical staff. As the data show, 
The informal nature of such payments makes them unpredictable for individual households that find themselves exposed to the financial risks of health care events. Previous studies have shown that these payments directly influence the welfare of the household. Households may have to cope by using their savings, selling assets or borrowing money (Lewis, 2000; Falkingham, 2004).

The informal nature and the dependence on health status and income rank informal payments among the most severe burdens imposed on individuals. In the absence of formal arrangements or a market for insurance against such risks (in Albania informal payments are also paid by a large share of individuals entitled to health insurance benefits) the burden is left to households and their social networks (Holzmann and Jorgensen, 1999). This refers mostly to support from other household members and to the coping strategies that the households employ on such occasions.

Previous research has shown that households facing catastrophic health care expenditures resort mostly to intra-household strategies for raising money to pay rather than to receiving help from extended households' members (Sauerborn et al., 1996). Households may decide to alter labour supply (i.e. if the household head falls ill other members may decide to work to substitute for the loss of incomes), sell property (or livestock in rural areas), or borrow money from relatives/banks (Lewis, 2000; Mwabu, 1986; Dercon and Krishnan, 2000). The strategies employed by households may differ depending on the available resources, severity of the health impairment and treatment needed, the level of the payments demanded, or the household member in question.

There are various theories on how resources within the household are allocated over members. It has been shown that the share of contributed income determines the share of expenditures on each of the household members (Bourguignon et al., 1993; Thomas, 1993; Browning et al., 1994). Other studies showed that female-headed households allocate resources more towards children, hence contributing to a better health status and higher enrolment rates (Thomas, 1990; Handa, 1994).

We can view informal payments as an investment in health care. Medical care, together with education and training are investments in human capital (Becker, 1962). The amounts invested in health care depend on the expected returns from such capital. Such expected returns are higher if health more critically depends on receiving health care, if remaining life expectancy is higher, if earnings are higher, etc. If we accept that informal payments help patients to obtain better treatment (and thus improve their health status) then we can assume that households will be more willing to allocate resources towards individuals with higher returns on health (Mincer and Polachek, 1974). In this case, higher income earners would be favoured to invest upon i.e. households would be more willing to spend on women or spouses earning wages or in children as they have a longer remaining life expectancy than adults.

Households also differ in their decisions to spend on health care. This may depend on the number of household members. Gary Becker (Becker, 1962) links the "quality" of

such payments may be voluntary or requested but their incidence is high for both inpatient and outpatient. 
children (the amount spent on each child) to the number of children in the household. Households tend to spend relatively more on each child if the number of children is lower. This theory will also have direct consequences for health care expenditures and informal payments. It implies that households with more children and extended households will be less willing to pay higher amounts for health care on each child.

Households in Albania rely on their social network for getting the support that public policies cannot offer. Previous studies have demonstrated that family is the main source for borrowing money (Carletto, 2005). Households also rely to a greater extent on their social network for avoiding informal payments or improving the delivery and the quality of services (Vian and Burak, 2006). Albanian social attitudes (especially in rural or deprived communities) tend to favour men. This creates gender inequalities and may also affect attitudes towards paying for health care. Such gender inequalities in Albania are reported in employment, health care, education and social life (Martiri, 2009).

\subsection{Descriptive statistics and methodology}

The data used in this study come from the Albanian Living Standard Measurement Survey (ALSMS) 2002 and 2005. Both samples in these two cross sectional surveys are country representative. The households sampled numbered 3600 in 2002 and 3638 in 2005. For our analysis we pool data for these two years. The questionnaires include information on household demography, education, incomes, type of illness (sudden or chronic) and health care payments. In addition, information is available on the ways that households raise money to pay for health care. All the variables that we have included in our analysis come from identical questions in these two years. Chapter 1 provides more information on the set up and health care variables included in ALSMS.

The informal payments to medical staff include both in-kind gifts and in-cash payments (all converted to their monetary value). The number of individuals who have visited ambulatory services was $3583^{15}$ while the individuals hospitalised numbered $1384^{16}$ from a total of 31101 individuals in the sample. We have further divided households in two types: nuclear and extended. The division is based on the type of kinship relations between household members. Nuclear households include only two generation families. Household members here are the household head, the spouse and children (single headed households are also included in this category). The extended households include more than two generations, multiple younger couples living together, or couples living together with more distant relatives.

Table 4.1 shows that about 26 per cent of the patients in outpatient care and 59 per cent of those using inpatient care have paid informally to medical staff. The incidence of payments varies little over nuclear or extended households. However, nuclear households are more likely to pay informally for their members (both in outpatient and inpatient care) and at the same time pay higher amounts for household members in both services. Informal payments paid per admission in inpatient care are much higher compared to

\footnotetext{
${ }^{15}$ From this total 2120 individuals have visited ambulatory services in 2002 and 1463 in 2005.

${ }^{16}$ From this total 707 individuals have been hospitalized in 2002 and 677 in 2005.
} 
those paid for outpatient care. Patients pay approximately 55 times more (5019.79/91.25) per visit for inpatient than for outpatient care. This shows once again that such informal payments are in fact implicit payments imposed by medical staff.

Table 4.1. The incidence and amounts paid informally for outpatient and inpatient health care

\begin{tabular}{lcccc}
\hline \hline \multicolumn{1}{c}{ HousEHOLD TYPES } & \multicolumn{2}{c}{ OUTPATIENT CARE } & \multicolumn{2}{c}{ INPATIENT CARE } \\
& $\begin{array}{c}\text { The incidence of } \\
\text { informal payments }\end{array}$ & $\begin{array}{c}\text { Amount paid } \\
\text { informally } \\
\text { (per visit) }\end{array}$ & $\begin{array}{c}\text { The incidence of } \\
\text { informal } \\
\text { payments }\end{array}$ & $\begin{array}{c}\text { Amount paid } \\
\text { informally } \\
\text { (per admission) }\end{array}$ \\
\hline Nuclear household & 0.27 & $104.78^{* *}$ & 0.60 & 5203.23 \\
Extended household & 0.25 & $73.74^{* *}$ & 0.58 & 4792.98 \\
Mean for the total sample & 0.26 & 91.25 & 0.59 & 5019.79 \\
\hline \hline
\end{tabular}

Note: Amounts are in Albanian Leks. All prices are deflated to 2002 prices. 100 ALL = 0.73 Euros in June 2002 (Bank of Albania, 2010). All series are deflated with 2002 prices. Stars indicate if the mean for the particular group is significantly different from the mean of all other groups.. ${ }^{* * *} \mathrm{p}<.01,{ }^{* *} \mathrm{p}<.05,{ }^{*} \mathrm{p}<.1$

Table 4.2 gives a detailed overview of the characteristics of children and spouses by household type. As we can observe, the education level of spouses in extended households is much lower than in nuclear households. Almost 71 per cent of the spouses in extended households have only primary education ( 8 or less years of education) and only 4 per cent of them have university education. Spouses in extended households are also older (with an average age of 48.85 years).

Table 4.2. Characteristics of spouses and children in nuclear and extended households

\begin{tabular}{lcccccc}
\hline \hline & \multicolumn{2}{c}{ SPOUSE OF THE HOUSEHOLD HEAD } & \multicolumn{2}{c}{ CHILDREN OF THE HOUSEHOLD HEAD } \\
& $\begin{array}{c}\text { Nuclear } \\
\text { Household }\end{array}$ & $\begin{array}{c}\text { Extended } \\
\text { Household }\end{array}$ & Total & $\begin{array}{c}\text { Nuclear } \\
\text { Household }\end{array}$ & $\begin{array}{c}\text { Extended } \\
\text { Household }\end{array}$ & Total \\
\hline Without education & $0.00^{* *}$ & $0.01^{* *}$ & 0.01 & $0.05^{* * *}$ & $0.03^{* * *}$ & 0.05 \\
Primary education & $0.55^{* * *}$ & $0.71^{* * *}$ & 0.6 & $0.68^{* * *}$ & $0.63^{* * *}$ & 0.67 \\
Secondary education & $0.36^{* * *}$ & $0.24^{* * *}$ & 0.33 & $0.22^{* * *}$ & $0.28^{* * *}$ & 0.23 \\
University education & $0.08^{* * *}$ & $0.04^{* * *}$ & 0.07 & 0.05 & 0.05 & 0.05 \\
Age & $43.71^{* * *}$ & $48.85^{* * *}$ & 45.13 & $14.49^{* * *}$ & $20.50^{* * *}$ & 16.13 \\
Has health insurance & $0.43^{*}$ & $0.45^{*}$ & 0.43 & $0.33^{* * *}$ & $0.30^{* * *}$ & 0.32 \\
\hline \hline
\end{tabular}

Note: Stars indicate whether the mean for each household type is significantly different from the mean of the other type $\left({ }^{* * *} \mathrm{p}<.01,{ }^{* *} \mathrm{p}<.05,{ }^{*} \mathrm{p}<.1\right)$.

Children are also more likely to have primary education and health insurance in nuclear households. This may be due to the fact that children in nuclear households are on average younger (14.5 years) compared to extended households (20.5 years). Therefore they are more likely to follow education and be covered by health insurance ( 33 per cent against 30 per cent in extended households). ${ }^{17}$ These first descriptive results show clearly that spouses and children in nuclear households seem to have invested more in human capital (they have on average more education). This may be due to a higher earning potential (as the data for spouses show).

${ }^{17}$ In Albania children 0-7 years old and those following education are automatically covered by health insurance. 
Households use different methods to cope with uninsured health expenditures. Borrowing money is one of the most frequently used methods among them (see Table 4.3) attesting for the mutual help among household and community members (in the absence of formal mechanisms). The data show that nuclear households are more likely to borrow money compared to extended households. The next two popular methods are selling agriculture products or animals. These methods are more popular for extended households which live mostly in rural areas and rely more on products or animals as a form of insurance (e.g. almost 24.5 per cent of extended households have declared to have sold animals for raising money against 17.6 per cent of nuclear households).

Table 4.3. Methods to raise money to pay for health care

\begin{tabular}{lccc}
\hline \hline & $\begin{array}{c}\text { NUCLEAR } \\
\text { HOUSEHOLDS }\end{array}$ & $\begin{array}{c}\text { EXTENDED } \\
\text { HOUSEHOLDS }\end{array}$ & $\begin{array}{c}\text { MEAN OF THE } \\
\text { TOTAL SAMPLE }\end{array}$ \\
\hline Method to raise money - borrow money & $0.653^{* * *}$ & $0.589^{* * * *}$ & 0.626 \\
Method to raise money - sell animal & $0.176^{* * *}$ & $0.245^{* * *}$ & 0.205 \\
Method to raise money - sell products & $0.125^{* * *}$ & $0.181^{* * *}$ & 0.149 \\
Method to raise money - sell valuables & $0.009^{* * *}$ & $0.004^{* * *}$ & 0.007 \\
Method to raise money - other methods & $0.110^{* *}$ & $0.097^{* *}$ & 0.104 \\
\hline \hline
\end{tabular}

Note: Stars indicate whether the mean for each household type is significantly different from the mean of the other type ${ }^{*}$ significant at $10 \%$; ${ }^{* *}$ significant at $5 \%$; ${ }^{* * *}$ significant at $1 \%$ ).

In order to investigate how individual characteristics influence informal payments to medical staff we use two different models for the probability of payments (the probit model) and amount paid (the Ordinary Least Squared model). The probability of paying informally can be considered as dependent on the individual characteristics of patients and other household members. Hence the probability of paying can be expressed as:

$$
P\left(y_{i}^{*}\right)=\left\{\begin{array}{cc}
x_{i} \beta+\varepsilon_{i} & \text { if } y_{i}>0 \\
0 & \text { if } y_{i}=0
\end{array}\right.
$$

Where $y_{i}$ refers to the amount paid informally to medical staff, $x_{i}$ denotes a vector characteristics of individual patients and their household members, $\beta$ represents a vector of estimated coefficients corresponding to such characteristics, and $\varepsilon_{i}$ is a vector of residuals errors that have a normal distribution.

Similarly, the amount paid informally to medical staff can also be considered as determined by individual characteristics of patients and their households. In such case the amount is expressed as:

$$
y_{i}=x_{i} \beta+\varepsilon_{i}
$$

This later equation is estimated using OLS. All models are run separately for nuclear and extended households. As our interest lies on testing for possible differences between coefficients for these two types of households, we use a generalised Hausman specification test (Weesie, 1999). This post-estimation test allows us to compare coefficients in the models estimated for nuclear and extended households. The advantage of such specification test is that it makes use of the sandwich covariance estimator to adjust for any 
heteroskedasticities in the outcomes. Our models are estimated separately for inpatient and outpatient care. For comparative purposes, we follow the same procedure to estimate similar models for the total amount of out-of-pocket expenditures for health care.

\subsection{Results and discussion}

Table 4.4 gives the probit estimation results for the incidence of informal payments in outpatient and inpatient care as well as the generalised Hausman tests for differences between coefficients for nuclear and extended households. Results show that generally households seem more likely to pay for spouses than for household's heads (the reference category) and that this is statistically significant in extended households for outpatient care. On the other hand, paying informally for children is less likely than paying for household heads. This is especially the case for outpatient care (where coefficients for both nuclear and extended households are statistically significant) and to a lesser extent for inpatient care. This significant effect in outpatient care may be due to the specifics of illnesses for each household member as for example women needing more health care than men (Cleary et al., 1982; Bertakis et al., 2000). The differences in the probability of paying informally between two types of households are not statistically significant both for outpatient and inpatient care, suggesting that patients are faced with similar probabilities of paying for these services. The positive (but not significant) coefficient for children living in nuclear households and visiting inpatient care may suggest that whenever households face an increased risk of paying informal payments (descriptive statistics showed that the probability of paying is very high in inpatient care) nuclear households may be more willing to pay for their children.

The number of children in the household lowers the probability of paying informally to medical staff especially for outpatient care (statistically significant). The number of siblings in the household lowers the probability of paying informally for health care (Behrman et al., 1980) and in addition children are more likely to be covered by health insurance. The effect is not as strong for inpatient care where the influence of health insurance is lower and informal payments are more spread. The nature of illness (having a sudden/acute condition) has a positive effect for both types of households in outpatient care. The results show that nuclear household patients with sudden illness have lower logs of probability to pay informally of 0.09 times compared with extended households. The nature of illness has the opposite effect for the inpatient care for both types of households.

The variable for the timing of the survey (2002/2005) shows that the incidence of informal payments has decreased for outpatient care for both types of households. However, this is not the case for inpatient care where informal payments have decreased for nuclear households but increased for the extended ones (for inpatient care this is 0.25 times higher for extended households compared with nuclear ones). The significant difference in coefficients, when the generalised Hausman test is applied, shows that when confronted with inpatient care such households are more likely to pay in 2005 than they were in 2002 and that this is definitely higher than for nuclear households. This can be due to the higher needs these households may have over time (e.g. having older household members who need extensive care). 


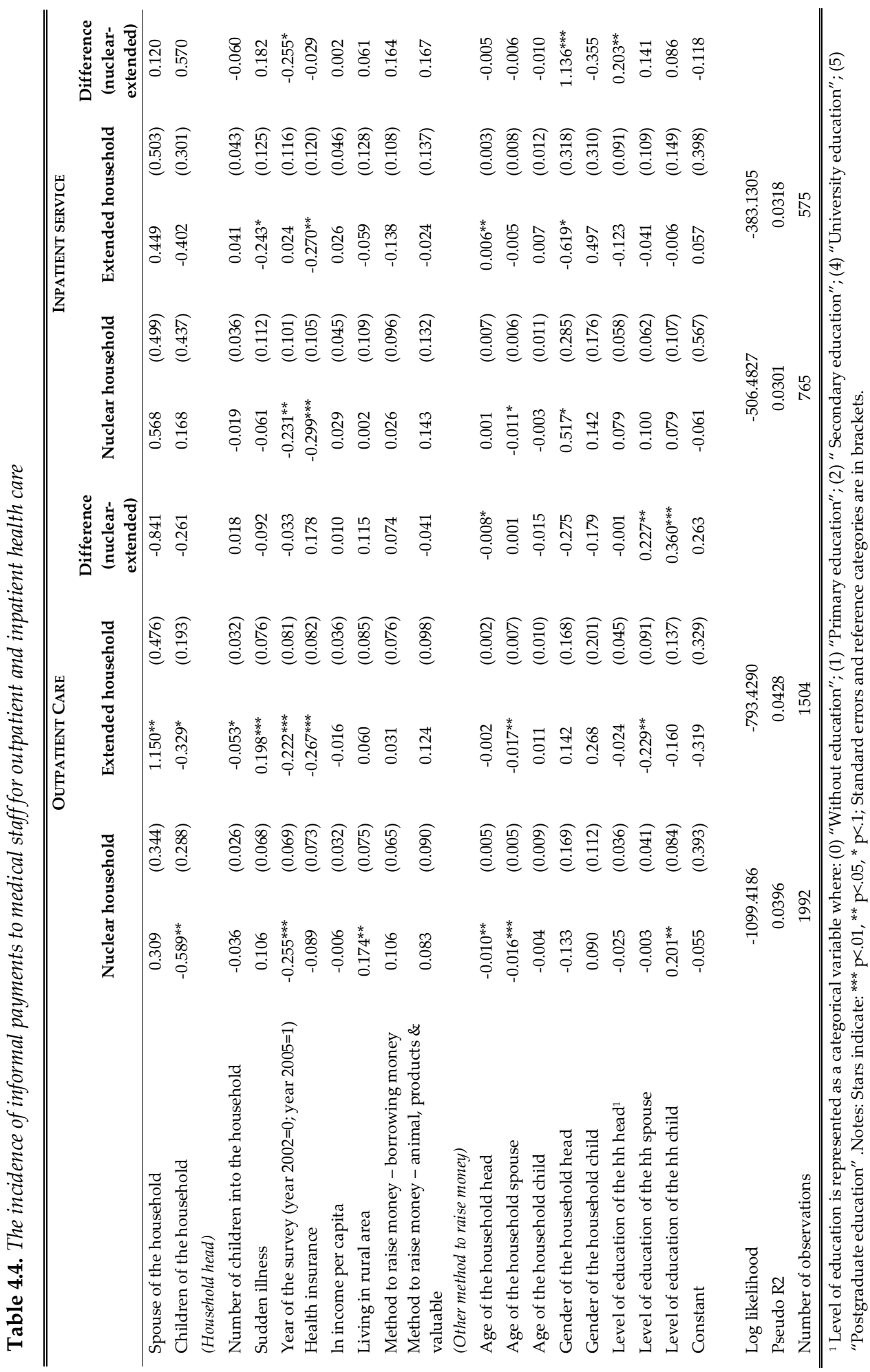


Health insurance decreases the probability of paying informally both for nuclear and extended households in inpatient and outpatients care. This is encouraging, especially for inpatient care where the link between the contributions and service provision has been weaker. On the contrary, household income per capita does not have any significant effects indicating that informal payments affect patients throughout income distribution. ${ }^{18}$

The effect of the methods chosen by the household to raise money for health care on the incidence of informal payments does not vary between different types of households. However, a generalised Hausman test rejects the hypothesis of equal coefficients between nuclear and extended households for the method to raise money. The differences show that it is more difficult for extended households to raise money through borrowing or selling products or valuables. This indicates that they may use more often other ways for raising money like for example transfers from other relatives (even though the survey does not allow us to control for this).

Age of the patient has a negative effect on the probability of paying informally, except for extended households in inpatient care. This confirms our expectations about investments in health care for aging members of such households. A higher education of the patient has a negative effect on informal payments. But, as expected, the generalised Hausman test shows more differences between types of households (especially for outpatient care where effects are statistically significant). Mincer and Polacheck (1974) argue that households invest more on members who will ensure higher returns in the future. Households choose to invest in those members with higher returns to human capital investments and children's payback time is longer and returns are higher (Becker, 1976). In fact, a higher education of the child in nuclear households increases the probability of informal payments to medical staff suggesting that people in such households are willing to invest more in human capital (therefore they are more likely to pay for their higher educated children). Being a nuclear household increases the log of paying informally by 0.36 times more (compared with extended households) in outpatient services. On the other hand, spouses with higher education in extended households are less likely to pay informally especially for outpatient care. Having more education (and probably less resources) translates to more bargain power with medical staff. On the same time having higher education gives more chance to work in the formal market and to have health insurance.

Table 4.5 gives the OLS estimation results for the amount paid informally as well as the generalised Hausman tests for differences between coefficients for nuclear and extended households. The amounts paid informally in outpatient and inpatient care differ significantly from each other. The amounts paid for inpatient care are much higher (due to the severity of the conditions) and households have to prioritise the allocation of health expenditures based on the particular position of household members.

\footnotetext{
18 Results using the total expenditures yield also similar results (available from the authors) but we have used household income to reflect better the income distribution.
} 


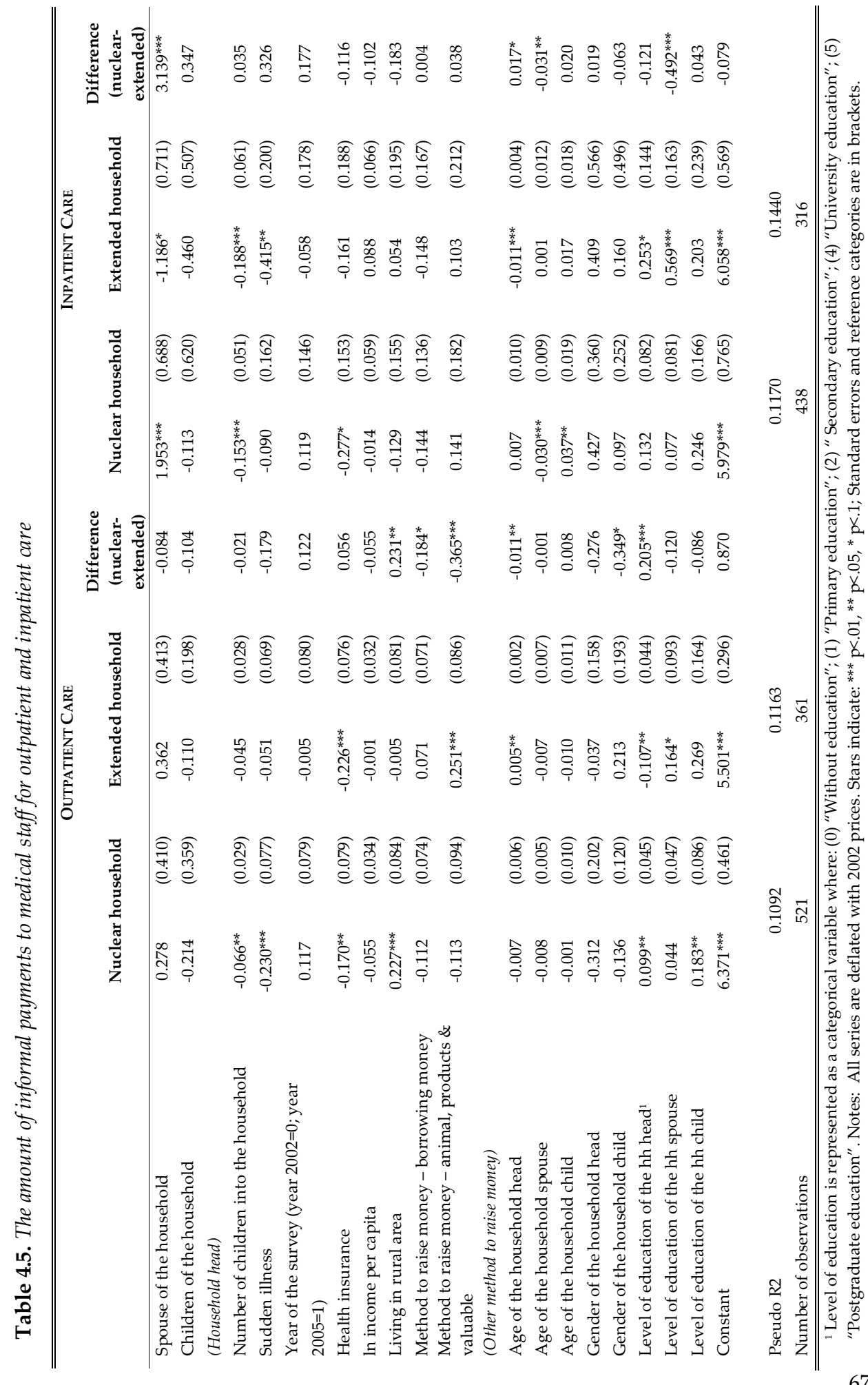


Results show that in inpatient care nuclear households and extended households differ significantly in the amount paid informally for spouses (as compared to the household head and children). Nuclear households pay significantly higher amounts for spouses than extended households. The differences are also confirmed by the generalised Hausman test. Extended households are concentrated mostly in rural areas and the average age is higher than in nuclear households. This means that extended households are more exposed to health risks, and therefore they allocate fewer resources mostly to spouses. Even though they seem more likely to pay for spouses (see the right side of Table 4.4) they allocate on average fewer resources to them. Another reason could be the lower bargaining power that spouses may have in extended households (they are less educated and less likely to work).

The number of children is negatively associated with the amount paid informally in both nuclear and extended households. The effect is larger for extended households visiting inpatient care. This is consistent with what Behrman et al., (1980) have found on investments on education. Households with many children are constrained to divide resources among a larger number of household members and therefore children with more siblings may receive fewer resources for health care than children with fewer siblings.

The coefficients indicating the years of the survey are not significant for neither the household types (contrary to what we observed in models for the incidence of paying) showing that informal payments have changed in numbers but not in substance (i.e. the amount paid). Health insurance appears to be important in lowering the amounts paid both for inpatient and outpatient care but the effect for extended households in inpatient care is lower than for nuclear ones. This may show that such households may have less bargaining power against medical staff.

The level of income per capita does not have any significant effect on the amount paid by both types of households. On the other hand, the generalised Hausman test indicates that methods to raise money for health care differ between types of households. When paying informally extended households are more likely to borrow or sell products, animals or valuables. This shows that shocks associated with health care events are more severe for these types of households. By affecting their income generating capabilities such events may have more long-term consequences for these households.

Age of the patient generally lowers the amount paid even though this effect may vary between types of households. For example, the Hausman tests show that older heads of extended households pay higher amounts for outpatient care but they pay lower amounts for inpatient care. Such change may be determined by the lower ability to pay for health care of the extended households.

Generally, households seem to be willing to pay more for males than for females and this may be again related to the theory of human capital (Albania is still a patriarchal society where males have more income generating power than females). Once more, education plays an important role in determining the amounts paid informally. Higher educated spouses in extended households pay significantly more than their counterparts in nuclear households. This indicates that education gives them more bargaining power 
within the household. Similar to the incidence of payments, nuclear households pay more for their higher educated children.

Table 4.6 presents estimates for the amounts paid out-of-pocket for inpatient and outpatient care. Out-of-pocket includes all the costs related to service fees, medicines, laboratory work, and transportation costs. In order to see the difference between out-ofpocket expenditures and informal payments, we have not included informal payments in the out-of-pocket payments. We use the same control variables in order to make results comparable with those on informal payments. The results confirm the trend for the total amount paid out-of-pocket in inpatient care for spouses and children. Households seem to pay more for spouses than they do for children (compared to the household head and other members of the households). This may be due to the better health insurance coverage of the children (paying less for formal fees or medicines) but also to the changes in specific health care needs.

The results show that out-of-pocket payments have decreased throughout the years for outpatient but not for inpatient care. As we can see from the table, health insurance turns out to be not significant for the amounts paid for inpatient care. This is evidence for the smaller role that such mechanisms have in this service.

The Hausman tests indicate that nuclear households are again more able to borrow money for health care than the extended ones when paying informally for outpatient care (and thus confirming their higher borrowing abilities). However both types of households do not show a clear pattern when paying for inpatient care demonstrating that the level of out-of-pocket payments can be well beyond their immediate strategies for raising money.

The age of patients has a negative effect on the amount of out-of-pocket payments for the adults while the age of children has (mostly) a positive effect. It appears that households tend to spend more on out-of-pocket for older children than for the younger ones. This may also be related to older children's ability to generate an income and have a better position within the household in terms of resource distribution. Contrary to what we have found for informal payments, education of the spouse increases the amount of out-ofpocket paid for nuclear households. This change may reflect the complex composition of out-of-pocket payments (including fees, medicines, laboratory, and transport) showing that higher educated women in nuclear households spend more resources on higher quality services (e.g. by buying more expensive drugs or laboratory tests).

The nature of informal payments is different from that of total out-of-pocket payments and this may also contribute to slightly different results. However, the comparable findings for most of the variables suggest that informal payments are well embedded in the health care system of the country. 


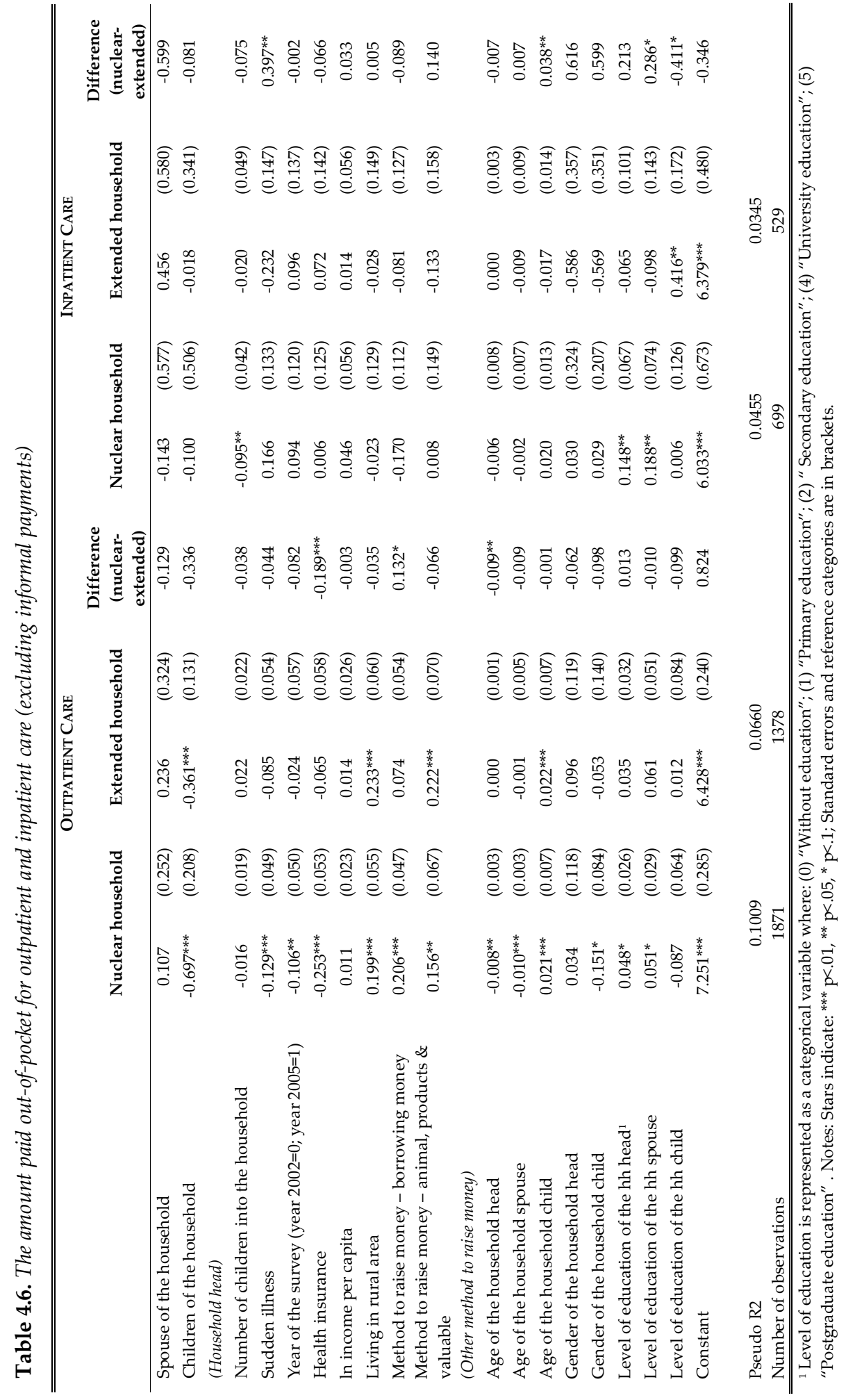




\subsection{Conclusions}

We do not find strong differences between household types in the probability of paying informally, indicating that these payments are widespread and requested, and imposed on all households. Contrary to that, for the amounts paid there are differences between households in the way they allocate resources between their members. If we consider informal payments as an indicator of investment in health care, we can say that nuclear households appear to be more likely to invest in the health care of children and spouses. They spend higher amounts on children and spouses (compared to the other members of the households) than extended households. Spouses and children in such households are also likely to get more education and more likely to earn income from employment.

The findings generally support the hypotheses of health care as a human capital investment and give insight into how households in Albania react to informal payments in health care. We consider such informal payments an uninsured risk (as it is also often not entirely dependent on health insurance). In such situations households choose to allocate their resources over the individuals with the highest earning potential or the highest bargaining power within the household.

Nuclear and extended households differ in their decisions to allocate resources over their members in investing in medical care. The main factors relate to the specific position of the member (whether he/she is the head, the spouse, or the child) but also on other factors like age, education and gender. Our results show that households seem to be more likely to allocate resources to spouses than to children. As children in Albania are more likely to be covered by health insurance this may indicate a better protection against informal payments for children, and thus, less informal payments for them. The effect may also reflect the different type of health care needed for children and spouses. We find no significant differences between households in choosing to pay for different households members, but there are more differences when the amount paid is considered. The results show that for inpatient care nuclear households pay significantly higher amounts for spouses demonstrating that spouses (which are in most of the cases females - see also Tables A4.1 and A4.2) may have better bargaining power in nuclear households. Descriptive statistics show that spouses in such households are on average older and better educated than in the extended households. They therefore may have higher income generating abilities and this may influence their bargaining power within the household. In fact, we show that education of the spouses influences significantly the amount paid informally in extended households (when compared to the nuclear ones).

The quality of human capital investments in children depends on the resources available, and resources available depend on the type of households. We show that both the incidence and the amount paid declines if households have a higher number of children. The education level of children seems to influence the decision on the amounts allocated for informal payments. Households choose to invest more on members that will ensure higher returns in the future (Mincer and Polachek, 1974) and children with higher education are the perfect example of this investment (Becker, 1967). Individuals also 
choose to pay (invest) more on males knowing that they may generate higher returns (this is also given the patriarchal Albanian society).

In general, we find that patients in inpatient care seem to be more exposed to informal payments to medical staff. This could due to limited health insurance for inpatient care and due to more severe health conditions treated. Higher payments and less protection from health insurance expose especially children and spouses to whom fewer resources are allocated. The positive effect that health insurance has on decreasing informal payments in outpatient care is encouraging. However, it is doubtful whether it may have the same effect in inpatient care where a more complex organisation and more resources are needed. Experiences from other former-socialist countries show that compared to tax-based funding, social health insurance may have a questionable social benefit (Rechel and McKee, 2009; Pavlova et al., 2000; Atanasova et al., 2011). This calls for more attention of policy makers in evaluating the social benefits (e.g. macro-efficiency and equity in the public health care sector) of introducing the health insurance in inpatient care in Albania.

Our findings show that in absence of protection by formal mechanisms individuals with less bargaining power in the household (e.g. household members with lower education) are likely to get fewer resources to pay for informal payments to medical staff for health care. Extended households will tend to pay for members with more bargaining power and will invest less in children. Such differences should be taken into account by public policies which should compensate this by redistribution mechanisms targeting disadvantaged groups. Such mechanisms include for example, cash transfers conditioned on utilisation of health care by small children and young mothers, and subsidised health care for particular age groups.

The immediate coping strategies of households (i.e. borrowing money or selling products, animals or valuables) cannot mitigate the increased risk of large payments for health care and may also hamper their long-term income generating capabilities. This calls for more attention towards policies protecting the vulnerable households against uninsured risks. The intra-household allocation of resources for health care to children and spouses is certainly susceptible to the provision of such formal protection. The possible crowding-out effects of private transfers towards public transfers or social health insurance certainly remains a field for further research in the future. Also governments should implement effective measures for dealing with informal patient payments in general. 


\subsection{Appendix 4A.}

Table A4.1. Descriptive statistics for nuclear and extended households for outpatient care

\begin{tabular}{|c|c|c|c|c|c|c|}
\hline \multirow[b]{2}{*}{$\begin{array}{l}\text { Incidence of the amount paid } \\
\text { informally }\end{array}$} & \multicolumn{2}{|c|}{ NUCLEAR FAMILIES } & \multicolumn{2}{|c|}{ EXTENDED FAMILIES } & \multicolumn{2}{|c|}{$\begin{array}{l}\text { MEAN OF THE TOTAL } \\
\text { SAMPLE }\end{array}$} \\
\hline & 0.262 & $(0.440)$ & 0.24 & $(0.427)$ & 0.252 & $(0.434)$ \\
\hline $\begin{array}{l}\text { Log of the amount paid } \\
\text { informally }\end{array}$ & $5.518^{*}$ & $(0.799)$ & $5.429^{*}$ & $(0.655)$ & 5.481 & $(0.744)$ \\
\hline $\begin{array}{l}\text { Log of the amount paid as out- } \\
\text { of-pocket payment }{ }^{1}\end{array}$ & $6.847^{* *}$ & $(1.019)$ & $6.770^{* *}$ & $(0.972)$ & 6.814 & $(1.000)$ \\
\hline Head of the household & $0.341^{* * *}$ & $(0.474)$ & $0.267^{* * *}$ & $(0.443)$ & 0.309 & $(0.462)$ \\
\hline Spouse of the household & $0.366^{* * *}$ & $(0.482)$ & $0.219^{* * *}$ & $(0.414)$ & 0.303 & $(0.460)$ \\
\hline Children of the household & $0.293^{* * *}$ & $(0.455)$ & $0.148^{* * *}$ & $(0.355)$ & 0.231 & $(0.421)$ \\
\hline $\begin{array}{l}\text { Number of children into the } \\
\text { household }\end{array}$ & $2.111^{* * *}$ & $(1.471)$ & $1.920^{* * *}$ & $(1.238)$ & 2.029 & $(1.379)$ \\
\hline Sudden illness & $0.457^{* *}$ & $(0.498)$ & $0.417^{* *}$ & $(0.493)$ & 0.44 & $(0.496)$ \\
\hline $\begin{array}{l}\text { Year of the survey (year 2002=0; } \\
\text { year } 2005=1 \text { ) }\end{array}$ & $0.393^{*}$ & $(0.489)$ & $0.424^{*}$ & $(0.494)$ & 0.406 & $(0.491)$ \\
\hline Health insurance & 0.571 & $(0.495)$ & 0.586 & $(0.493)$ & 0.578 & $(0.494)$ \\
\hline Log income per capita & $8.425^{* *}$ & $(1.100)$ & $8.333^{* *}$ & $(1.115)$ & 8.386 & $(1.108)$ \\
\hline Living in rural area & $0.440^{* * *}$ & $(0.496)$ & $0.504^{* * *}$ & $(0.500)$ & 0.467 & $(0.499)$ \\
\hline $\begin{array}{l}\text { Method to raise money - } \\
\text { borrowing money }\end{array}$ & $0.437^{* * *}$ & $(0.496)$ & $0.362^{* * *}$ & $(0.481)$ & 0.405 & $(0.491)$ \\
\hline $\begin{array}{l}\text { Method to raise money - animal, } \\
\text { products \& valuable }\end{array}$ & $0.161^{* * *}$ & $(0.368)$ & $0.197^{* * *}$ & $(0.398)$ & 0.176 & $(0.381)$ \\
\hline $\begin{array}{l}\text { Method to raise money - other } \\
\text { methods }\end{array}$ & $0.070^{* * *}$ & $(0.256)$ & $0.045^{* * *}$ & $(0.208)$ & 0.059 & $(0.237)$ \\
\hline Age of the household head & $19.315^{* *}$ & $(27.881)$ & $17.243^{* *}$ & $(29.185)$ & 18.424 & $(28.464)$ \\
\hline Age of the household spouse & $18.297^{* * *}$ & $(25.238)$ & $12.356^{* * *}$ & $(23.938)$ & 15.741 & $(24.858)$ \\
\hline Age of the household child & $2.777^{* *}$ & $(6.504)$ & $2.283^{* *}$ & $(7.623)$ & 2.564 & $(7.011)$ \\
\hline Gender of the household head & $0.044^{* * *}$ & $(0.206)$ & $0.064^{* * *}$ & $(0.245)$ & 0.053 & $(0.223)$ \\
\hline Gender of the household child & $0.150^{* * *}$ & $(0.357)$ & $0.059^{* * *}$ & $(0.235)$ & 0.111 & $(0.314)$ \\
\hline $\begin{array}{l}\text { Level of education of the hh } \\
\text { head }^{2}\end{array}$ & $0.751^{* * *}$ & $(1.411)$ & $0.438^{* * *}$ & $(1.079)$ & 0.616 & (1.288) \\
\hline $\begin{array}{l}\text { Level of education of the hh } \\
\text { spouse }\end{array}$ & $0.627^{* * *}$ & (1.156) & $0.291^{* * *}$ & $(0.761)$ & 0.482 & (1.019) \\
\hline $\begin{array}{l}\text { Level of education of the hh } \\
\text { child }\end{array}$ & $0.187^{* * *}$ & $(0.563)$ & $0.123^{* * *}$ & $(0.488)$ & 0.160 & $(0.533)$ \\
\hline
\end{tabular}

${ }^{1}$ Out-of-pocket payments here are including service fees, medicines, laboratory work and transportation costs.

${ }^{2}$ Level of education is represented as a categorical variable where: $(0)$ "Without education"; (1) "Primary education"; (2) "Secondary education"; (4) "University education"; (5) "Postgraduate education"

Note: In outpatient care the amount of informal payments is the average per visit. Stars indicate whether the mean for each household type is significantly different from the mean of the other type $\left({ }^{* * *} p<.01,{ }^{* *} p<.05,{ }^{*} p<.1\right)$. All prices are deflated to 2002 prices. $100 \mathrm{ALL}=0.73$ Euros in June 2002 (Bank of Albania, 2010. 
Table A4.2. Descriptive statistics of nuclear and extended households for inpatient care

\begin{tabular}{|c|c|c|c|c|c|c|}
\hline \multirow[b]{2}{*}{$\begin{array}{l}\text { Incidence of the amount paid } \\
\text { informally }\end{array}$} & \multicolumn{2}{|c|}{ NUCLEAR FAMILIES } & \multicolumn{2}{|c|}{ EXTENDED FAMILIES } & \multicolumn{2}{|c|}{$\begin{array}{l}\text { MEAN OF THE TOTAL } \\
\text { SAMPLE }\end{array}$} \\
\hline & 0.573 & $(0.495)$ & 0.55 & $(0.498)$ & 0.563 & $(0.496)$ \\
\hline $\begin{array}{l}\text { Log of the amount paid } \\
\text { informally }\end{array}$ & 6.015 & $(1.443)$ & 6.066 & $(1.498)$ & 6.037 & $(1.466)$ \\
\hline $\begin{array}{l}\text { Log of the amount paid as out- } \\
\text { of-pocket payment }{ }^{1}\end{array}$ & 6.215 & $(1.448)$ & 6.304 & $(1.433)$ & 6.253 & $(1.442)$ \\
\hline Head of the household & $0.297^{* * *}$ & $(0.457)$ & $0.217^{* * *}$ & $(0.413)$ & 0.263 & $(0.440)$ \\
\hline Spouse of the household & $0.409^{* * *}$ & $(0.492)$ & $0.210^{* * *}$ & $(0.408)$ & 0.324 & $(0.468)$ \\
\hline Children of the household & $0.294^{* * *}$ & $(0.456)$ & $0.144^{* * *}$ & $(0.352)$ & 0.23 & $(0.421)$ \\
\hline $\begin{array}{l}\text { Number of children into the } \\
\text { household }\end{array}$ & $2.471^{* * *}$ & $(1.413)$ & $2.024^{* * *}$ & $(1.334)$ & 2.279 & $(1.397)$ \\
\hline Sudden illness & 0.248 & $(0.432)$ & 0.25 & $(0.434)$ & 0.249 & $(0.433)$ \\
\hline $\begin{array}{l}\text { Year of the survey (year 2002=0; } \\
\text { year } 2005=1 \text { ) }\end{array}$ & $0.464^{*}$ & $(0.499)$ & $0.515^{*}$ & $(0.500)$ & 0.486 & $(0.500)$ \\
\hline Health insurance & 0.434 & $(0.496)$ & 0.45 & $(0.498)$ & 0.441 & $(0.497)$ \\
\hline Log income per capita & 8.282 & $(1.155)$ & 8.255 & $(1.270)$ & 8.27 & $(1.205)$ \\
\hline Living in rural area & $0.482^{* * *}$ & $(0.500)$ & $0.581^{* * *}$ & $(0.494)$ & 0.525 & $(0.500)$ \\
\hline $\begin{array}{l}\text { Method to raise money - } \\
\text { borrowing money }\end{array}$ & $0.557^{* * *}$ & $(0.497)$ & $0.463^{* * *}$ & $(0.499)$ & 0.516 & $(0.500)$ \\
\hline $\begin{array}{l}\text { Method to raise money - animal, } \\
\text { products \& valuable }\end{array}$ & $0.197^{* *}$ & $(0.398)$ & $0.249^{* *}$ & $(0.433)$ & 0.219 & $(0.414)$ \\
\hline $\begin{array}{l}\text { Method to raise money - other } \\
\text { methods }\end{array}$ & 0.056 & $(0.230)$ & 0.038 & $(0.192)$ & 0.049 & $(0.215)$ \\
\hline Age of the household head & 15.641 & $(25.092)$ & 13.52 & $(26.347)$ & 14.731 & $(25.650)$ \\
\hline Age of the household spouse & $17.507^{* * *}$ & $(22.662)$ & $10.694^{* * *}$ & $(21.897)$ & 14.584 & $(22.582)$ \\
\hline Age of the household child & 3.222 & $(7.037)$ & 2.621 & $(8.434)$ & 2.964 & $(7.670)$ \\
\hline Gender of the household head & 0.037 & $(0.188)$ & 0.033 & $(0.179)$ & 0.035 & $(0.184)$ \\
\hline Gender of the household child & $0.128^{* * *}$ & $(0.334)$ & $0.052^{* * *}$ & $(0.223)$ & 0.096 & $(0.294)$ \\
\hline $\begin{array}{l}\text { Level of education of the hh } \\
\text { head }^{2}\end{array}$ & $0.576^{* * *}$ & $(1.227)$ & $0.287^{* * *}$ & $(0.778)$ & 0.452 & $(1.068)$ \\
\hline $\begin{array}{l}\text { Level of education of the hh } \\
\text { spouse }\end{array}$ & $0.682^{* * *}$ & $(1.160)$ & $0.278^{* * *}$ & $(0.748)$ & 0.509 & $(1.024)$ \\
\hline $\begin{array}{l}\text { Level of education of the hh } \\
\text { child }\end{array}$ & $0.239^{* *}$ & $(0.646)$ & $0.155^{* *}$ & $(0.571)$ & 0.203 & $(0.616)$ \\
\hline
\end{tabular}

${ }^{1}$ Out-of-pocket payments here are including service fees, medicines, laboratory work and transportation costs.

${ }^{2}$ Level of education is represented as a categorical variable where: (0) "Without education"; (1) "Primary education"; (2) "Secondary education"; (4) "University education"; (5) "Postgraduate education"

Note: In inpatient care the amount of informal payments is the average per day hospitalised. Stars indicate whether the mean for each household type is significantly different from the mean of the other type $\left(^{* *} \mathrm{p}<.01,{ }^{* *} \mathrm{p}<.05,^{*} \mathrm{p}<.1\right)$. All prices are deflated to 2002 prices. 100 ALL $=0.73$ Euros in June 2002 (Bank of Albania, 2010 


\section{Chapter 5. PAYING INFORMALLY \\ IN THE ALBANIAN HEALTH \\ CARE SECTOR: \\ A TWO-TIERED STOCHASTIC \\ FRONTIER MODEL}

This chapter is based on the following article:

Tomini S, Groot W, Pavlova M. (2011). Paying informally in the Albanian health care sector: A twotiered stochastic frontier model. The European Journal of Health Economics, 2011. DOI: 10.1007/s10198-011-0331-1. 


\begin{abstract}
Informal payments are deeply ingrained in the health care sector of most Central, Eastern and Southern European countries. Evidence suggests that the price paid informally to medical staff is negotiated either directly or indirectly between patients and medical staff. The aim of this chapter is to measure the imperfect information that exists on the amount that has to be paid informally to medical staff. We measure the extent to which patients pay more than the amount medical staff expect informally and the extent to which medical staff request less than patients are willing to pay informally. A two-tiered stochastic frontier model is developed to estimate indicators of patients' and medical staff's imperfect information on informal payments and the effects on the amount the other party is minimally expecting or maximally willing to pay informally. The estimates are based on informal payments to medical staff in the inpatient health care sector in Albania. We use data from the Albania Living Standards Measurement Survey 2002 and 2005. The pooled samples include 707 individual who have visited inpatient health care services in these two years. Our results show that medical staff has less information on the patients' maximum willingness to pay informally than patients have on medical staff's minimum expected amount. These estimates do not depend on categories of illnesses but on certain sociodemographic characteristics.
\end{abstract}




\subsection{Introduction}

As pointed out in previous chapters paying informally for health care services is a wide spread phenomenon in many Central, Eastern and Southern European countries. Evidence from many countries suggests that the amount paid informally, is negotiated between patients and physicians either directly or indirectly (Belli and Shahriari, 2002; Shahriari et al., 2001; Vian and Burak, 2006). The process is described as an 'unofficial health care market' (Szende and Culyer, 2006) where physicians participate directly in the negotiation process, or the negotiation is done by their 'brokers'19 (Vian et al., 2006). Despite the fact that the existence of informal payments is widely recognised, little evidence is available on the role of information that patients and physicians have, in determining the amount paid informally.

The aim of this chapter is to estimate the imperfect information that exists on the amount paid informally to medical staff for inpatient health care and measure its effect on the actual amount paid. Imperfect information in health care markets is mostly studied either from the perspective of information on medical conditions and treatment (Arrow, 1963), or health insurance markets (Akerlof, 1970; Rothschild and Stiglitz, 1976). However, physicians may (mis)use their power and market position to impose extra payments on patients. As it is often the case in post-communist countries (Ensor, 2004), these extra payments refer to money paid informally as gifts or under-the-table payments. Both physicians and patients are aware of the "costs and benefits" involved, and are active players in this "informal market". Such payments allow patients to jump the queue, receive higher quality of service and sometimes to receive more care (World Bank, 2006; Lewis, 2000; Liaropoulos et al., 2008). From an economic perspective, informal payments can be seen as a way to allocate scarce resources, where the market prevails over the rationing systems thought up by the government. The market price (or the amount paid informally) is influenced by the information that the medical staff has on the patient's willingness to pay, and information that the patient has on the medical staff's expected amount.

As otherwise similar patients may pay different amount informally, we focus on the information that both parties (patients and providers) have on the final amount paid. Here, the maximum willingness to pay refers to the maximum amount that the patient intends to pay, and the minimum expected amount refers to the amount medical staff at least expects to receive informally and is not related to the direct costs of health care. These are derived from variation in the actual amount paid informally. We develop a two-tiered stochastic frontier model to measure the effect of imperfect information of medical staff and patients on the amount paid informally (Polachek andYoon, 1987; Groot and Oosterbeek, 1994; Groot and Maassen van den Brink, 2005).

\footnotetext{
19 'Brokers' are evidenced by Vian et al., 2006 as people (not necessarily medical staff) who serve as intermediaries between patients and doctors. An example can be the nurse who tells how much a patient should give to the doctor (some time this is also done by guards, etc),
} 
We use data from the Albanian Living Standards Measurement Survey 2002 and $2005^{20}$ (ALSMS) to obtain estimates of informal payments for inpatient care. As in other chapters of this dissertation informal payments here refer to gifts paid to medical staff either in cash or in kind.

As mentioned in Chapter 1 in the period 2002-2005 (when the data for our analysis were collected), the financing of the health sector in the country was fragmented, with the Health Insurance Institute paying for most of the salaries of primary care physicians, selected drugs and few high-end diagnostics (World Bank, 2006). All other public health care costs were covered by the Ministry of Health budget. Formal payments were limited to a small fees paid mostly for outpatient care, while services in inpatient care were supposed to be "free of charge". Despite this, the scarcity of drugs, low paid medical staff and inefficiency of the system has led to a situation where patients pay for (otherwise free) drugs or services..$^{21}$

The chapter is divided in seven sections. Section two reviews the international empirical evidence on informal payments and discusses the main aspects of informal payments in the Albanian health care sector. Section three outlines the theoretical model, while section four and five discuss the dataset and empirical results. Section six provides the concluding remarks.

\subsection{Theoretical background}

There are no studies available that have analysed imperfect information of medical staff and patients on the amount paid informally in health care. The studies reviewed here include studies on the process of paying informally (when do patients pay informally, what is paid for, to whom and how) and the determinants of informal payments and in post-communist countries.

Studies find that both patients and medical staff may influence the amount paid informally. Ensor (2004) argues that one of the main types of informal payments is when medical staff misuse their power and market position to impose extra payments, (other reasons include payments for extra services due to insufficient funding). Carlton and Perloff (1989) emphasise that the availability of information may influence the price of a good by lowering it. ${ }^{22}$ This implies that the actual amount paid informally to medical staff is determined by the knowledge of consumers and providers about the actual "informal market" price.

We assume that determinants of the actual amount paid informally for inpatient care are factors related both to the demand for health care (e.g. including income or wealth, education, and age), and supply side factors (e.g. quality of the physician's service and

\footnotetext{
${ }^{20}$ Albania Living Standard Measure Survey. World Bank. www.worldbank.org/lsms.

${ }^{21}$ Although Albanian legislation provides for free inpatient hospital care for all, out-of-pocket expenditures in the event of hospitalisation are substantial, with informal payments accounting for at least one-quarter of all payments (World Bank, 2006).

22 Carlton and Perloff (1989) show that improving information can lower the prices. When information is more available customers may better estimate the real price.
} 
type of treatment). Patients' motives to pay informally to medical staff in hospitals are implicitly linked to patients' maximum willingness to pay informally for better quality and access to health care. Looking at the attitudes of patients towards publicly provided care in Bulgaria, Pavlova et al., (2002) find that individuals are willing to pay if they are offered good quality and quick access.

Wealth is usually considered an important determinant of health care demand. Evidence shows that usually those who cannot afford to pay for health care find alternative means (i.e. using saving, or borrowing money) to pay for such services (Falkingham, 2004; Shahriari et al., 2001; Thompson and Witter, 2000). As a result, wealth and income are believed to be less important in determining the amount paid than informal payments. Although it is usually stated that in post-communist countries the rich pay more for health care than the poor (Balabanova, 1999; Ensor and Savelyeva, 1998; Novak et al., 1996), when it comes to the amount paid informally, no significant differences are documented between these groups (Shahriari et al., 2001; Thompson and Witter, 2000).

Age and education, as determinants of health care demand, are also believed to influence the amount of informal payments. Evidence suggests that elderly patients pay lower amounts for health care (Shahriari et al., 2001) and higher educated people higher amounts (Liaropoulos et al., 2008). However, the evidence remains mixed on how these two factors influence informal payments to medical staff, depending also on the type of services (Vian, 2006).

On the supply side, informal payments are believed to be triggered by restrictive circumstances like the low wages of medical staff in the public sector (Ensor and Savelyeva, 1998; Healy and McKee, 1997; Shahriari et al., 2001). Shahriari et al., (2001) argue that with the increase of the number of physicians, the equilibrium price that they charge should go down. In public health care of most post-communist countries, the prices for services are fixed and what is observed in practice is a large variety of services that would match patients' increased expectations. Generally, the highest informal payments are observed in hospitals and the lowest payments are made to general practitioners (Shahriari et al., 2001). Given the specifics of some treatments (e.g. giving births) medical staff may also be approached for an informal payment before the services are provided to secure their availability. In these cases, negotiations over the price may also be done in advance (Belli and Shahriari, 2002).

Studies looking at the determination of prices related to informal payments (in Albania or elsewhere) are limited. However, there is evidence showing that the way patients are asked for such payments vary. Based on qualitative data, a study conducted in Albania (Vian et al., 2006), reports that patients mainly get information on the amounts to be paid by: (i) asking directly the nurse or the physician, or (ii) getting information from relatives or friends who have had similar procedures. The authors also mention that the process often is not hidden at all, and in cases of inpatient treatment (i.e., surgeries), the amount is often agreed beforehand while the payment is done after the treatment or operation. The amount paid is not always fixed and is determined by certain characteristics of both parties. Attributes of patients (e.g. economic status, place of residence, political or 
intellectual status) and features of providers (e.g. qualification of medical staff, speciality, location of facility, etc) influence the amount of informal payments (Vian and Burak, 2006).

\subsection{Methodology and model}

In this section, we present the two-tiered stochastic frontier model used to measure the effect of imperfect information on informal payments in inpatient care, and also discuss some of its limitations.

We start by assuming that both patients and medical staff have less than perfect information about the minimum expected informal payments or maximum willingness to pay informally respectively. The main reasons behind this imperfect information are the nature of informal health payments. Direct payments and gifts to medical staff in Albania are not legally allowed, but they are very often tolerated. However, medical staff may face legal consequences if they explicitly ask for such payments. Often, patients are aware of this, but they are also aware of the fact that without such payments, they may be denied the service, or that the quality of services delivered will be simply poorer. Given this, patients could try to get a certain quality of treatment with the lowest amount of "gift" possible. They could try to seek good quality medical staff and pay just the 'minimum expected amount' for a particular service. However, in the absence of perfect information, patients may end up paying higher amounts than the minimum expected amount. The difference between the actual payment and the medical staff's minimum expected amount represents "patient's ignorance". On the other hand, the medical staff could try to maximise the profits by asking for the amount that the patient is willing to pay. However, the informal nature of such payments increases the costs of gathering information and medical staff may also end up in getting lower amounts than the maximum that patient would be willing to pay informally. The difference between the actual payment and patient's maximum willingness to pay informally represents "medical staff's ignorance" (Groot and Oosterbeek, 1994; Groot and Maassen van den Brink, 2005).

We assume that informal payments are a linear function of characteristics of medical staff and patients, respectively. The medical staff' characteristics are represented in our model by illnesses or diseases (I). The patient's characteristics include: demographic variables $(G)$, insurance status (S), the ln of household income (Y), level of education (E), number of days stayed in hospital (D) and whether the 'gift' to medical staff was voluntary or expected/requested (R). The logarithm of the amount expected to be paid informally $\left(\mathrm{IP}^{*}\right)$ is determined by:

$$
\ln I P^{*}=\beta_{0}+\beta_{1} I_{i}+\beta_{2} G_{i}+\beta_{3} S_{i}+\beta_{4} \ln Y_{i}+\beta_{5} E_{i}+\beta_{6} D_{i}+\beta_{7} R_{i}
$$

where $\beta$ are coefficients that measure the impact of medical staff and patients characteristics on the amount paid informally. In our empirical analysis, we have used the natural logarithm of the amount paid informally as this yielded better fitted models.

The observed ( $(n)$ amount of informal payment $I P$ is assumed to be stochastic and can be above or below the actual payment $I P^{*}$ depending on the characteristics of patients and medical staff that we mentioned above. The size of the deviation from actual informal payment represents the effect of imperfect information of medical staff and patients. Let $v$ 
(medical staff imperfect information) and $w$ (patient imperfect information) represent respectively the negative and positive deviations of $\ln I P^{*}$ and $\eta$ represents the normal error term. The observed level of informal payments is then related to the expected level by:

$\ln P_{i}=\log I P_{i}^{*}+v_{i}+w_{i}+\eta_{i}$

If we combine equations (2) and (1) we obtain:

$\ln I P=\beta_{0}+\beta_{1} I_{i}+\beta_{2} G_{i}+\beta_{3} S_{i}+\beta_{4} \ln Y_{i}+\beta_{5} E_{i}+\beta_{6} D_{i}+\beta_{7} R_{i}+\eta_{i}+v_{i}+w_{i}$

We assume that $v$ and $w$ are one-sided error terms with expectations $E\left(v_{i}\right)=-\mu_{v}<0$ and $E\left(w_{i}\right)=\mu_{w}>0$. The term $\mu_{v}$ is the negative deviation of informal payment from the actual payment, which can be interpreted as medical staffs' informal market ignorance. Likewise, $\mu_{w}$ is the positive or upward bias in paying informally and can be seen as representing patients' informal market ignorance.

Equation (4) constitutes a two-tiered stochastic frontier model developed by Polachek and Yoon (1987). In order to derive the likelihood function, the following assumptions regarding the error components are made: $\eta$ has a normal distribution with zero mean and variance $\sigma_{u}^{2} ;-v$ and $w$ follow the exponential distribution with $\mu_{v}$ and $\mu_{w}$ respectively; and $\eta, v$ and $w$ are independent. Polacheck and Yoon (1987) derive the likelihood function for this stochastic frontier model as:

$$
\begin{aligned}
& \log L=n \log \left(\frac{\theta_{u} \theta_{v} \theta_{w}}{\theta_{v}+\theta_{w}}\right)+\left[\theta_{u}+\theta_{v} \sum_{i}^{n} \varepsilon_{i}+\frac{n}{2} \theta_{v}^{2}\right]+ \\
& \sum_{1}^{n} \log \left\{1-\Phi\left(\theta_{u} \varepsilon_{i}+\theta_{v}\right)+\left[1-\Phi\left(-\theta_{u} \varepsilon_{i}+\theta_{w}\right)\right] * \exp \left[-\frac{1}{2}\left(2 \theta_{u} \varepsilon_{i}+\theta_{v}-\theta_{w}\right)\left(\theta_{v}+\theta_{w}\right)\right]\right\}
\end{aligned}
$$

Where:

$$
\begin{aligned}
& \theta_{u}=\frac{1}{\sigma_{u}} \\
& \theta_{v}=\frac{1}{\mu_{v}} \\
& \theta_{w}=\frac{1}{\mu_{w}} \\
& \varepsilon_{i}=\eta_{i}+v_{i}+w_{i}=\ln I P_{i}-\left(\beta_{0}+\beta_{1} I_{i}+\beta_{2} G_{i}+\beta_{3} S_{i}+\beta_{4} \ln Y_{i}+\beta_{5} E_{i}+\beta_{6} D_{i}+\beta_{7} R_{i}\right)
\end{aligned}
$$

$\Phi($.$) is the distribution function of the standard normal distribution and n$ is the number of observations $\theta_{v}$ and $\theta_{w}$ measure relative medical staff's and patient's informal market information, while $\mu_{v}$ and $\mu_{w}$ are the medical staff and patient informal market ignorance. 
The disadvantage of the above model is that negative and positive stochastic deviations based on medical staff and patient informal market ignorance (measured by $\mu_{v}$ and $\mu_{w}$ ) are assumed to be the same for everyone. To avoid this, we have parameterised them (Groot and Oosterbeek, 1994; Groot and Maassen van den Brink, 2005). This way, we allow these parameters to vary with observable characteristics:

$$
\begin{aligned}
& \theta_{v i}=\alpha_{v 0}+\alpha_{v 1} G_{\text {rural }}+\alpha_{v 2} D_{i}+\alpha_{v 3} R_{i}+\alpha_{v 4} I 1_{i}+\alpha_{v 5} I 2_{i}+\alpha_{v 6} I 6_{i} \\
& \theta_{w i}=\alpha_{w 0}+\alpha_{w 1} G_{\text {rural }}+\alpha_{w 2} D_{i}+\alpha_{w 3} R_{i}+\alpha_{w 4} I 1_{1}+\alpha_{w 5} I 2_{i}+\alpha_{w 6} I 6_{i}
\end{aligned}
$$

The first terms of equations 5 and 6 represent characteristics of patients like if they come from rural areas $\left(G_{\text {rural }}\right)$, days spent in hospital $\left(D_{i}\right)$ and if the gift was requested/expected $\left(R_{i}\right)$. Other variables in these equations represent information on illnesses and diseases I1, I2 and I6 represent the illness and diseases of the categories 1, 2 and 6 respectively (see Table 5.2 for the full list of categories of illnesses/diseases). Category 1 includes very mild conditions or no conditions; category 2 is more related to blood and cardiovascular diseases; and category 6 groups together diseases of digestive organs and those caused by infections. The choice of these categories was based on the different impact that these illnesses/diseases have on the health status but also on the characteristics of the data (categories 1 and 2 have the highest incidences among all others)

\subsection{Data}

The data for estimating the two-tiered stochastic frontier model are taken from the Albania Living Standard Measurement Survey (ALSMS) 2002 and 2005. These datasets include a set of questions on health care visits and treatments concerning inpatient services. The variables that we use in our analysis come from identical questions used in these two years. Individuals are asked if they have visited inpatient health care services in the last 12 months. They have provided information on the amounts they have spent as out-of-pocket payments (including gifts to medical staff, drugs, laboratory work, transport, and other treatment payments). Based on the information available in the survey, we have only used the information about gifts paid to medical staff in the inpatient services (hospitals).2324 The data we use come from two modules of ALSMS: the individual module, and the household module.

The individual module includes information on 707 individuals who visited inpatient services in 2002 and 701 individuals in 2005. For our analysis, we have omitted observations with missing values or zero amount of informal payments. Our final sample consists of 748 individuals who have visited inpatient services either in 2002 or 2005 and have paid informally. The control variables included in the models represent

\footnotetext{
${ }^{23}$ Based on broader definitions of informal payments in health care, they may include also other expenses made privately that otherwise were supposed to be free of charge (i.e. medicines purchased outside the hospital, etc). This detailed information can not be obtained from LSMS 2002 and 2005, and therefore it is not used in this chapter.

${ }^{24}$ The individual amounts of gifts paid in 2005 are deflated to reflect 2002 prices.
} 
characteristics of the patient (demand side), type of illness/disease (see previous Chapters and Appendix 2A).

Table 5.1 shows the difference in characteristics between patients paying informally on voluntary bases to medical staff and those who are requested or expected. As we can see the mean value of informal payments is significantly higher for patients who have been requested or expected to pay (the amount paid informally is approximately 2 times higher when it is requested or expected compared to voluntary payments). The value of these amounts can increase significantly when the patients are threatened not to receive the service. The share of patients being requested or expected to pay informally, is larger in 2005 (56 per cent) than in 2002 showing that the situation has become worse in 2005 . The share of rural residents is much higher and statistically significant among those who have been requested or expected to pay informally (61 per cent). The difference in the level of per capita income, health insurance or level of education is not statistically significant between groups where these informal payments are voluntary and requested or expected respectively.

Table 5.1. Sample means of individual characteristics for patients that have paid voluntary or have been requested or expected to pay informally

\begin{tabular}{lcccc}
\hline \hline VARIABLES & \multicolumn{2}{c}{$\begin{array}{c}\text { VOLUNTARY INFORMAL } \\
\text { PAYMENTS }\end{array}$} & \multicolumn{2}{c}{$\begin{array}{c}\text { REQUESTED OR EXPECTED } \\
\text { INFORMAL PAYMENTS }\end{array}$} \\
\hline $\begin{array}{l}\text { Amount of informal payments per day } \\
\text { hospitalised (in Albanian Leks) }\end{array}$ & $751.16^{* * *}$ & $(1452.31)$ & $1339.22^{* * *}$ & $(3047.39)$ \\
Year of survey a & $0.37^{* * *}$ & $(0.48)$ & $0.56^{* * *}$ & $(0.50)$ \\
Monthly income per capita (in Albanian Leks) & 6269.79 & $(6165.31)$ & 7233.32 & $(10153.21)$ \\
Rural resident & $0.48^{* * *}$ & $(0.50)$ & $0.61^{* * *}$ & $(0.49)$ \\
Has health insurance & 0.41 & $(0.49)$ & 0.39 & $(0.49)$ \\
Level of education b & 1.40 & $(0.63)$ & 1.32 & $(0.60)$ \\
Number of observations & & 312 & & 436 \\
\hline \hline
\end{tabular}

Note: Stars indicate if the mean for the group is significantly different from the mean of other groups $\left({ }^{* * *} \mathrm{p}<.01,{ }^{* *}\right.$ $\left.\mathrm{p}<.05,{ }^{*} \mathrm{p}<.1\right)$; Standard deviations are in brackets.

All prices are deflated to 2002 prices. $100 \mathrm{ALL}=0.73$ Euros in June 2002 (Bank of Albania, 2010)

a Year of survey is " 0 " for 2002 and " 1 " for 2005

b Education level is categorical (" 0 " none education; " 1 " primary education; " 2 " secondary education; " 3 " university education)

In order to increase the precision of the parameter estimates of our independent variables, we have reduced the number of variables on acute and chronic illnesses or diseases by running a factor analysis on the 27 different types of them. We have extracted eight factors (representing 8 groups of acute and chronic illnesses) with a factor loading 0.2 or more. In total, in both years there are 4906 individuals who provided information on acute illnesses and 3654 on chronic illnesses. Out of these individuals, 954 individuals have reported on both acute and chronic illness during these years. To estimate the factor loadings, we have added one additional category for each variable, 'no chronic disease' (for those reporting only on chronic illness) and 'no acute illness' (for those reporting only on sudden illnesses). 
Table 5.2. Diseases and illness grouped according to the factor analysis

\section{CATEGORY 1}

no chronic diseases; acute illness cold / flu; no acute illness

\section{CATEGORY 2}

chronic diseases of blood and blood producing; chronic other disability; acute illness heart

\section{Category 3}

chronic congenital

abnormalities; acute

illness headache

\section{Category 4}

chronic diseases of respiratory organs; acute illness lung

\section{Category 5}

chronic nervous system and sense organ diseases; acute illness kidney; acute illness other trauma

\section{CAtegory 6}

chronic infectious diseases; chronic diseases of digestive organs; acute illness stomach; acute other illness

\section{CAtegory 7}

chronic diseases of urinary-genital system; acute illness liver; acute illness broken bone

\section{CATEgory 8}

chronic endocrine diseases; acute illness diarrhoea; acute illness ear/nose/throat
Category 1 includes very mild conditions or no conditions at all. Conditions grouped here are: acute cold / flu, having no chronic diseases, or having no acute illness.

Category 2 is more related with blood and cardiovascular diseases and includes: chronic diseases of blood and blood producing organs, other chronic disabilities and acute heart conditions. All these conditions have similar consequences and affect the patients' abilities (they contribute to disability, and lower the quality of life).

Category 3 groups together diseases which are more related with chronic anomalies and acute disorders and includes: chronic congenital abnormalities and acute headache. They all share common consequences, (i.e. constant or abrupt pain).

Category 4 groups diseases which are related with respiratory organs like; chronic respiratory organs diseases, and acute lung illnesses. All these conditions have similar causes and consequences, share the same symptoms and they also may lead to irreversible conditions.

Category 5 groups together conditions of the nervous system, kidney and other traumas. Conditions included here are: chronic nervous system and sense organ diseases, acute kidney illnesses and other acute traumas. They all bring psychological problems as they are associated with pain and sensitivity losses.

Category 6 groups together diseases of digestive organs and those caused by infections and include: chronic infectious diseases, chronic diseases of digestive organs, acute stomach illnesses and other acute illnesses. All these conditions have similar causes (infectious diseases, immunologic causes, or dietetic issues), and share similar symptoms (nausea, diarrhoea, and similar pain).

Category 7 includes chronic diseases of urinary-genital system, acute liver illnesses, and acute broken bone illnesses. These conditions share similar consequences (broken bones are related with issues of other internal organs resulting from traumas, such as liver rupture, and urinary problems).

Category 8 includes chronic endocrine diseases, acute diarrhoea illnesses, and acute ear/nose/throat illnesses. Most of these conditions can be seen as related to one another (i.e. diabetes causes diarrhoea, disorders of thyroids are related to difficulties in swallowing, etc). 
Most of the factors combine diseases which are either related (categories 1 and 8), or can be symptoms of common causes (categories 4 and 6), or can have common consequences (categories 2, 3, 5, 6, 7), or have in common that they provide serious discomfort or pain (categories 5, 6, 7).

\section{$5.5 \quad$ Results}

Table 5.3 presents the estimation results of three sets of estimates: the ordinary least square (OLS), two-tiered stochastic frontier model with constant terms for the one-side error terms only, and two-tiered stochastic frontier model in which the one-sided error terms vary by different characteristics. We use the OLS model as a benchmark for the results of the two-tiered stochastic frontier estimates. The estimation results of the OLS model and the stochastic frontier estimations show that the statistically significant parameter estimates are overall similar.

Household size appears to be negatively related to the amount paid informally and the effect is statistically significant in the three estimated models. The results are comparable to the results of other studies on the effect of household size in reducing the amount allocated for health care or informal payments (Behrman et al., 1980). Larger households can be more exposed to the risk of being sick, have less to spend per capita, and can also call upon informal care from the other family members. They are more likely to have young children or elderly individuals, and therefore, more likely to make use of health services. The same holds for people living in rural areas. Income per capita is also more likely to be low in larger households, which reduces their ability to pay. ${ }^{25}$ An additional argument is the lack of a universal child benefit in Albania which makes large households more economically vulnerable.

Rural residents also appear to pay lower amounts informally. Previous evidence (Vian and Burak, 2006) suggests that rural residents may pay less when getting services within their village or community but they are likely to pay more when visiting facilities in big cities. Giving the limitations of our data, we cannot control for such effects.

Age is represented by dummy variables and the category 16-30 years old is tested against the other categories. The positive coefficient for this category shows that on average older individuals pay smaller amounts informally in inpatient health care services (probably because of more frequent health care visits and lower income at the same time). This is in the same line with findings of previous studies (Balabanova and McKee, 2002).

Patients who are married and living together pay higher amounts informally to medical staff compared to patients who are widowed, divorced or single. This may also indicate the extent of intra-family support through adults of working age. Higher income patients pay also higher amounts suggesting a close link between income and ability to pay (Falkingham, 2004; Gotsadze et al., 2005).

25 A World Bank Report (Albania - Urban Growth, Migration and Poverty Reduction, World Bank 2007) mentions that in 2005 on average a rural resident had about 14 per cent less per capita consumption if compared to an urban resident. 
Table 5.3. Parameter estimates OLS and two-tiered stochastic frontier model

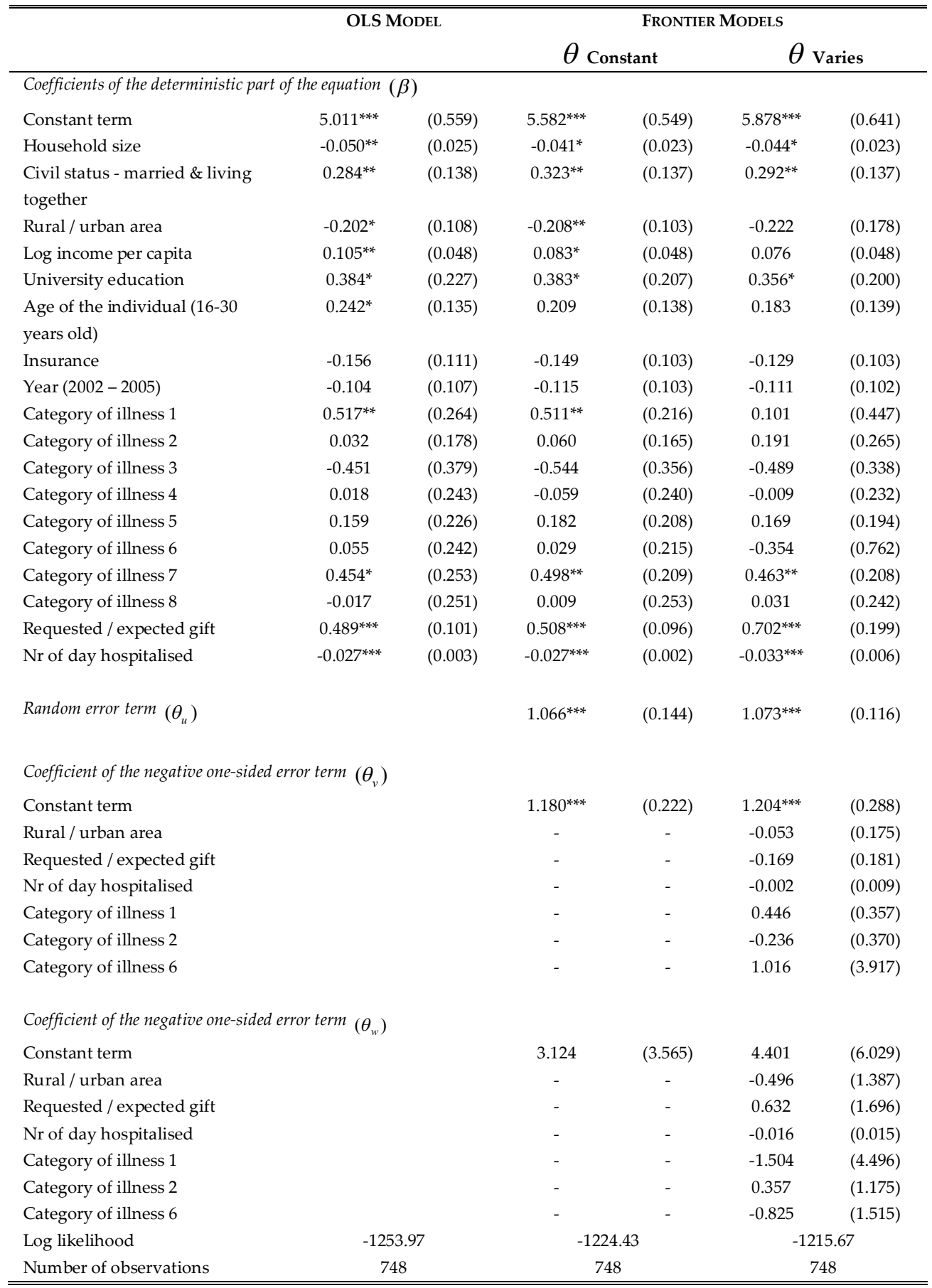

Note: Stars indicate: ${ }^{* * *} \mathrm{p}<.01,{ }^{* *} \mathrm{p}<.05,{ }^{*} \mathrm{p}<.1$. Standard errors are in brackets. 
Higher educated people pay higher informal payments to medical staff. This can relate to the higher opportunity costs that they face when ill, which may increase their willingness to pay for health care. Higher educated people invest more in their health and are also more able to generate income and therefore can afford to pay more for better services or fast recovery (Becker, 1967; Mincer and Polachek, 1974).

Health insurance decreases the amount paid informally but its effect is not always statistically significant. This shows that such insurance is of little relevance. This is mainly because in 2002 and 2005 there was no direct and clear link between the Albanian health insurance and inpatient care services (World Bank, 2006).

Out of eight categories of illnesses or diseases only category 1 and category 7 appear to have a statistically significant effect on the amount paid informally to medical staff. Category 1 includes very mild conditions or no conditions at all. The positive and statistically significant effect may indicate that patients who do not use health care often are more likely to pay informally if compared to other categories. Category 7 includes internal organ disorders (liver and urinary-genital system) or broken bones. The positive and statistically significant effect may indicate that patients with severe and lifethreatening illnesses or diseases pay higher amounts compared to patients with milder illnesses or diseases. The lower level of significance for other categories presents evidence for the homogenous amounts paid informally for illnesses and diseases. This shows that the amount of informal payments is not much influenced by patients' illnesses or diseases.

Patients pay higher amounts informally when they are asked for or when they are expected to pay (the coefficient indicating whether the informal payments were requested is positive and statistically significant in the three models). This shows that informal payments in Albania are not "gratitude payments" and that medical staff can influence the amount paid. The number of days hospitalised negatively influences the amount paid informally. This relationship shows that patients with more hospitalisation days may have more information on the informal amount expected from the medical staff and at the same time they may also have less income (income is negatively correlated with health status).

\subsection{Estimation of ignorance about informal payments}

The lower part of Table 5.3 gives the estimates of the parameterised specification of $\theta_{v}$ and $\theta_{w}$ when both $\theta$ s are constant and when they vary by different characteristics. Except for the intercept in the medical staffs' equation, all other parameters are statistically not significant implying that imperfect information of medical staff and patient is virtually constant in our model and varies little by the characteristics included in the analysis. Table 5.4 gives the estimated values of the two one-side error terms for both medical staff and patients. We interpret these terms as indicators of the effect of imperfect information on the amount paid informally. The table gives the mean for total sample or sub-samples (Groot and Oosterbeek, 1994; Groot and Maassen van den Brink, 2005). For each individual in our sample, the observed value of the informal payment is either below or above the mean value of these payments. The difference indicates the imperfect information that patients and medical staff have on the amount the other party is requesting or willing to pay respectively. 
Table 5.4. Imperfect information of medical staff and patients for various subgroups

\begin{tabular}{lcc}
\hline \hline & $\begin{array}{c}\text { MEDICAL STAFF's } \\
\text { IMPERFECT INFORMATION }\end{array}$ & $\begin{array}{c}\text { PATIENT'S } \\
\text { IMPERFECT INFORMATION }\end{array}$ \\
\hline Constant & 0.56 & 1.43 \\
Varies by characteristics & 0.57 & 1.45 \\
Total sample (mean) & 0.55 & 1.31 \\
Rural area resident & 0.53 & 1.23 \\
Requested / expected gift & 0.56 & 1.29 \\
Nr of day hospitalised & 0.64 & 1.47 \\
Category of illness 1 & 0.51 & 1.24 \\
Category of illness 2 & 0.70 & 1.35 \\
Category of illness 6 & & \\
\hline \hline Medical staff's imperfect information: $E\left(e^{w}\right)=1 /\left(1-\mu_{w}\right)$ Patient's imperfect information: $E\left(e^{v}\right)=1 /\left(1+\mu_{v}\right)$
\end{tabular}

We calculate the means of medical staff and patients' imperfect information of $\mathrm{v}$ and $\mathrm{W}$ for the sample as a whole and for some specific groups. ${ }^{26}$ The results indicate that imperfect information for medical staff and patient is similar when $\theta \mathrm{s}$ are assumed to be constant and when the $\theta$ s vary by sample characteristics. For example for the total sample patients pay on average $45 \%$ more than the minimum value expected by medical staff (as the error term is normalised to 1 , the deviance is calculated as $1.45-1=45 \%$ for the positive error term). On the other hand, patients pay on average $43 \%$ less that the maximum that they are willing to pay informally (for the negative error term, the deviance is calculated 1$0.57=43 \%$ ). Generally, we observe that medical staff imperfect information is relatively larger than imperfect information of patients for most of the groups. This indicates that medical staff has less information on the amount that patients are willingness to pay informally than the patient has on the expected value of the medical staff.

Table 5.5 presents the maximum amounts that patients are willing to pay informally to medical staff, the minimum amounts that medical staff are expecting, as well as the averages of the actual amounts paid. The values calculated in the table are based on the coefficients of imperfect information indicators in Table 5.4.27 The results show that the highest medical staff's expected value is for the residents of rural areas who also pay the highest amount. Another category with high expected value is the one representing patients to whom informal payments are requested or expected. Medical staff in these cases can set their expectations higher than average knowing that they can impose such payments.

\footnotetext{
${ }^{26}$ Indicators on imperfect information for patients and medical staff are calculated based on equations (5) and (6). Values are calculated for each observations and the table displays means for the whole sample. Different categories in the table represent the means for that sub-sample (i.e. imperfect information for patient living in rural is calculated taking into account only those who live in these area).

${ }^{27}$ Patient's willingness to pay informally is calculated as the realistic value paid (the mean of the amount paid informally for that particular service) over the difference between hundred percent and imperfect information indicator of patients.
} 
Table 5.5. Willingness to pay informally to medical staff and amount expected by medical staff for various groups

\begin{tabular}{|c|c|c|c|}
\hline & $\begin{array}{l}\text { MEDICAL STAFF'S } \\
\text { MINIMUM EXPECTED } \\
\text { AMOUNT }\end{array}$ & $\begin{array}{l}\text { PATIENT'S MAXIMUM } \\
\text { WILLINGNESS TO PAY }\end{array}$ & $\begin{array}{c}\text { THE MEAN OF ACTUAL } \\
\text { AMOUNT PAID }\end{array}$ \\
\hline Total sample (mean) & 710 & 2020 & 1114 \\
\hline Rural area resident & 875 & 1979 & 1359 \\
\hline Requested / expected informal payments & 730 & 1441 & 1114 \\
\hline Nr of day hospitalised & 580 & 1279 & 903 \\
\hline Category of illness 1 & 508 & 1582 & 833 \\
\hline Category of illness 2 & 573 & 1143 & 865 \\
\hline Category of illness 6 & 548 & 1441 & 933 \\
\hline
\end{tabular}

Note: ${ }^{*}$ ) The amount paid informally is the average per day hospitalised. Amounts are in Albanian Leks All prices are deflated to 2002 prices. 100 ALL = 0.73 Euros in June 2002 (Bank of Albania, 2010)

Illnesses categories 1, 2 and 6 do not appear to have a big impact on the medical staff minimum expected amount (though as we mentioned before they also have little explanatory power on the imperfect information of medical staff or patients). ${ }^{28}$ Medical staff's expected values for all these categories appear to be lower than the total sample showing that the amount medical staff is expecting does not depend significantly on the illness but rather on other characteristics of the patients. The lowest patient's willingness to pay informally estimated in our analysis is for category 2, which includes long lasting chronic conditions showing that patients in this category are less willing to pay (as they know that such conditions will last longer).

\subsection{Discussion}

Generally, the findings show that the amount paid as informal payment to medical staff is not entirely dependent on the level of income but depends also on socialdemographic characteristics (i.e. the household size, rural/urban area, education, and civil status). This suggests that the final amount paid is (to a great share) prone to the particular social situation and position of the patient seeking inpatient health care. Therefore, the actual amount paid informally can be considered as the final outcome of a (explicit or implicit) negotiating process between patients and medical staff. The information that each party has on the other's minimum expected amount or maximum willingness to pay influences the actual amount paid.

We found that medical staff has less information on the patient's maximum willingness to pay informally than patients have on medical staff's minimum expected amount. This seems reasonable as patients can gather more information on the medical staff's minimum expected amount (using their personal network) than the medical staff can gather on patient's maximum willingness to pay (information is more costly to obtain by medical staff than by patients). This finding is consistent with what previous studies have found on the ways that patients use to get informed on the doctor's expected informal

${ }^{28}$ Category 7 is omitted from these calculations as the model could not converge when this was included. 
payments (Vian and Burak, 2006). We show that thanks to this information patients can reduce the amount of actual payment paid. However, the actual mean payment remains slarge and in all cases is larger than the medical staff's expected value. Groups like rural residents or those to whom informal payments are requested from seem to be more vulnerable to such payments as they also pay the highest amounts. It looks like medical staff is expecting much more from such patients having more information on them (e.g. knowing that patients coming from distant areas have higher opportunity costs as travelling costs and time costs are higher since hospitals are located in urban areas).

Although we have tried to use the full potential of the ALSMS data, there are some limitations to what we can actually explore on the interactions between patients and medical staff. Our data provide limited information on the specific treatment performed, and on medical staff's characteristics (i.e. position, salary, etc). Moreover, we cannot distinguish between payments made to physicians or other medical and supporting staff. Our analysis is therefore limited only to the amounts paid informally to medical staff. This may lead to an underestimation of informal payments in Albania. The specific way the questions are asked in the ALSMS and the context of the country do not allow us to distinguish between other formal and informal payments even if other categories of out-ofpocket payments are considered.

\subsection{Conclusion}

In this chapter, we have shown that the actual amount paid informally to medical staff is influenced by imperfect information that patients and medical staff have on each other maximum willingness to pay or minimum expected amount. By using a two-tiered stochastic frontier model we have estimated indicators of such imperfect information and the effect on the actual amount paid. These indicators are an important tool in understanding how characteristics of patients or medical staff can increase or reduce informal payments. Despite the fact that patients seem to have on average better information than medical staff on the amount that the other party is requesting informally, we show that the mean of amount paid remains considerable and the highest payments are imposed on vulnerable group of society. Such amounts call for more measures that limit the phenomenon in the health care sector. Policymakers could use the information on expected payment or maximum willingness to pay informally to adjust the estimates on formal costs or to calculate the increase in patient's fees that would be accepted both from medical staff and patients. Future research could try to refine such measures by differentiating between different types of treatments and services. 


\subsection{Appendix 5A.}

Table A5.1. Descriptive statistics

\begin{tabular}{|c|c|c|}
\hline VARIABLES & MEAN & STD. DEV. \\
\hline Informal payments made to the medical staff (in Lek) & 1113.60 & $(2566.64)$ \\
\hline Household size & 5.28 & $(2.00)$ \\
\hline Civil status - married \& living together & 0.68 & $(0.46)$ \\
\hline Civil status - widow \& divorced & 0.06 & $(0.25)$ \\
\hline Civil status - single & 0.09 & $(0.29)$ \\
\hline Rural/urban area & 0.55 & $(0.49)$ \\
\hline Income per capita & 6864.53 & $(8819.93)$ \\
\hline Age of the individual ( $0-15$ years old) & 0.18 & $(0.38)$ \\
\hline Age of the individual ( $16-30$ years old) & 0.21 & $(0.41)$ \\
\hline Age of the individual ( $31-50$ years old) & 0.28 & $(0.44)$ \\
\hline Age of the individual (51-65 years old) & 0.18 & $(0.38)$ \\
\hline Age of the individual - 65_plus & 0.13 & $(0.34)$ \\
\hline None educated & 0.01 & $(0.11)$ \\
\hline Primary education & 0.55 & $(0.49)$ \\
\hline Secondary education & 0.21 & $(0.40)$ \\
\hline University education & 0.05 & $(0.21)$ \\
\hline Health insurance & 0.40 & $(0.49)$ \\
\hline Year (2002 - 2005) & 0.46 & $(0.49)$ \\
\hline Category of illness 1 & 0.53 & $(0.49)$ \\
\hline Category of illness 2 & 0.16 & $(0.37)$ \\
\hline Category of illness 3 & 0.01 & $(0.13)$ \\
\hline Category of illness 4 & 0.05 & $(0.23)$ \\
\hline Category of illness 5 & 0.06 & $(0.24)$ \\
\hline Category of illness 6 & 0.05 & $(0.23)$ \\
\hline Category of illness 7 & 0.05 & $(0.21)$ \\
\hline Category of illness 8 & 0.04 & $(0.21)$ \\
\hline Requested/expected gift & 0.58 & $(0.49)$ \\
\hline Nr of day hospitalised & 16.18 & $(19.31)$ \\
\hline Number of observations & \multicolumn{2}{|c|}{748} \\
\hline
\end{tabular}

Note: *) The amount of informal payments is the average per day hospitalised. Standard deviations are in brackets. All prices are deflated to 2002 prices. $100 \mathrm{ALL}=0.73$ Euros in June 2002 (Bank of Albania, 2010) 
Chapter 6. CONCLUDING REMARKS 


\subsection{Introduction}

This dissertation contributes to the knowledge on informal payments in the health care systems of transition economies. The main goal is to shed new light on the causes of informal payments in public health care and to understand how such payments affect the allocation of resources at the micro-level between patients and medical staff and within households in Albania. Informal payments in this dissertation are measured through the informal 'gifts' paid to medical staff in public health care services. Although classified as gifts, these payments are often requested or expected and represent a considerable part of out-of-pocket payments in health care in Albania. They are paid directly to the medical staff and do not include payments for drugs, diagnostic services or other health care commodities. Gaining access to treatment, jumping the queue or getting better quality care are the main reasons for such informal payments. The amount paid is not fixed and varies greatly among patients, providers, treatment and other relevant or irrelevant characteristics. The timing and form can also differ depending on patients and medical staff characteristics. The payments may anticipate (ex-ante) or postdate (ex-post) the visit or treatment, and can be paid in cash or as in-kind gifts.

Informal payments are considered in this dissertation as a way to allocate scares resources where the market prevails over the rationing systems thought up by the government. This definition allows looking at such payments both as a consequence of poor governance (inability to provide sustainable alternatives of health care financing and tolerance towards informal practices) and also as a result of demand-supply interactions. The analysis throughout the dissertation is based on the household-level data from Albania Living Standard Measurement Survey (ALSMS) 2002-2005-2008.

\subsection{Main statements based on the research findings}

This section presents the main findings of the dissertation focusing on the research aims presented in the introduction. The main findings are presented in the form of six main statements and a short elaboration of the results is given for each of them. Subsequently, they are followed by the policy recommendations, limitations and the suggestions for further research.

Despite the decrease of absolute poverty in Albania in recent years, the high amount paid out-of-pocket for health care expenditures (including informal payments to medical staff) has increased the risk of poverty for vulnerable households.

The high prevalence of out-of-pocket payments can increase the financial risks associated with health care events. Household may run the risk of poverty if such payments are larger than a certain share of the total household expenditures. Both formal and informal payments have contributed to increasing such risk. Data from ALSMS 2002, 2005 and 2008 are used to analyse the extent to which out-of-pocket health spending impoverish the households in Albania. By using a multiyear analysis, chapter 2 of this dissertation presents the dynamics of out-of-pocket payments over time and the share of 
informal payments on total out-of-pocket health care spending. Different thresholds are used to compare out-of-pocket payments to total non-health spending and various indicators are estimated for different sub-groups.

The empirical results demonstrate an increase in real value terms of out-of-pocket payments in 2005 and 2008. Informal payments, formal payments and private health care spending have particularly contributed in this increase. The catastrophic headcounts for all thresholds show that out-of-pocket spending may lead to catastrophic health care expenditures in Albania. Although such catastrophic payments have decreased over the years, this has not been the case for patients from the poorest quintiles which now face higher risks of falling in extreme poverty. These patients have experienced a rise especially in informal payments paid in both outpatient and inpatient care and also on non-direct costs (i.e. transportation costs).

Policy recommendations - The existence of catastrophic health care expenditures should raise the concern of policy makers. Catastrophic health care expenditures do not only impose a higher poverty risk for people seeking health care but may also impose barriers to access for them. The Albanian authorities should seriously consider the reduction of total out-of-pocket payments which amount to almost $60 \%$ of total expenditures for health in the country (WHO, 2010). This is best achieved through ensuring the effectiveness and attractiveness of formal mechanisms of health care financing (i.e. general tax revenues and health care insurance). While improving the effectiveness of such mechanisms requires a better coordination and allocation of resources, the attractiveness could be raised by adopting the structure of contributions and co-payments so that they better reflect the income distribution. Some of the suggested measures in this regard could be fee exemptions or price subsidies for vulnerable groups which have proven effective in reducing catastrophic payments in other countries (Pradhan and Prescott, 2002). Since non-direct costs related to transportation are becoming an increasing burden for the patients in poor quintiles, measures like subsidised transportation for the poor or a better distribution of health care centres would also help in this regard.

Limitations - One of the main limitations in studying the impoverishing effect of outof-pocket and informal payments is the lack of information on those patients that needed health care but could not afford it. The ALSMS collects information only on patients that have sought health care and does not allow estimating the gap that needs to be filled in order to ensure equal access for everyone. Another limitation of the study is that the effect of informal payments is most likely underestimated. The data provided by ALSMS allows distinguishing only the part of informal payments paid as 'gifts' to medical staff. Other definitions of informal payments would include more types of informal payments (see also Table 1.1 in Chapter 1). Running the same analysis with additional data (allowing for a more comprehensive definition of informal payments) may provide more insights on the overall causes of informal payments and the burden imposed on households.

As many other surveys, ALSMS may be potentially limited by a response bias in answering questions on health care and health status. Questions and situations may be perceived differently among different income or education groups. Moreover, the survey is 
randomized based on CENSUS 2001 information (demographic, geographical and socioeconomic information) but not necessarily based on health and health care related information. This may lead to an underrepresentation of certain groups (especially high utilization groups like the elderly or chronically ill).

Further research - Further research should be focused on identifying the effect of outof-pocket and informal payments on people who cannot afford such payments and are therefore denied access to health care. Another interesting aspect for future research is also the investigation of the effectiveness of policy measures, like fee exemptions and price subsidies, in reducing the risk of falling in poverty among particular health care seekers addressed by these policies.

Cultural factors can be seen as a mechanism that enables the existence of a system of informal payments in public health care in Albania, while governance failure, lack of accountability and economic shortages are the driving causes of the widespread and high amounts paid informally.

Informal payments are considered in this dissertation as a consequence of a series of factors. Such factors can be grouped as cultural (i.e., the culture to express the gratitude through gifts), economic (free health care, inadequate funding, low salaries/investments), and governance-related (lack of accountability, weak rule of law, and increased corruption) causes. They are considered here in different models and tested using the evidence provided by ALSMS.

While previous studies have indentified possible causes for informal payments, they have been mainly based on descriptive analysis of the data. This dissertation employs a new approach to look at such causes by exploring the demand-side factors (i.e. patient's characteristics) and supply-side factors (i.e. provider's characteristics) and looking at the way they influence the probability of paying and the amount paid informally. Tobit and Heckman selection model are used in chapter 3 to determine the amount paid informally to medical staff while propensity score matching is used to investigate how characteristics of patients paying informally have changed over years.

Drawing a clear distinction between different causal models may be a difficult task as they may also be interrelated to each other. Considering that cultural factors were also mentioned in previous studies (Vian et al., 2006) we expected such model to play a stronger role in determining informal payments in Albania. Contrary to this, the analysis in chapter 3 shows that this is not the case. While cultural factors can be broadly considered as enabling the existence of informal payments, they cannot justify the widespread and the high amounts paid (especially in inpatient care). The widespread of payments in outpatient and inpatient care, the relative exploitation of certain groups of patients (e.g. rural patients visiting hospitals in Tirana) provide evidence in favour of the governance-related issues. The influence of economic-related issues would be a reason for the amounts paid informally to resemble 'fee-for-service' payments (e.g. varying based on the type and intensity of service delivered). The different amounts paid for outpatient and 
inpatient care, and the positive influence of education, income on payments in inpatient services support the existence of these economic-related issues.

Policy recommendations - The main aim of public health care policies related to informal payments should be the elimination of such practices. ${ }^{29}$ Such aim although explicitly stated in strategy papers $(\mathrm{MoH}, 2004)$, has not yet materialised in practice. From an economic perspective, informal payments in many CEE and FSU countries make up for a relatively small part of out-of-pocket payments (Lewis, 2007). This makes that they are easily ignored by policy makers. Moreover, as it is shown in this dissertation and numerous previous studies (Delcheva et al., 1997; Chawla et al., 1998; Ensor and Witter, 2001), such payments are used to fill in the gaps created by increasing demand and the non-responsiveness of supply. This further lowers the interest of policy makers in developing effective strategies against such payments. Such strategies would require multiple measures linked to the financing and governance of the health care.

In brief, effective policy measures against informal payments will have to ensure the rule of law (and deal with the informal and illegal aspect of such payments), to increase accountability of public providers, to create rewarding incentives for medical staff and to provide adequate resources.

The enforcement of the laws punishing informal payments is closely related to their informal and illegal nature. Direct payments to medical staff in Albania are not legal and paying 'under-the-table' for extra or better service is considered a form of corruption (and punishable by law). Future measures would require specific sanctions for medical staff engaging in inappropriate behaviour (i.e. explicitly requesting/expecting informal payments). In addition, public providers should also be held more accountable - that is answerable for processes and outcomes (Lewis and Pettersson, 2009) - and further sanctions should be imposed if such outputs have not been delivered.

Low wages and weak incentives for medical staff present a potential impediment for eradicating informal payments in public health care (Ensor and Savelyeva, 1998; Ensor and Witter, 2001; Chawla et al., 1998; Lewis, 2002; Vian et al., 2006). Medical staff's wages can only increase by generating additional revenues. It is often argued that converting informal payments into formal fees (so that they can generate revenues for the institution and not the medical staff alone) can solve the problem of informal payments. However, neither the increase in wages nor formal charges are a panacea for eradicating informal payments (Lewis and Pettersson, 2009). Formalising informal payments may even create adverse effects for patients. If informal payments are formalised medical staff will need to pay revenue taxes and other fiscal obligations on these revenues. This may lead to further increases in the charges patients have to pay in order to keep net revenues for physicians at the same levels as before. On the other hand such formalisation also formalises the barriers to access to health care for patients who cannot afford to pay.

\footnotetext{
29 As demonstrated in chapter 1 informal payments affect the efficiency of health care systems, increase corruption and unethical behaviour of medical staff and also deepen the inequalities in health care delivered penalising the poor and vulnerable.
} 
Money should not be an argument in the relation between patient and physician. Therefore, the government needs to be very careful in dealing with informal payments. One of the most important messages that needs to be communicated to the public is that health care is not 'free' any more (as was once created the impression under the 'Semashko' system). People need to use 'formal' channels to contribute to the system (contribute through health insurance or general taxes). The increased revenues could then be used to compensate medical staff and invest more in health care equipment and facilities. In addition, such measures would be much more effective if accompanied by measures to strengthen professional norms and career opportunities for medical staff.

While an immediate increase in the overall public health budget may be difficult in Albania, a lot can be done to increase the effectiveness in collecting and allocating the available resources. Evidence has shown that in outpatient care where contractual agreements exist with the Health Insurance Institute (HII), informal payments are less frequent and amounts paid are lower for patients having health insurance. Although this alone is not sufficient (as the results of chapter 3 show) the contracting of the inpatient care through the HII and the increase in the number of insured population would decrease the incidence and the amounts of informal payments.

Limitations - One of the limitations in investigating the determinants of informal payments is that the ALSMS data do not allow us to distinguish between payments made to physicians or other medical staff, nor do they capture the payments made through favours rendered. Furthermore, it is not possible to link the existing information with other aspects of interactions between medical staff and patients (e.g. the social connections and knowing the physicians beforehand) or with the attitude towards corruption in the particular health care facility (e.g. the number of prosecuted cases for corruption in a certain region or facility and/or number of penalised physicians for unethical behaviour).

In addition, the ALSMS household-level data cannot be directly linked with indicators of some of the factors enabling or causing informal payments. Indicators such as the persistence of the culture of gift (e.g. historical data on gifts in the health sector or the extent of gifts in the other sectors) cannot be linked to household level data. The same is also true for health budget indicators. The shares of regional financing, regional differences in medical staff's wages, etc., are not collected by ALSMS and therefore not primarily included in the analysis.

Further research - Understanding the main causes of informal payments is only the first step in understanding the phenomena and designing ways to restrict it. Further research should involve the assessment of the proposed measures. The individual and aggregate analyses of policy measures like fee formalisation, resource allocation, increased accountability, and better incentives for health care providers should be further investigated in order to judge on their applicability in Albania and other CEE and FSU countries. 


\section{Fragmented measures taken over the last years, like financing primary care through health insurance and increasing wages of general practitioners, have had little impact on informal payments paid to medical staff in Albania.}

The investigation of the informal payments paid by similar individuals over the years requires longitudinal surveys which in many countries are not available. In the current dissertation, this is overcome by using the potential of three cross section surveys ALSMS 2002, 2005 and 2008 (chapter 3) and applying propensity score matching techniques to match patients paying informally over the years.

The past reforms and re-organisation of health care system in Albania have mainly dealt with expanding the health insurance scheme in primary health care. The main measures against informal payments have been limited to the contracting of primary care services through the HII and increasing the salaries for primary care physicians. However, salaries of medical staff have not been indexed constantly and the expansion of health insurance has not been accompanied by an increase in the number of people contributing to health insurance. Moreover the contracting of secondary or tertiary care by the HII has lagged behind.

The analysis of the changes in informal payments paid by similar individuals during the period from 2002 to 2008 in Albania suggests a moderate effect of such measures on reducing informal payments. The results show that the amounts paid informally for individuals with similar characteristics have not changed much between 2002 and 2005 and has decreased slightly between 2005 and 2008 (making the effects less clear between 2002 and 2008).

Having had health insurance during the years 2002 and 2008 has always decreased the probability of paying However, the results from propensity score matching show that the effect of health insurance has decreased between 2002 and 2008 in both the services. Such weaker role of health insurance in the last years (especially in outpatient care where the financing is done entirely through health insurance) does not create the required incentives that would push the informal market workers in the social health insurance scheme.

The propensity score matching techniques show that the burden of informal payments bore by patients in the lowest quintiles or patients with difficulties to pay for health care is at times similar (or larger) than that of others. The policy measures have failed to lower the informal payments for these categories.

Policy recommendations - One of the aims of public policies addressing informal payments should be to identify measures that would reduce informal payments and improve the performance of the health care system. Policies during the last years in Albania have failed to keep up with the positive outcomes of the first measures in this regard. The persistence of the phenomenon over the years calls for more affirmative action in addressing the economic and governance-related causes. Medical staff should be punished if they use their power to extract informal payments. On the other hand, they also should be rewarded appropriately for their performance. Resources should be directed more towards the basic necessities (like providing medical supplies) or protecting the poor. 
Limitations - The main limitations in studying the effects of policy measures on informal payments between 2002 and 2008 go back to the lack of detailed data on medical staff. While the effects of informal payments on individuals are measurable, the effects of such payments on medical staff remain largely unknown. It is often argued that such payments are not equally distributed among practitioners and that higher ranked physicians capture most of these payments. However, little empirical evidence exists to document this and to measure the incentives that such payments create for medical doctors.

Further research - One of the areas that could be explored in future is certainly the effect of informal payments on the behaviour of medical staff. Medical staff may also be more or less motivated in the presence of informal payments. Such motivation may differ based on the specialization, rank or the access that medical staff have on such informal payments. The understanding of these incentives is important especially when considering the shortfall that some of the CEE and FSU countries may have due to the brain drain and migration of medical doctors, or when considering how attractive are medical studies for the new generations in these countries.

\section{Albanian households - when confronted with informal payments in health care - allocate their resources strategically over household members favouring individuals with higher earnings potential or more bargaining power within the household.}

Health care expenditures can be considered as investments in human capital (Becker, 1964; Grossman, 1972b). However, informal payments in health care may impose a heavy burden on households' expenditures (considered as uninsured risks). For this reason, households may decide to allocate their resources in a way that differs between household members and that may favour some members over others. Households may decide to invest more on members with the highest bargaining power, higher earnings capacity or with higher returns on human capital (i.e. the children). Chapter 4 employs generalised Hausman specification test to compare coefficients of probit and OLS models for the probability and the amount paid informally in nuclear and extended households. This approach allows exploring the allocation of resources among household members and also comparing the results between different types of households.

The analysis of intra-household differences in the probability of paying informally shows few differences between nuclear households (households including only parents and children) and extended households (including parents, children and other members). This indicates that payments are widespread and occur among all types of households. However there are differences in how the two types of households allocate their resources over their members. Nuclear households allocate higher amounts of informal payments to children and spouses compared to extended households while children in extended households tend to pay lower amounts. Bargaining power within the household may also affect the recourses allocated for informal payments by disadvantaging the lower educated and the women. 
The analysis in the study in chapter 4, as in the other parts of this dissertation, shows that the consequences of informal payments fall more heavily on the most vulnerable. Having to face such uninsured risks, households will tend to cover the members with more bargaining power and higher earning potential.

Policy recommendations - One of the main concerns policy makers should have with regard to informal payments are the barriers these payments create to have access to health care. The main aim of health policy is to ensure sustainable and equitable health care policies. Households may choose to reduce payments for the most vulnerable members (i.e. women or children living in extended households). Future strategies against informal payments should ensure better protection of such groups by ensuring that they have access to adequate health care services.

Limitations - ALSMS data are limited in the information they contain on household members who need health services but cannot afford them (e.g. information on household members that were denied treatment is given only at the household level and no amounts required informally to be able to get such treatment are given). This limits the possibilities of analysing the barriers to health care raised because of the informal payments. Such analysis would reveal more about the negative effects of such payments especially for the poorest households.

An additional limitation is the lack of detailed information on the exact amount that the employed and other income earner bring to the household. The availability of such information would better reveal the bargaining power of individuals within the household and the influence on the decision to pay informally for health care.

Further research - The focus of future studies should be on those members of households that have not visited health care or have delayed treatment due to informal payments. This would allow understanding the restriction and equity aspects imposed by such payments also between household members. It would also help in better identifying the members of households that need to be protected by public policies.

The extent of the imperfect information that patients have on the medical staff's minimum expected amount of informal payment and the extent of the imperfect information that medical staff have on patient's maximum willingness to pay informally differs by characteristics of the patient and the treatment received, and influences the actual amount paid informally.

Medical staff have little information on the maximum amount that patients are willing to pay informally. On the other hand, given the informal nature of these payments, patients also face uncertainty and have little information on the medical staff's minimum expected amount. Chapter 5 develops a two-tiered stochastic frontier model to measure how this imperfect information is influenced by individual characteristics of patients and medical staff in the inpatient care. Estimates of imperfect information are calculated for the whole sample and for separate characteristics of patients and providers. To the best of our knowledge, such analysis has not been performed before. More importantly, it helps to increase our knowledge about the information that patients and medical staff have on the 
price to be paid informally when the market overrides the financing systems thought up by the government.

Characteristics of patients (like urban/rural residence, or days hospitalised) and characteristics of medical staff (like the speciality of treatment or the fact that the payment is requested or expected) can increase or reduce the information on the amount that the other party's willing to pay or expecting to get, and thereby, it influences the actual amount paid informally. The findings suggest that medical staff have less information on patients' maximum willingness to pay informally compared to the information that patients have on the minimum amounts medical staffs' expect to receive. This finding is consistent with the findings of previous studies on informal payments in Albania (Vian and Burak, 2006) suggesting that patients collect prior information on the payment that physicians expect to receive. Results from the two-tiered stochastic frontier model demonstrate that the highest amount medical staff expect to receive are for residents of rural areas or for patients from whom informal gifts are requested/expected. This shows that medical staff can differentiate the expected amounts by what patients are willing to pay. They set expectations higher than average, knowing that such patients pay also higher amounts informally (Chapter 3).

In general, the results from the analysis in chapter 5 show that medical staff's expected values for illness categories appear to be lower than the average expected payments (showing that the expected amounts do not depend significantly on the illness but rather on other characteristics of the patients). Such finding is very important and reinforces the previous statement that the main causes of informal payments are to be seen in governance-related and economic causal factors.

Policy recommendations - The main aim of policy measures in this regard is to have good estimates of the monetary amounts that patients are willing (and able) to pay for having quality health care services and the monetary amounts that medical staff would require to stay motivated. The estimates generated in Chapter 5 can be used to adjust the formal fees so that they would be accepted by patients. Similarly, the information on the minimum expected amount could be used to adjust the wages of medical staff.

The higher amounts that medical staff expects from residents of rural areas call for more attention towards this population group. Such expectations are most likely built on the higher opportunity costs that such patients face (e.g. extra travel expenditures, lost days of works, etc). Policy makers should carefully assess any inequalities in access that such groups may have and develop measures addressing them (e.g. provide quality services in regional hospitals by creating incentives for specialists to take the jobs in such hospitals).

Limitations - Although the analysis in Chapter 5 uses the full potential of the Albanian LSMS data, there are some limitations to what can actually be explored between patients and medical staff. The survey data provide little information on the type of treatment performed on patients and their prior contacts with medical staff. This limits the accuracy in measuring the amount of imperfect information. Furthermore, questions on the rank, salary or specialisation of medical staff are not asked in the survey. This makes it difficult to measure the effects of the interaction between medical staff and patients. 
Consequently, it is difficult to capture the effect of the bargaining process between medical staff and patients on the final price paid informally.

As mentioned previously, the specific way the questions are asked in the ALSMS does not allow us to distinguish between formal and informal payments (if other categories of out-of-pocket payments are considered). This may lead to an underestimation of informal payments in Albania and therefore the estimated amounts that patients are willing to pay refers only to the gifts paid to medical staff.

Further research - The interaction between patients and medical staff is certainly one of the fields where future research should be focused on. Additional information on the treatments (e.g. type and intensity) and medical staff would allow us to better understand the bargaining process that determines the final amount paid informally.

Informal payments in Albania are a way to allocate resources where the market prevails over the rationing system thought up by the government, but they lack progressive redistributive effects and their burden falls mostly on the poor and the vulnerable.

The results throughout the various studies of this dissertation have shown that informal payments prevail in an environment characterised by a lack of good governance and adequate resources. From this perspective, individuals consider informal payments as a way to gain access and/or receive better quality care and medical staff. However, the analyses have shown that such payments tend to be regressive (most often the poor pay a similar amount as the rich) (Chapter 3) and are more likely to be charged to the lower educated or rural residents (Chapter 3). Moreover, medical staff also impose higher amounts on those patients who have more difficulties to pay for health care (Chapter 3). Previous studies have argued that informal payments may actually have redistributive effects, such as price discrimination by physicians by charging more to the rich. Such effects are not observed in Albania.

The final aim of health care policies should be to set up a health system that is efficient, sustainable and equitable. Informal payments may seem as a good alternative when governance in the sector is weak and the resources are scarce. However, they cannot be considered as a long-term solution to such problems. As shown throughout this dissertation, informal payments seriously lack progressive redistributive effects and the protective mechanisms that public policies should ensure and therefore they burden mostly the poor and vulnerable. The reduction of this phenomenon should always be seen as a consequence of a series of measures that would provide solid financing mechanisms, increase efficiency in using the available resources and moreover ensure an equitable health care system. 


\section{BIBLIOGRAPHY}

Abel-Smith B, Falkingham J. (1995). Financing Health Services in Krygyzstan: The extent of private payments. Report for the British Government Know-How Fund (KHF). London School of Economics, London, U.K.

Adam G. 1989. Gratuity for doctors and medical ethics. The Journal of Medicine and Philosophy; 14, 315-322.

Akerlof G. (1970). The Market for 'Lemons': Qualitative Uncertainty and the Market Mechanism. The Quarterly Journal of Economics; 84, 3, 488-500.

Allin S, Davaki K, Mossialos E. (2006). Paying for 'free' health care: The conundrum of informal payments in post-communist Europe. Transparency International. Global Corruption Report 2006. Special Focus - Corruption in Health:62-75.

Aristakesyan M, Margaryants H, Makarova T. (2005). Health care systems in transition: Armenia health care financing. XXVII Annual Aspher Conference, Yerevan, Armenia.

Arrow J.K. (1963). Uncertainty and the welfare economics of medical care. The American economic review; $3,5$.

Atanasova E, Pavlova M, Velickovskia R, Nikova B, Moutafova E, Groot W. (2011). What have10 years of health insurance forms brought about in Bulgaria? Re-appraising the Health Insurance Act of 1998. Health Policy; 10.1016/j.healthpol.2010.12.001.

Baeza C, Packard T.G. (2005). Beyond Survival: Protecting Households from the Impoverishing Effects of Health Shocks in Latin America. Washington, DC: World Bank.

Bakacsi G, Takacs S, Karacsonyi A, Imrek V. (2002): East-European Cluster: Tradition and Transition. Journal of World Business; 37, 69-80.

Balabanova D, McKee M. (2002). Understanding informal payments for health care: the example of Bulgaria. Health Policy; 62, 243-273.

Balabanova D. (1999). Informal payments for health care in Bulgaria, unpublished. London: Health Services Research Unit, London School of Hygiene and Tropical Medicine.

Balabanova D, McKee M. (2002). Understanding informal payments for health care: the example of Bulgaria. Health Policy; 62, 243-273.

Balázs P. (1991). Gratitude Payment Paradigm: Subjectively about Health Care Reform. Valóság; 4, 39 - 44 .

Balázs P. (1996). Our underlying interest in dealing with gratitude payment. Lege Artis Medicinae; 6, 660-663.

Bank of Albania. (2010). Exchange Rate Archive for 2002, accessed on April 2010 (http://www.bankofalbania.org/web/exchange_rates_archive_2372_2.php). 
Basmann R.L. (1960). On Finite-Sample Distributions of Generalized Classical Linear Identifiability Test Statistics. Journal of the Americal Statistical Association; 55: 650659.

Becker G.S. (1962). Investment in Human Capital: A Theoretical Analysis. The Journal of Political Economy; 70, 5: 9-49.

Becker G.S. (1967). Human Capital and the Personal Distribution of Income: An Analytical Approach. University of Michigan, Institute of Public Administration.

Behrman J. (1988). Nutrition, health, birth order and seasonality: intra-household allocation among children in rural India. J. Development Economics; 28:43-63.

Behrman J.R, Zdenek H, Taubman P, Wales T.J (1980). Socioeconomic Success: A Study of the Effects of Genetic Endowments, Family Environment and Schooling. Amsterdam: North-Holland.

Belishova A, Hana E, Adhami A. (2010). Sigurimi shëndetësor në Shqipëri. Instituti i Shërbimit të Kujdesit Shëndetësor.

Belli P, Shahriari H. (2002).Qualitative Study on Informal Payments for health Services in Georgia. Health, Nutrition and Population (HNP) Discussion Paper.

Belli P. (2002). Formal and informal household spending on health: a multicountry study in Central and Eastern Europe. Harvard School of Public Health.

Berki S.E. (1986). A look at catastrophic medical expenses and the poor. Health Affairs; 138-45.

Bertakis K.D, Azari R, Helms L.J, Callahan E.J, Robbins J.A. (2000). Gender Differences in the Utilization of Health Care Services. The Journal of Family Practice; 49, 2.

Bonilla-Chacin M.E. (2003). Health and poverty in Albania: Background paper for the Albania Poverty Assessment, Europe and Central Asia Sector for Human Development. Washington, DC, World Bank; 1-59.

Bourguignon F, Browning M, Chiappori P.A, Lechene V. (1993). Intra Household Allocation of Consumption: a Model and some Evidence from French Data. Recent Advances in Economic Theory; 137-156.

Bredenkamp C, Mendola M, Gragnolati M. (2010). Catastrophic and impoverishing effects of health expenditure: new evidence from the Western Balkans. Health Policy and Planning; $1-8$.

Browning M, Bourguignon F, Chiappori P.A, Lechene V. (1994). Incomes and outcomes: a structural model of intra-household allocation. Journal of Political Economy; 102: 1067-1096.

Carletto C, Davis B, Stampini M. (2005). Familiar faces, familiar places: the role of family networks and previous experience for Albanian migrants. ESA Working Paper; 05-03, Rome, FAO. 
Carlton W.D, Perloff M.J. (1989). The economics of information. Food Marketing Policy Center. Research report Nr.5. Department of Agricultural Economics and Rural Sociology. The University of Connecticut.

Chawla M, Berman P, Kawiorsk D. (1998). Financing health services in Poland: New evidence on private expenditures. Health Economics; 7, 337-346.

Cleary P.D, Mechanic D, Greenley J.R (1982). Sex Differences in Medical Care Utilization: An Empirical Investigation. Journal of Health and Social Behaviour; 23(2): 106-119.

Cowell F.A. (1995). Measuring inequality. London and New York: Prentice Hall/Harvester Wheat sheaf.

Dabalen A, Kilic T, Wane W. (2008). Policy Research Working Paper 4783. The World Bank.

Daskalova N, Tomev L, Ivanova V, Nikolova A, Naydenova Z, Trakieva D. (2005). Health care reforms and privatisation - social and economic consequences. Caseof Bulgaria. Sofia, Institute for Social and Trade Union Research.

Dehejia R.H, Wahba S. (2002). Propensity Score-Matching Methods For nonexperimental causal studies. The Review of Economics and Statistics, MIT Press; 84, 1: 151-161.

Delcheva E, Balabanova D, McKee M. (1997). Under-the-counter payments for health care: Evidence from Bulgaria. Health policy; 42: 89-100.

Dercon S, Krishnan P. (2000). In Sickness and in Health: Risk-Sharing within house-holds in Rural Ethiopia. Journal of Political Economy; 108, 4: 688-727.

DGESAEO-EC. (2008). Social inclusion and social protection in Albania. DirectorateGeneral for Employment, Social Affairs and Equal Opportunities European Commission.

Ensor T, Savelyeva L. (1998). Informal payments for health care in the Former Soviet Union: some evidence from Kazakstan. Health Policy Plan; 13, 1, 41-9.

Ensor T, Witter S. (2001). Health Economics in low income countries: Adapting to the reality of the unofficial economy. Health Policy; 57: 1-13.

Ensor T. (2004). Informal payments for health care in transition economies. Social Science and Medicine; 58, 237-246.

Falkingham J. (2004). Poverty, out-of-pocket payments and access to health care: evidence from Tajikistan. Social Science and Medicine; 58: 247-258.

Feeley FG, Sheiman IM, Shishkin S. (1999). Health sector informal payments in Russia. Boston, MA, Boston University Press.

Gaal P, Belli P, McKee M, Szocska M. (2006). Informal Payments for health care: Definitions, distinctions, and dilemmas. Journal of Health politics, Policy and Law; 31: 2.

Gaal P, Evetovis T, McKee M. (2006). Informal payments for health care: Evidence from Hungary Health Policy; 77: 86-102. 
Gaal P, McKee M. (2005). Fee-for-service or donation? Hungarian perspectives on informal payment for health care. Social Science and Medicine; 60,7, 1445-1457.

Gertler P, Gruber J. (2002). Insuring consumption against illness. American Economic Review; 92: 51-70.

Goldstein E, Preker AS, Adeyi O, Chellaraj G. (1996). Trends in health status, service and finance: The transition in central and Eastern Europe. Volume 1. Washington: The World Bank.

Gordeev V.S, Pavlova M, Groot W. (2010). Two decades of reforms. Appraisal of the financial reforms in the Russian public healthcare sector. Health Policy; 10.1016.

Gotsadze G, Bennett S, Ranson K, Gzirishvili D. (2005). Health Care-seeking behaviour and out-of-pocket Payments in Tbilisi, Georgia. Health Policy and Planning; 20, 4.

Groot W, Maassen van den Brink H. (2005). Optimism, pessimism and the compensating income variation of cardiovascular disease: A two-tiered quality of life stochastic frontier model. Social Science and Medicine; 65, 1479-1489.

Groot W, Oosterbeek H. (1994). Stochastic reservation and offer wages. Labour Economics; 1: 383-390.

Grossman M. (1972b). On the concept of health capital and the demand for health. Journal of Political Economy; 80, 223-255.

Handa S. (1994) Gender, Headship and Intra household Resource Allocation. World Development; 22, 10:1535-1547.

Healy J, McKee M. (1997). Health sector reform in Central and Eastern Europe: the professional dimension. Health policy and planning; 12, 4, 286-295.

Heckman J.J, Ichimura H. Todd P.E. (1997). Matching as an econometric evaluation estimator: Evidence from evaluating a job training program. The Review of Economic Studies; 64,4: 605-654.

Holzmann R, Jorgensen S. (1999). Social Protection as Social Risk Management: Conceptual Underpinnings for the Social Protection Sector Strategy Paper. Social Protection Discussion Paper No. 9904, The World Bank, Washington, D.C.

Hotchkiss D.R, Hutchinson P.L, Malaj A, Berruti A.A. (2005). Out-of-pocket payments and utilization of health care services in Albania: Evidence from three districts. Health Policy; 75, 18-39.

IDRA. (2010). Corruption in Albania: Perception and Experience - Survey 2010 Summary of findings. Institute for Development Research and Alternatives.

Killingsworth J, Hossain N, Hedrick-Wong Y, Thomas S, Rahman A, Begum T. (1999). Unofficial fees in Bangladesh: price, equity and institutional issues. . Health Policy and Planning; 14, 2: 152-163. 
Leive A, Xu K. (2008). Coping with out-of-pocket health payments: empirical evidence from 15 African countries. Bulletin of the World Health Organisation; Vol 86, pp 849856.

Lerberghe W.V, Conceicao C, Damme W.V, Ferrinho P. (2002). When staff is underpaid: dealing with the individual coping strategies of health personnel. Bulletin of the World Health organization; 80: 581-584.

Lewis M. (1999). Informal health payments in Eastern Europe and Central Asia: Issues, trends and policy implications. Paper prepared for the European observatory on health care systems meeting, December 3-4, Venice Italy. Mimeo. Washington, DC: The World Bank.

Lewis M. (2000). Who is paying for health care in Eastern Europe and Central Asia? Human Development Sector Unit Europe and Central Asia region. The World Bank, Washington, D.C.

Lewis M. (2002). Informal health payments in central and eastern Europe and the former Soviet Union: issues, trends and policy implications. European observatory on Health Care system series. Funding health care: options for Europe.

Lewis M. (2006). Governance and corruption in public health care systems. Working paper number 78. Washington, DC: Centre for Global Development.

Lewis M. (2007). Informal Payments and the Financing of Health Care in Developing and Transition Countries. Health Affairs; 26, 4.

Lewis M, Pettersson G. (2009). Governance in Health Care Delivery. Raising Performance. Policy Research Working Paper 5074. The World Bank Development Economics Department \& Human Development Department.

Liaropoulos L, Siskou O, Kaitelidou D, Theodorou M, Katostaras T. (2008). Informal payments in public hospitals in Greece. Health Policy; 87:72-81.

Liaropoulos L, Tragakes E. (1998). Public private financing in the Greek health care system: implications for equity. Health Policy; 43: 153-169.

Mæstad O, Mwisongo A. (2007) Informal Payments and the Quality of Health Care in Tanzania: Results from Qualitative Research. CMI Working Paper.

Martiri E. (2009). Transport Services and Women's Access to Education, Healthcare, and Employment in Albania: The Cases of Tirana, Kamez, and Bathore. (In: Who Decides? Development, Planning, Services, and Vulnerable Groups, ed. Pallai K.), Open Society Institute-Budapest; 13-54.

McKee M. (1991). Health services in Central and Eastern Europe: past problems and future prospects. Journal of Epidemiology Community Health; 45:260-265.

McPake B, Asiimwe D, Mwesigye F, Ortenblad L, Stree P. (1999). Informal economic activities of public health workers in Uganda: implications for quality and accessibility of care. Social Science and Medicine; 49: 849-865. 
Miller W, Grødeland Å.B, Koshechkina T.Y. (2000). If you pay, we'll operate immediately. Journal of Medical Ethics; 26, 305-311.

Mincer J, Polachek S. (1974). Family Investment in Human Capital: Earnings of Women. Journal of Political Economy; 82, 2: S76-S108.

Ministry of Health of Albania and Institute of Public Health. (2004). Financial Sustainability Plan for the National Immunization Program.

Ministry of Health of Albania. (2000). Albanian public's perceptions of the health care system. Tirana, Albania: World Bank Project.

Ministry of Health of Albania. (2004). The long-term strategy for the development of Albanian Health System. April.

Ministry of Health of Albania. database http://www.moh.gov.al/statistik/Aktiviteti 20i 20insitucioneve 20paresore.xls. (Accessed on December 2010)

Mwabu G.M. (1986). Health care decisions at the household level: Results of a rural health survey in Kenya. Social Science and Medicine; 22, 3:315-319.

Novak J, Goldin V, Danilenko A. (1996). Household Survey of South Kazakhstan Oblast, Abt Associates, Bethesda, Maryland.

Nuri B, Tragakes E. (2002). Health Care Systems in Transition. Copenhagen, European Observatory on Health Care Systems; 4(6).

O'Donnell O, van Doorslaer E, Rannan-Eliya R.P, Somanathan A. (2005). Explaining the incidence of catastrophic payments for health care: Comparative evidence from Asia. EQUITAP Working Paper Nr.5. Erasmus University, Rotterdam, Netherlands, and Institute of Policy Studies, Colombo, Sri Lanka.

Pavlova M, Groot W, Merode (van) G. (2002). Public attitudes towards patient payments in Bulgarian public health care sector: results of a household survey. Health Policy; 59, 1 24.

Pavlova M, Groot W, van Merode F. (2000). Appraising the financial reform in Bulgarian public health care sector: the Health Insurance Act 1998. Health Policy; 53:185-99.

Polachek S, Yoon B. (1987). A two-tiered earnings frontier estimation of employer and employee information in the labor market. Review of Economics and Statistics; 69, 296-302.

Pradhan M, Prescott N. (2002). Social risk management options for medical care in Indonesia. Health Economics; 11: 431-46.

Preker A.S, Feachem R.A. (1994). Health and health care. In: N Barr (ed). Labour markets and social policy in Central and Eastern Europe: The transition and beyond. New York: Oxford University.

Rechel B, McKee M (2009). Health reform in Central and Eastern Europe and the former Soviet Union. The Lancet; 374:1186-1195. 
Rothschild M, Stiglitz J. (1976). Equilibrium in Competitive Insurance Markets: An Essay on the Economics of Imperfect Information, Quarterly Journal of Economics; 90, 629649 .

Russell S. (2004). The economic burden of illness for households in developing countries: A review of studies focusing on malaria, tuberculosis, and human immunodeficiency Virus/Acquired Immunodeficiency Syndrome. American Journal of Tropical Medicine and Hygiene; 71: 147-55.

Sargan J.D. (1958). The estimation of economic relationships using instrumental variables. Econometrica; 26, 393-415.

Sauerborn R, Adams A, Hien M. (1996). Household strategies to cope with the Economic costs of illness. Social Science and Medicine; 43, 3: 291-301.

Shahriari H, Belli P, Lewis M. (2001). Institutional issues in informal health payments in Poland: report on the qualitative part of the study, health, nutrition and population. Washington, DC, Population Reproductive Health Thematic Group of the World Bank.

Shishkin S, Kacevicius G, Ciocanu M. (2006). Evaluation of health financing reform in the Republic of Moldova. Copenhagen, WHO Regional Office for Europe.

Stepurko T, Pavlova T, Gryga I, Groot W. (2010). Empirical studies on informal patient payments for health care services: a systematic and critical review of research methods and instruments. BMC Health Services Research; 10:273.

Stiglitz J.E. (1988). Economics of the Public Sector (2nd edn). W.W. Norton \& Company: New York.

Szende A, Culyer J.A. (2006). The inequity of informal payments for health care: The case of Hungary. Health Policy; 75, 262-71.

Tambor M, Pavlova M, Woch P, Groot W. (2010). Diversity and dynamics of patient costsharing for physicians' and hospital services in the 27 European Union countries. European Journal of Public Health; 1:6.

Thomas D (1993). The distribution of income and expenditure within the household. Annales d'Économie et de Statistique; 29: 109-135.

Thomas D. (1990). Intra-household resource allocation: an inferential approach. Journal of Human Resources; 25: 635-664.

Thompson R, Witter S. (2000). Informal payments in transitional economies: Implications for health sector reform. International Journal of Health Planning and Management; 15, 3:169-187.

Thompson R, Xavier A. (2002). Unofficial payments for acute state hospital care in Kazakhstan. A model of physician behaviour with price discrimination and vertical service differentiation. 
Vian T, Burak J.L. (2006). Beliefs about informal payments in Albania. Health Policy Planning; 21, 5: 392-401.

Vian T, Grybosk K, Sinoimeri Z, Halld R. (2006). Informal payments in government health facilities in Albania: Results of a qualitative study. Social Science and Medicine 62: 877-887.

Vlădescu C, Scîntee G, Olsavszk V. (2008). Romania Health System Review Health System in Transition; 10,3 .

Wagstaff A, van Doorslaer E. (2003). Catastrophe and impoverishment in paying for health care: with applications to Vietnam 1993-98. Health Economics; 12: 921-34.

Wagstaff A. (2007). The economic consequences of health shocks: Evidence from Vietnam. Journal of Health Economics; 26: 82-100.

Waters H, Anderson G, Mays J. (2004). Measuring financial protection in health in the United States. Health Policy; 69: 339-349.

Watson P. (2006). Unequalizing Citizenship: The Politics of Poland's Health Care Change. Sociology; 40, 6: 1079-1096.

Weesie J. (1999). Seemingly unrelated estimation and the cluster-adjusted sandwich estimator. Stata Technical Bulletin; 52:34-47.

WHO database: http://www.who.int/entity/nha/country/alb.xls. (Accessed on December 2010).

WHO, World tables on NHA data http://www.who.int/entity/nha/country/nha_ratios_and_pc_levels_en_1995-2009.xls (Accessed on December 2010).

Wlodarczyk W.C, Zajac M. (2002). Poland. In: Fried BJ, Gaydos LM. World health systems: challenges and perspectives. Chicago, IL, Health Administration Press and AUPHA Press; 279-299.

World Bank. (1993). World development report: Investing in health. Oxford: Oxford University Press.

World Bank. (1995a). Averting the old age crisis. Oxford: Oxford University Press.

World Bank. (2006). Albania Health Sector Note. Report No. 32612-AL, Washington DC.

World Bank. (2007). Albania: Urban Growth, Migration and Poverty Reduction. A Poverty Assessment. Poverty Reduction and Economic Management Unit Europe and Central Asia Region. World Bank. Report No. 40071- AL.

World Bank. Albanian Living Standards Measurement Survey. www.worldbank.org/lsms.

World Bank and Albania Institute of Statistics (INSTAT). (2003). Albania Living Standard Measurement Survey 2002. Basic Information Document. Updated October 2005

World Health Organisation. (1996). European health care reform: analysis of current strategies. Copenhagen: WHO. 
World Health Organization. (2000). World Health Report 2000. Geneva, Switzerland: World Health Organization.

World Health Organisation. (2005). Sustainable health financing, universal coverage and social health insurance. 115th World Health Assembly Resolution EB115.R13. Geneva.

Wynia M.K, Latham S.R, Kao A.C, Berg J.W, Emanuel L. (1999). Medical professionalism in society. The New England journal of medicine; 341, 21: 1612-1616.

Xu K, Evans D.E, Kawabate K, Zeramdini R, Klavus J, Murray C.J.L. (2003). Household Catastrophic Health Expenditure: A Multicountry Analysis. Lancet; 362: 111-17.

Xu K, Evans D.E, Carrin G. (2007). Protecting households from catastrophic health spending. Health Affairs; 26: 972-983. 


\section{SAMENVATTING}

Formele en informele eigen betalingen door patiënten zijn een belangrijke bron van financiering van de gezondheidszorg in de meeste voormalige communistische landen van Midden-en Oost-Europa (CEE) en voormalige Sovjet-Unie (FSU). De gezondheidszorg van deze landen heeft een aantal gemeenschappelijke kenmerken, zoals de erfenis van het voormalige "Semashko" systeem, lage publieke investeringen in de gezondheidszorg, gebrek aan goed bestuur en toenemende corruptie. Onder dergelijke omstandigheden, vinden eigen betalingen in de gezondheidszorg vaak plaats buiten de door de overheid ingestelde formele kanalen. Deze ongereguleerde eigen betalingen worden vaak bestempeld als 'onder-de-tafel betalingen', 'enveloppe betalingen', 'under-the-counter betalingen', 'giften', en zelfs 'zwart geld'. Ze worden meestal gedefinieerd als betalingen aan zorgaanbieders, voor diensten die worden geacht te zijn verstrekt zonder kosten voor de patiënt. Deze kunnen verschillende vormen aannemen van contante betalingen tot bijdragen in natura of het geven van geschenken tot informele doorberekening van kosten. Vanuit een meer pragmatisch perspectief kunnen de informele betalingen in de gezondheidszorg worden opgevat als strategieën toegepast door patiënten en medisch personeel om om te gaan met slechte medische prestaties en gebrek aan middelen. Patiënten betalen informeel om bijvoorbeeld naar een hogere plaats op de wachtrij te springen, een betere kwaliteit van dienstverlening of meer zorg te ontvangen. Eveneens maken aanbieders van medische zorg gebruik van deze betalingen als een middel om hun lage lonen te verhogen.

Het belangrijkste doel van dit proefschrift is om nieuw licht te werpen op de oorzaken van informele betalingen in de openbare diensten voor gezondheidszorg en te begrijpen hoe dergelijke betalingen van invloed zijn op de toewijzing van middelen op micro-niveau tussen patiënten, medisch personeel en huishoudens in Albanië. Informele betalingen in dit proefschrift worden gemeten door middel van informele 'giften' betaald aan medisch personeel in de publieke gezondheidszorg. Hoewel deze betalingen als cadeau zijn bedoeld, worden ze vaak gevraagd of verwacht en vertegenwoordigen ze een aanzienlijk deel van eigen bijdragen in de gezondheidszorg in Albanië.

Albanië is één van de laatste landen in Midden- en Oost Europa die zich vanuit een gecentraliseerd systeem heeft ontwikkeld tot een markteconomie. Deze veranderingen gingen gepaard met veel economische en sociale uitdagingen, waarvan de gezondheidszorg één van de sectoren was die het hardst getroffen werd. Informele betalingen zijn de laatste 20 jaar gebruikelijk in Albanië vooral voor zorg waarbij een opname vereist is. Deze zorg zou gratis moeten zijn voor de gehele bevolking (inclusief langdurige behandeling), ongeacht of de patiënten verzekerd zijn of niet. De situatie is bijzonder dramatisch voor arme mensen die tot vier keer meer moesten betalen dan rijke mensen.

De universele gezondheidszorg, geërfd van het vorige communistische regime in Albanië, had een wijdverspreide openbare gezondheidszorg en een beperkt aantal particuliere aanbieders. In de periode 2002-2008 (waarin de gegevens voor de analyse van dit proefschrift werden verzameld), was de financiering van de gezondheidssector in het land gefragmenteerd omdat het Health Insurance Institute het grootste deel van de 
salarissen van huisartsen betaalde evenals geselecteerde medicijnen en -voor zover aanwezig- diagnostiek van hoge kwaliteit. Alle andere openbare gezondheidszorgkosten werden gedekt door het budget van het Ministerie van Volksgezondheid. Ondanks de schaarste aan medicijnen, de laag betaalde medische staf en de inefficiëntie van het systeem leidde dit tot situaties waarin patiënten moesten betalen voor de (anders gratis) medicijnen of diensten. Formele betalingen bleven beperkt tot enkele vergoedingen voor poliklinische zorg.

Het proefschrift bestaat uit een serie empirische studies waarin met behulp van gegevens uit de 'Albanian Living Standards Measurement Survey' (ALSMS) 2002, 2005, 2008, het fenomeen van de informele betalingen voor de gezondheidszorg wordt onderzocht.

Het tweede hoofdstuk van het proefschrift onderzoekt het catastrofisch effect van de eigen bijdragen kosten en informele betalingen dat huishoudens in armoede duwt. Kosten voor de gezondheidszorg worden beschouwd als catastrofisch als ze voor individuen of huishoudens tot een significante daling van de levensstandaard leiden, nu of in de toekomst. De resultaten tonen aan dat deze uitgaven kunnen bijdragen aan armoede onder Albanese huishoudens. Zowel het armoede percentage als de armoede kloof worden groter nadat er eigen betalingen zijn gedaan voor gezondheidszorg. Dit leidt tot een verhoogde kans op armoede onder patiënten. De gevolgen kunnen nog dramatischer zijn als we bedenken dat arme mensen minder mogelijkheden hebben om toegang te krijgen tot medische hulp.

Het derde hoofdstuk onderzoekt de oorsprong en de oorzaken van informele betalingen. Deze oorzaken zijn gegroepeerd in (i) het culturele model, (ii) het economische model, en (iii) het bestuurlijk model. Door het beheersen van de belangrijkste factoren aan de vraagzijde, is geprobeerd om te bepalen wie betaalt, voor wat en hoeveel. Het culturele model beschouwt informele betalingen als specifiek gedrag van patiënten, om hun dankbaarheid te uiten in de vorm van giften voortkomend uit waarden en tradities. Het economische model verklaart informele betalingen aan de toegenomen vraag naar zorg, onvoldoende budget, maar verklaart ook ineffectief beleggingsbeleid. Het bestuurlijk model verklaart deze betalingen van gebrek aan controle en verantwoording in de gezondheidszorg, een zwak rechtsstelsel en zwakke corruptiecontrole.

Voor Albanië, werd het cultureel model in eerste instantie beschouwd als een veelbelovend model om informele betalingen te verklaren. Echter, de resultaten bevestigen niet deze verwachting. Een reeks van feiten en cijfers lijken een voorkeur te geven aan factoren gerelateerd aan de economische en bestuurlijke modellen. Ook al is het moeilijk om een duidelijke scheidslijn tussen deze twee modellen te trekken. Een laag budget voor de gezondheidszorg, de ongelijkheden tussen landelijke en stedelijke gebieden evenals het gebrek aan verantwoording en de aanwezigheid van corruptie, worden gezien als enkele van de belangrijkste oorzaken van informele betalingen.

Hoofdstuk vier analyseert de verschillen binnen een huishouden in de uitgaven aan informele betalingen voor gezondheidszorg indien verschillende leden van een huishouden zorg nodig hebben. In landen als Albanië, waar gezinnen hun patriarchale structuur behouden hebben, is het belangrijk om te kijken of de besluitvorming over de 
uitgaven voor gezondheidszorg afhankelijk is van de positie die de patiënt heeft in het huishouden. De resultaten tonen aan dat huishoudens strategisch middelen toewijzen aan gezondheidszorg, door te investeren in menselijk kapitaal dat de hoogste opbrengst heef. Huishoudens met ouders en kinderen investeren veel meer in kinderen dan uitgebreide huishoudens. Het aantal kinderen heeft een negatieve invloed op de omvang van de bedragen die betaald worden voor elk kind. De onderhandelingsbevoegdheden binnen de huishoudens zijn ook van invloed op de toewijzing van middelen voor de gezondheidszorg waardoor de lager opgeleide echtgenoten worden benadeeld.

Informele betalingen worden in hoofdstuk vijf beschouwd als een manier om schaarse middelen toe te wijzen, waar de markt prevaleert boven rantsoeneringsystemen opgezet door de overheid. De marktprijs (of het informeel betaalde bedrag) wordt beïnvloed door de informatie die de medische staf heeft op het maximale bedrag dat de patiënt bereid is om informeel te betalen, en informatie die de patiënt heeft over het minimumbedrag dat de medische staf verwacht. De resultaten suggereren dat medisch personeel minder informatie heeft over het maximale bedrag dat de patiënt bereid is om op informele wijze te betalen dan de informatie die de patiënten hebben over wat de medische staf verwacht. Als gevolg van de gebrekkige informatie kunnen patiënten het daadwerkelijke bedrag van de gift verminderen. Echter, de daadwerkelijke gemiddelde betaling blijft nog steeds groot en in alle gevallen is het groter dan de waarde van het bedrag dat de medische staf verwacht te ontvangen.

Informele betalingen lijken een alternatief als het bestuur in de sector zwak is en de middelen schaars zijn. Echter, ze kunnen niet worden beschouwd als een lange termijn oplossing voor dergelijke problemen. Het uiteindelijke doel van gezondheidszorgbeleid moet zijn het opzetten van een systeem voor gezondheidszorg, dat efficiënt, duurzaam en rechtvaardig is. Zoals beschreven in dit proefschrift, hebben informele betalingen geen herverdelingseffecten en geen beschermende mechanismen die worden gegarandeerd door overheidsbeleid waardoor ze meestal een last vormen voor de armen en kwetsbaren. Dit proefschrift suggereert dat de reductie van dit fenomeen altijd moet worden gezien als een gevolg van een reeks van maatregelen dat voorziet in solide financieringsmechanismen, verhoging van efficiëntie in het gebruik van de beschikbare middelen en bovendien het zorgen voor een billijke gezondheidszorg.

Gedurende de laatste jaren is het in het beleid in Albanië niet gelukt om informele betalingen te elimineren. De hardnekkigheid van het fenomeen door de jaren heen (en de algemene publieke opvatting), roept op tot meer actievere aanpak van de economische en bestuurlijk gerelateerde oorzaken. Echter, de Albanese praktijk heeft tot nu toe aangetoond dat dergelijke maatregelen, zoals het contracteren van de intramurale diensten via Health Insurance Institute en de toename van het aantal verzekerden, het doen van informele betalingen en de omvang van deze bedragen kan verlagen. Aan de andere kant zijn mensen nodig om 'formele' kanalen te gebruiken om bij te dragen aan het systeem (door een bijdrage te kiezen via ziektekostenverzekering of algemene belastingen), maar geld mag geen rol spelen bij de toegang tot de gezondheidszorg. De strategieën voor het omgaan met informele betalingen dienen vergezeld te gaan van een juiste beoordeling van het effect op de totale kosten van de gezondheidszorg ten laste van huishoudelijke budgetten evenals met een juiste bescherming voor de armen. 


\section{PËRMBLEDHJE}

Pagesat direkte formale dhe joformale të bëra nga pacientët janë një burim i rëndësishëm financimi i shërbimit të kujdesit shëndetësor në shumicën e vendeve ishkomuniste të Europës Qendrore dhe Lindore (EQL) dhe ish-vendet e Bashkimit Sovjetik (BS). Sistemet e kujdesit shëndetësor të këtyre vende kanë disa tipare të përbashkëta si trashëgiminë e sistemit 'Semashko', investimet e ulta publike në kujdesin shëndetësor, mungesën e mirëqeverisjes dhe korrupsionin në rritje. Në rrethana të tilla, ndodh shpesh që pagesat për kujdesin shëndetësor të bëhen jashtë kanaleve zyrtare të vendosura nga qeveria. Këto pagesa direkte joformale janë etiketuar shpesh si 'pagesa në zarf' 'pagesa nën dorë', 'dhurata', madje edhe 'pagesa korruptive'. Në literaturë këto pagesa joformale janë përkufizuar kryesisht si pagesa që i bëhen ofruesve të kujdesit shëndetësor për shërbimet që janë falas ndaj pacientëve. Nga një pikëpamje më praktike, pagesat joformale në kujdesin shëndetësor mund të konceptohen si strategji të përshtatura nga pacientët dhe nga stafi i kujdesit shëndetësor për t'u përballuar me performacën e dobët dhe mungesën e të ardhurave dhe investimeve. Pacientët paguajnë në mënyrë joformale për të mënjanuar rradhët e pritjeve, për të marrë cilësi më të lartë shërbimi, ose thjesht për të pasur më shumë kujdes shëndetësor. Ofruesit e kujdesit shëndetësor i pranojnë këto pagesa si një mjet për të rritur pagat e ulëta.

Qëllimi kryesor i këtij dizertacioni është të hedhë dritë mbi shkaqet e pagesave joformale në shërbimet publike të kujdesit shëndetësor në Shqipëri si dhe për të kuptuar se si pagesa të tilla ndikojnë në shpërndarjen e burimeve në nivelin mikro-ekonomik midis pacientëve, midis personelit të kujdesit shëndetësor, si dhe midis pjesëtarëve të familjes. Në këtë dizertacion pagesat joformale maten duke përdorur informacionin mbi 'dhurata' joformale që i paguhen stafit të kujdesit shëndetësor në shërbimet publike. Edhe pse janë klasifikuar si dhurata, shpesh ndodh që këto pagesa kërkohen direkt ose indirekt (pritet që pacienti të paguajë) nga punonjësit e kujdesit shëndetësor. Si të tilla, pagesat joformale përfaqësojnë një pjesë të konsiderueshme të pagesave direkte në kujdesin shëndetësor në Shqipëri.

Shqipëria është një nga vendet e fundit në Evropën Qendrore dhe Lindore që ka lëvizur nga një sistem ekonomik i centralizuar drejt ekonomisë së tregut. Ndryshimet u shoqëruan me shumë sfida ekonomike dhe sociale, dhe kujdesi shëndetësor ishte një nga sektorët që 'vuajti' më shumë. Gjatë dy dekadave të fundit pagesat joformale kanë qenë shumë të zakonshme në Shqipëri veçanërisht në shërbimet spitalore ku shërbimi ofrohej falas për të githë popullsinë (duke përfshirë edhe trajtimin afatgjatë), pa marrë parasysh nëse pacientët ishin të siguruar apo jo. Situata ka qenë veçanërisht dramatike për pacientët në 20 përqinshin më të ulët në shpërndarjen e të ardhurave të cilët raportojnë se paguajnë katër herë më shumë se pacientët në 20 përqindëshet më të larta.

Shqipëria trashëgoi një sistem shëndetësor të përhapur gjeografikisht në të githë vendin. Gjatë periudhës 2002-2008 (periudhë në të cilën janë mbledhur të dhënat për analizën e këtij dizertacioni), financimi i shërbimit shëndetësor në vend ishte i fragmentuar. Instituti i Sigurimeve të Kujdesit Shëndetësor (ISKSH) paguante për shumicën e pagave të mjekëve të kujdesit parësor, ilaçet e listës së rimbursimit dhe disa analizave të shternjta. Të gjitha shpenzimet e tjera të kujdesit shëndetësor publik 
mbuloheshin nga buxheti i Ministrisë së Shëndetësisë. Gjate atyre viteve pagesat direkte formale ishin kryesisht të përqendruara në kujdesin parësor dhe sekondar. Pavarësisht nga kjo, mungesa e barnave mjekësore, pagat e ulta të personelit shëndetësor dhe inefiçensa e sistemit shëndetësor në përgjithësi çuan në situatën ku pacientët duhet të paguanin për ilaçet ose shërbimet (megjithëse këto të fundit ishin të parashikuara të ishin falas).

Ky dizertacion përbëhet nga një seri studimesh empirike që përdorin të dhënat e Anketës së Vlerësimit të Standardeve të Jetesës (AVSJ) 2002, 2005, 2008 për të vlerësuar fenomenin e pagesave joformale në kujdesin shëndetësor në Shqipëri.

Kapitulli i dytë i dizeratcionit analizon efektin katastrofik që kanë pagesat direkte dhe joformale (si pjesë e pagesave direkte) në shtyrjen e familjeve në varfëri. Konsiderohen katastrofike ato shpenzime të kujdesit shëndetësor që i detyrojnë individët apo familjet e tyre të ulin standardin e jetesës tani apo në të ardhmen. Rezultatet tregojnë se këto shpenzime mund të kontribuojnë në varfërimin e familjeve shqiptare. Njëkohësisht raporti i varfërisë dhe thellësia e varfërisë rriten me rritjen e shpenzimeve për kujdesin shëndetësor. Kjo tregon një rritje të rrezikut të rënies në varfëri tek individët që marrin kujdes shëndetësor. Këto pasoja bëhen edhe më dramatike kur merret në konsideratë që njerëzit e varfër nuk kërkojnë kujdes shëndetësor.

Kapitulli i tretë analizon origjinën dhe shkaqet e pagesave joformale. Këto shkaqe janë parë të grupuara në tre grup modele (i) modeli kulturor, (ii) modeli ekonomik, dhe (iii) modeli i qeverisjes. Duke kontrolluar për faktorët nga ana e kërkesës, është përpjekur për të identifikuar kush paguan, për çfarë, dhe sa.

Modeli kulturor i shpjegon pagesat joformale si një lloj i veçantë sjelljeje (që e ka zanafillën në traditat dhe vlerat e vendit) i pacientëve të cilët shprehin mirënjohjen e tyre duke ofruar dhurata. Modeli ekonomik i shpjegon pagesat joformale me rritjen e kërkesës për kujdes shëndetësor, buxhetin e pamjaftueshëm të alokuar, si dhe politikat joefektive të investimeve. Modeli i qeverisjes i lidh këto pagesa me mungesën e kontrollit dhe llogaridhënies në sektorin e kujdesit shëndetësor, mos funksionimin e ligjit dhe mosluftimin e korrupsionit. Modeli kulturor u konsiderua fillimisht modeli më premtues për të shpjeguar pagesat joformale në Shqipëri. Megjithatë, rezultatet nuk konfirmuan pritjet. Një seri faktesh treguan se janë pikërisht modeli ekonomik dhe ai i qeverisjes ata që shpjegojnë ekzistencën e këtyre pagesave. Megjithëse është e vështirë të hiqet një vizë ndarëse midis këtyre dy modeleve, buxhet i ulët për kujdesin shëndetësor, pabarazia në kujdesin shëndetësor ndërmjet zonave rurale dhe urbane, mungesa e llogaridhënies dhe ekzistenca e korrupsionit janë parë si disa nga shkaqet kryesore të pagesave joformale në Shqipëri.

Kapitulli i katërt i këtij dizertacioni analizon sesi ndryshojnë këto pagesa joformale kur anëtarë të ndryshëm brenda familjes kanë nevojë për kujdes shëndetësor. Në vende si Shqipëria, ku familjet kanë ruajtur strukturën e tyre patriarkale, është e rëndësishme të shikohet nëse vendimmarrja për shpenzimet shëndetësore varet nga pozicioni që ka individi në familje. Rezultatet tregojnë se familjet i shpërndajnë strategjikisht burimet për kujdesin shëndetësor duke favorizuar individët me kapital njerëzor dhe kthyeshmëri më të lartë. Familjet e përbëra vetëm me prindër dhe fëmijë investojnë më tepër tek fëmijët se sa familjet e zgjeruara. Numri i fëmijëve ndikon negativisht në ulen e këtyre pagesave për çdo 
fëmijë. Fuqia vendimmarrëse brenda familjes ka ndikim në shpërndarjen e burimeve për kujdes shëndetësor duke disfavorizuar gratë me shkollim të ulët.

Pagesat joformale në kapitullin pestë janë konsideruar si një mënyrë shpërndarjeje e burimeve të pamjaftueshme, ku tregu mbizotëron mbi sistemet e racionimit të hartuara nga qeveria. Çmimi i tregut (ose shuma e paguar joformalisht) ndikohet nga informacioni që personeli shëndetësor ka mbi gatishmërinë e pacientit për të paguar joformalisht, dhe informacioni që pacienti ka mbi pagesën që personeli shëndetësor pret nga ai. Rezultatet tregojnë se personeli shëndetësor ka më pak informacion mbi gatishmërinë e pacientit për të paguar joformalisht krahasuar kjo me informacionin që pacientët kanë mbi sasinë e pritshme të personelit shëndetësor. Për shkak të mungesës së këtij informacioni pacientët mund të zvogëlojnë sasinë aktuale të pagesës. Megjithatë, pagesa aktuale në të gjitha rastet e studiuara mbetet më e lartë sesa pagesa e pritur nga stafi mjeksor.

Pagesat joformale në sistemin shëndetësor mund të shikohen si një strategji alternative, kur kemi një qeverisje joefektive dhe kur burimet janë të pamjaftueshme. Megjithatë, ato nuk mund të konsiderohen kurrësesi si një zgjidhje afatgjatë. Qëllimi kryesor i politikave të kujdesit shëndetësor është të ndërtojë një sistem të kujdesit shëndetësor efikas, të qëndrueshëm dhe të barabartë për të githë. Siç përshkruhet edhe në këtë dizertacion, pagesat joformale nuk kanë efekt rishpërndarës dhe në to mungojnë mekanizmat mbrojtëse, të cilat sigurohen nga politikat publike. Barrën kryesore të këtyre pagesave e mbajnë shtresat e varfëra dhe të pambrojtura të popullsisë. Ky disertacion argumenton se reduktimi i fenomenit të pagesave joformale duhet të shoqërohet me një sërë masash që të sigurojnë qëndrueshmëri financiare, rritje të efikasitetit në përdorimin e burimeve të disponueshme dhe mbi të gjitha sigurimin e një sistemi të barabartë të kujdesit shëndetësor.

Politikat qeveritare dhe masat e ndërmarra ndër vite për eliminimin e pagesave joformale në Shqipëri kanë dështuar. Vazhdimësia e këtij fenomeni gjatë githë këtyre viteve (dhe perceptimi i përgjithshëm publik) bën thirrje që vëmendja të përqëndrohet kryesisht në adresimin e shkaqeve që lidhen me modelin ekonomik dhe atë të qeverisjes. Megjithatë, evidencat në Shqipëri tregojnë se kontraktimi i shërbimeve spitalore nëpërmjet Institutit të Sigurimeve Shëndetësore dhe rritja e numrit të personave të siguruar mund të ulë incidencën dhe masën e pagesave joformale. Nga ana tjetër njerëzit duhet të përdorin kanale 'formale' për të kontribuar në sistemin shëndetësor (sigurimet shëndetësore ose tatimet), por paratë nuk duhet të jenë asnjëherë një problem në qasjen ndaj kujdesit shëndetësor. Strategjitë që do të ndërmerren për uljen apo eleminimin e pagesave joformale duhet të shoqërohen me vlerësime të kostos së përgjithshme të kujdesit shëndetësor mbi buxhetin e familjes dhe me mbrojtjen e duhur për shtresat e varfëra dhe të pambrojtura të shoqërisë. 


\section{BIOGRAPHY}

Sonila Tomini was born on 14 November 1975 in Tirana, Albania. She studied Business Management at the Faculty of Economics, University of Tirana (Albania) and also graduated with a Master's degree in European Economic Studies from Tirana University (Albania) and Bamberg University (Germany). Sonila also holds a Master's degree in Public Policy and Human Development from Maastricht University (The Netherlands). Her fields of expertise include Health Economics, Health Systems Analysis, Public Policy Analysis, Social Policy, etc.

Sonila's academic experience has been built by working for 4 years as Research Fellow at Maastricht Graduate School of Governance and as PhD researcher for ASSPRO CEE 2007 Project (a European Commission financed project assessing patient payment policies in Central and Eastern Europe). Next to her academic activities Sonila has been working also as a consultant for World Bank's Human Development Sector. She is constantly involved in research related to health sector and supervision of various master theses. Her work on the patient payments in health care has resulted in several working papers and articles and has been presented on varying academic conferences (such as 7th World Congress on Health Economics, 8th European Conference on Health Economics, 25th Annual Congress of European Economic Association, World Bank Conference on Western Balkans Poverty and Inclusion 2010, etc). Parts of her research have been published by international peer-review journals. 


\section{MGSoG Dissertation Series}

Jinjing Li

Dynamic Microsimulation in Public Policy Evaluation

MGSoG Dissertation Series, nr 24 (2011)

\section{Aziz Atamanov}

Rural Nonfarm Employment and International Migration as Alternatives to Agricultural

Employment: The Case of Kyrgyzstan

MGSoG Dissertation Series, nr 23 (2011)

Frieda Vandeninden

Poverty Alleviation: Aid and Social Pensions

MGSoG Dissertation Series, nr 22 (2011)

Juliana Nyasha Tirivayi

The Welfare Effects of Integrating AIDS Treatment with Food Transfers:

Evidence from Zambia

MGSoG Dissertation Series, nr 21 (2011)

Agnieska Ewa Sowa

Who's Left Behind? Social Dimensions of Health Transition and Utilization of Medical Care in Poland

MGSoG Dissertation Series, nr 20 (2011)

Emmanaouil Sfakianakis

The Role of Private Actors in the Provision of Public Goods with Applications to Infrastructure and Financial Stability

MGSoG Dissertation Series, nr 19 (2011)

Siu Hing Lo

White Collars Green Sleeves

An Interonganizational Comparison of Determinants of Energy-Related Behaviors among Office

Workers

MGSoG Dissertation Series, nr 18 (2011)

Treena $\mathrm{Wu}$

Constraints to Human Capital Investment in Developing Countries:

Using the Asian Financial Crisis in Indonesia as a Natural Experiment

MGSoG Dissertation Series, nr 17 (2011)

Henry Espinoza Peña

Impact Evaluation of a Job-Training Programme for Disadvantaged Youths:

The Case of Projoven

MGSoG Dissertation Series, nr 16 (2011) 
Florian Tomini

Between Family and Friends

Understanding the Interdependency of Private Transfers

MGSoG Dissertation Series, nr 15 (2010)

Michał Polakowski

The Institutional Transformation of Social Policy in East Central Europe:

Poland and Hungary in comparative and historical perspective

MGSoG Dissertation Series, nr 14 (2010)

Maha Ahmed

Defining, Measuring and Adressing Vulnerability:

The Case of Post Conflict Environments

MGSoG Dissertation Series, nr 13 (2010)

Pascal Beckers

Local Space and Economic Success

The role of spatial segregation of migrants in the Netherlands

MGSoG Dissertation Series, nr 12 (2011)

Victor Cebotari

Conflicting Demands in Ethnically Diverse Societies

Ethnopolitical Contention and Identity Values in Europe

MGSoG Dissertation Series, nr 11 (2010)

Dennis Gyllensporre

Competing and Complementary Perspectives on the EU as a Crisis Management Actor:

An Examination of the Common Security and Defence Policy through the Lenses of Idealism and

Realism

MGSoG Dissertation Series, nr 10 (2010)

Judit Vall Castello

Business Cycle and Policy Effects on Labour Market Transitions of Older and Disabled Workers in Spain

MGSoG Dissertation Series, nr. 9 (2010)

Keetie Roelen

False Positives or Hidden Dimentions: The definition and measurement of child poverty

MGSoG Dissertation Series, nr. 8 (2010)

Denisa Maria Sologon

Earning Dynamics in Europe

MGSoG Dissertation Series, nr. 7 (2010)

Melissa Siegel

Money and Mobility: Migration and Remittances

MGSoG Dissertation Series, nr. 6 (2010)

Jessica S. Hagen-Zanker

Modest Expectations: Causes and effects of migration on migrant households in 
source countries

MGSoG Dissertation Series, nr. 5 (2010)

Mirtha R. Muniz Castillo

Human Development and Autonomy in Project Aid: Experiences from four

bilateral projects in Nigaragua and El Salvador

MGSoG Dissertation Series, nr. 4 (2009)

Christiane Arndt

Governance Indicators

MGSoG Dissertation Series, nr. 3 (2009)

Britta Augsburg

Microfinance - Greater Good or Lesser Evil?

MGSoG Dissertation Series, nr. 2 (2009)

Geranda Notten

Measuring and Managing Poverty Risks

MGSoG Dissertation Series, nr. 1 (2008) 